NBER WORKING PAPER SERIES

\title{
BEYOND THE BALANCE SHEET MODEL OF BANKING: IMPLICATIONS FOR BANK REGULATION AND MONETARY POLICY
}

\author{
Greg Buchak \\ Gregor Matvos \\ Tomasz Piskorski
}

Amit Seru

Working Paper 25149

http://www.nber.org/papers/w25149

\author{
NATIONAL BUREAU OF ECONOMIC RESERACH \\ 1050 Massachusetts Avenue \\ Cambridge, MA 02138 \\ October 2018, Revised July 2022
}

This paper was previously titled "The Limits of Shadow Banks". Buchak is at Stanford Graduate School of Business (GSB), Matvos is at Northwestern University and the National Bureau of Economic Research (NBER), Piskorski is at Columbia GSB and NBER, and Seru is at Stanford GSB, the Hoover Institution, the Stanford Institute for Economic Policy Research (SIEPR), and NBER. We thank the National Science Foundation (Award 1628895) for financial support. We thank Sumit Agarwal, Adrien Auclert, Anat Admati, Matteo Benetton, John Cochrane, Dean Corbae, Ramona Dagostino, Anthony DeFusco, Peter DeMarzo, Darell Duffie, Andrea Eisfeldt, Mark Egan, Neil Esho, Andreas Fuster, Paul Goldsmith-Pinkham, Itay Goldstein, Ben Hebert, Erik Hurst, Arvind Krishnamurthy, Debbie Lucas, Chris Mayer, Guillermo Ordonez, Chris Palmer, Karen Pence, Tarun Ramodarai, Alexi Savov, Antoinette Schoar, David Scharfstein, Hyun Shin, Jeremy Stein, Johannes Stroebel, Amir Sufi, Adi Sunderam, Joe Vavra, Arlene Wong, and seminar participants at AQR, Bank for International Settlements, Columbia GSB, European Central Bank, Harvard Business School, Hoover Institution, Housing Finance Policy Center, Indian School of Business, MIT Sloan, Stanford GSB, Yale University, UCLA, University of Texas at Austin, Washington University in St. Louis, Boston College, UNC, University of Rochester, Kellogg School of Management, University of Illinois at Urbana Champagne, and participants at ASSA meetings (Econometric Society), Kellogg Housing and Macroeconomics Conference, Midwest Finance Association Conference, NBER Monetary Economics, NBER Summer Institute, Wharton Conference on Liquidity and Financial Fragility, Stanford Institute of Theoretical Economics Financial Regulation Conference, Office for Financial Research Financial Stability Conference, FDIC Financial Technology Conference, Summer Real Estate Symposium, Central Bank Research Association annual meeting, and the San Francisco Federal Reserve Conference on Advances in Financial Research for helpful comments. We also thank Susan Cherry, Monica Clodius, Sam Liu, and Yilan Zheng for outstanding research assistance. First Version: February 2018. The views expressed herein are those of the authors and do not necessarily reflect the views of the National Bureau of Economic Research.

NBER working papers are circulated for discussion and comment purposes. They have not been peerreviewed or been subject to the review by the NBER Board of Directors that accompanies official NBER publications.

(C) 2018 by Greg Buchak, Gregor Matvos, Tomasz Piskorski, and Amit Seru. All rights reserved. Short sections of text, not to exceed two paragraphs, may be quoted without explicit permission provided that full credit, including $(C$ notice, is given to the source. 
Beyond the Balance Sheet Model of Banking: Implications for Bank Regulation and Monetary

Policy

Greg Buchak, Gregor Matvos, Tomasz Piskorski, and Amit Seru

NBER Working Paper No. 25149

October 2018, Revised July 2022

JEL No. G2,L5

\section{$\underline{\text { ABSTRACT }}$}

Bank balance sheet lending is commonly viewed as the predominant form of lending. We document and study two margins of adjustment that are usually absent from this view using microdata in the $\$ 10$ trillion U.S. residential mortgage market. We first document the limits of the shadow bank substitution margin: shadow banks substitute for traditional—deposit-takingbanks in loans which are easily sold, but are limited from activities requiring on-balance-sheet financing. We then document the balance sheet retention margin: banks switch between traditional balance sheet lending and selling loans based on their balance sheet strength, behaving more like shadow banks following negative shocks. Motivated by this evidence, we build and estimate a workhorse structural model of the financial intermediation sector. Banks and shadow banks compete for borrowers. Banks face regulatory constraints but benefit from the ability to engage in balance sheet lending. Critically, departing from prior literature, banks can also choose to access the securitization market like shadow banks. To evaluate distributional consequences, we model a rich demand system with income and house price differences across borrowers. The model is identified using spatial pricing policies of government-sponsored entities and bunching at the regulatory threshold. We study the quantitative consequences of several policies on lending volume and pricing, bank stability, and the distribution of consumer surplus across rich and poor households. Both margins we identify significantly shape policy responses, accounting for more than $\$ 500$ billion in lending volume across counterfactuals. Secondary market disruptions such as quantitative easing have significantly larger impacts on lending and redistribution than capital requirement changes once we account for these margins. We conclude that a regulatory policy analysis of the intermediation sector must incorporate the intricate industrial organization of the credit market and the equilibrium interaction of banks and shadow banks.

Greg Buchak

Graduate School of Business

Stanford University

655 Knight Way

Stanford, CA 94305b

buchak@stanford.edu

Gregor Matvos

Kellogg School of Management

Northwestern University

2211 Campus Drive

Global Hub 4361

Evanston IL, 60208

and NBER

gregor.matvos@kellogg.northwestern.edu
Tomasz Piskorski

Columbia Business School

3022 Broadway

Uris Hall 810

New York, NY 10027

and NBER

tp2252@columbia.edu

Amit Seru

Stanford Graduate School of Business

Stanford University

655 Knight Way

and NBER

aseru@stanford.edu 


\title{
Beyond the Balance Sheet Model of Banking: Implications for Bank Regulation and Monetary Policy
}

\author{
Greg Buchak, Gregor Matvos, Tomasz Piskorski, and Amit Seru*
}

This Version: JULY 2022

Bank balance sheet lending is commonly viewed as the predominant form of lending. We document and study two margins of adjustment that are usually absent from this view using microdata in the $\$ 10$ trillion U.S. residential mortgage market. We first document the limits of the shadow bank substitution margin: shadow banks substitute for traditional - deposit-taking — banks in loans which are easily sold, but are limited from activities requiring on-balance-sheet financing. We then document the balance sheet retention margin: banks switch between traditional balance sheet lending and selling loans based on their balance sheet strength, behaving more like shadow banks following negative shocks. Motivated by this evidence, we build and estimate a workhorse structural model of the financial intermediation sector. Banks and shadow banks compete for borrowers. Banks face regulatory constraints but benefit from the ability to engage in balance sheet lending. Critically, departing from prior literature, banks can also choose to access the securitization market like shadow banks. To evaluate distributional consequences, we model a rich demand system with income and house price differences across borrowers. The model is identified using spatial pricing policies of government-sponsored entities and bunching at the regulatory threshold. We study the quantitative consequences of several policies on lending volume and pricing, bank stability, and the distribution of consumer surplus across rich and poor households. Both margins we identify significantly shape policy responses, accounting for more than $\$ 500$ billion in lending volume across counterfactuals. Secondary market disruptions such as quantitative easing have significantly larger impacts on lending and redistribution than capital requirement changes once we account for these margins. We conclude that a regulatory policy analysis of the intermediation sector must incorporate the intricate industrial organization of the credit market and the equilibrium interaction of banks and shadow banks.

Keywords: Shadow Banks, Balance Sheet Capacity, Market Segmentation, Capital Requirements, Lending, Mortgages, GSEs, Unconventional Monetary Policy

\footnotetext{
* This paper was previously titled "The Limits of Shadow Banks". Buchak is at Stanford Graduate School of Business (GSB), Matvos is at Northwestern University and the National Bureau of Economic Research (NBER), Piskorski is at Columbia GSB and NBER, and Seru is at Stanford GSB, the Hoover Institution, the Stanford Institute for Economic Policy Research (SIEPR), and NBER. We thank the National Science Foundation (Award 1628895) for financial support. We thank Sumit Agarwal, Adrien Auclert, Anat Admati, Matteo Benetton, John Cochrane, Dean Corbae, Ramona Dagostino, Anthony DeFusco, Peter DeMarzo, Darell Duffie, Andrea Eisfeldt, Mark Egan, Neil Esho, Andreas Fuster, Paul Goldsmith-Pinkham, Itay Goldstein, Ben Hebert, Erik Hurst, Arvind Krishnamurthy, Debbie Lucas, Chris Mayer, Guillermo Ordonez, Chris Palmer, Karen Pence, Tarun Ramodarai, Alexi Savov, Antoinette Schoar, David Scharfstein, Hyun Shin, Jeremy Stein, Johannes Stroebel, Amir Sufi, Adi Sunderam, Joe Vavra, Arlene Wong, and seminar participants at AQR, Bank for International Settlements, Columbia GSB, European Central Bank, Harvard Business School, Hoover Institution, Housing Finance Policy Center, Indian School of Business, MIT Sloan, Stanford GSB, Yale University, UCLA, University of Texas at Austin, Washington University in St. Louis, Boston College, UNC, University of Rochester, Kellogg School of Management, University of Illinois at Urbana Champagne, and participants at ASSA meetings (Econometric Society), Kellogg Housing and Macroeconomics Conference, Midwest Finance Association Conference, NBER Monetary Economics, NBER Summer Institute, Wharton Conference on Liquidity and Financial Fragility, Stanford Institute of Theoretical Economics Financial Regulation Conference, Office for Financial Research Financial Stability Conference, FDIC Financial Technology Conference, Summer Real Estate Symposium, Central Bank Research Association annual meeting, and the San Francisco Federal Reserve Conference on Advances in Financial Research for helpful comments. We also thank Susan Cherry, Monica Clodius, Sam Liu, and Yilan Zheng for outstanding research assistance. First Version: February 2018.
} 


\section{Section I: Introduction}

Policymakers and researchers have long viewed balance sheet lending by deposit-taking institutions - traditional banks - as the predominant way loans are supplied to households and firms (Sunderam 2015). Under this view, banks use deposits to extend loans, which they hold on their balance sheet until repayment or default. Therefore, traditional banks have been the main focus of regulation and supervision in financial intermediation. The bank balance sheet view omits two important aspects of modern financial intermediation.

First, a substantial share of financial activity has migrated to the less regulated shadow banking sector. ${ }^{1}$ For instance, following the increase in bank regulation after the 2008 financial crisis, the share of shadow bank loan origination more than doubled in the $\$ 10$ trillion U.S. residential mortgage market. Shadow banks now account for the majority of new mortgage originations (Buchak et al. 2018). Financial intermediation regulation therefore needs to account for this "shadow bank migration margin" of adjustment in the supply of financial intermediation. ${ }^{2}$ In this paper, we document the shadow bank migration margin primarily for activities which do not require on-balancesheet financing. Banks, by virtue of deposit financing, retain an advantage in balance-sheet intensive activities. In other words, differences in financing result in market segmentation.

Second, banks themselves sell over $50 \%$ of the originated loans instead of holding them on their balance sheet (see Buchak et al. 2018, Irani et al. 2018, Seru 2019). We document a new margin of adjustment by traditional banks, which we call the "balance sheet retention margin." When faced with shocks, traditional banks adjust their business models, switching from on-balance-sheet lending to off-balance-sheet lending. The two sets of facts we document suggest that the allocation of intermediation activity and risks between banks and shadow banks is determined by the industrial organization of financial intermediation as well as the changing business models of banks. We then build a workhorse structural model of the financial intermediation sector and demonstrate that these margins of adjustment are central to understanding consequences of policies such as capital requirements and monetary policy.

We explore the interaction of banks and shadow banks in two main residential mortgage market segments in the U.S. - the conforming market and the jumbo market - for two broad reasons. First, these two segments account for the vast majority of the $\$ 19.5$ trillion $^{3}$ residential mortgages originated during our sample period (Beraja et al. 2019; Wong 2018; Palmer 2015). Second, the institutional difference between these segments allows us to study the role of balance sheet capacity. Originating conforming mortgages does not require as much balance sheet capacity since these loans are eligible for purchase by Government-Sponsored Enterprises (GSEs). Jumbo mortgages, on the other hand,

\footnotetext{
${ }^{1}$ See Gennaioli, Shleifer, and Vishny (2013); Ordonez (2018); and Moreira and Savov (2017) for models of shadow banking, and Greenwood and Scharfstein (2013) and Adrian and Ashcraft (2016) for a comprehensive review.

${ }^{2}$ For instance, the banking regulation proposal of the Minneapolis Federal Reserve, the "Minneapolis Plan," discusses taxing activity that migrates to shadow banking following higher capital requirements: https://www.minneapolisfed.org/publications/special-studies/endingtbtf/final-proposal/summary-of-the-minneapolisplan-to-end-too-big-to-fail.

${ }^{3}$ Mortgage Bankers Association estimates for 1-4 unit family homes [accessed August 12, 2019] https://www.mba.org/Documents/Research/Historical\%20Mortgage\%20Origination\%20Estimates.xlsx.
} 
are not eligible for GSE support and - especially since the disappearance of the private securitization market after the financial crisis - are more difficult to securitize; the vast majority of jumbo loans are retained on the lenders' balance sheets. We exploit this difference to understand the role of banks' balance sheet capacity in shaping the migration of activity between banks and shadow banks.

We begin by documenting large swings in the share of balance-sheet intensive (jumbo) mortgage originations during this period. From 2007 to 2009 the share of jumbo originations declined precipitously relative to easy-to-sell (conforming) mortgages, from about $28 \%$ to $9 \%$, only to reverse back to $30 \%$ by 2014 . These market swings coincided with a dramatic migration of mortgage origination activity to shadow banks (Buchak et al. 2018). We document that the migration was limited to the conforming sector, where shadow banks gained 30\% of market share from 2008 to 2017. In balance-sheet intensive jumbo mortgages, shadow banks did not gain substantial market share; traditional banks' share persisted close to or a above $80 \%$ despite large declines in the quantity they lent during the Great Recession.

We argue that this market segmentation arises because traditional banks and shadow banks differ in their ability to extend balance-sheet intensive (jumbo) and easy-to-sell (conforming) mortgages. Traditional banks' comparative advantage in the jumbo market arises from their ability to retain these loans on their balance sheets. To separate this explanation from alternatives, we exploit the sharp size discontinuity in the ability to securitize a mortgage. Any mortgage that exceeds the conforming loan limit becomes a jumbo mortgage and is much more difficult to securitize. This institutional feature is also a source of variation in our structural estimation.

Most alternative explanations for banks' comparative advantage in jumbo lending suggest that this advantage would increase continuously with mortgage size. For example, if richer borrowers prefer borrowing from banks, one would imagine that borrowers' demand for banking services would increase continuously with mortgage size, as one transitions from conforming to jumbo mortgages. Instead, we find a sharp 30 percentage point (pp) increase in banks' market share at the conforming limit. Moreover, balance sheet capacity is the likely cause of market segmentation, as opposed to other regulatory differences between banks and shadow banks. We compare better-capitalized banks with larger balance sheet capacity to less well-capitalized banks, which face the same regulation. The market share of well-capitalized banks jumps by about $10 \%$ at the conforming limit. These results are consistent with the view that the limited balance sheet capacity of shadow banks prevents migration of balance-sheet intensive activities to the shadow banking sector.

The behavior of mortgage prices is also consistent with our hypothesis. The relative price differential between jumbo mortgages and conforming mortgages (jumbo spread) experienced significant variation during our sample period. Periods during which jumbo origination quantity was low were periods of high jumbo spreads, and vice versa. Moreover, the jumbo spread decreased with the aggregate relative capitalization of jumbo versus conforming lenders. The contemporaneous decrease in quantity and increase in price suggests supply shocks (balance sheet capacity of jumbo lenders) contributed to these aggregate changes. 
Last, we show that banks themselves face an important margin of adjustment to balance sheet capacity shocks, the aforementioned balance sheet retention margin. Banks adjust to a decline in balance sheet capacity by decreasing lending on balance sheet and increasing originations of loans that are easier to securitize. In other words, banks' business models are adaptable. Banks that are flush with capital behave as standard balance sheet models of banking would suggest: they use their capital to extend loans, which they retain on their balance sheets. However, as banks' balance sheet capacity declines, they switch to originating mortgages, which they can sell, behaving more like shadow banks.

Motivated by this evidence, we build and estimate a workhorse structural model of the financial intermediation sector. It incorporates competition from shadow banks and banks' abilities to choose to lend on balance sheet and to sell loans. The model has several goals. First, we want to understand how the industrial organization of intermediation and the choice of bank business model determine who originates which types of mortgages, and at which interest rates. Second, we want to use the model to quantitatively analyze the consequences of capital requirements, access to secondary loan markets, and unconventional monetary policy on lending volume and pricing, bank stability, and the distribution of consumer surplus across rich and poor households. In the process, we quantify the importance of the shadow bank migration and balance sheet retention margins for policy analysis.

The supply side of the model is determined by competing banks and shadow banks, which offer differentiated mortgages in the jumbo and conforming markets. The central innovation is in modeling banks. As is common in banking models, banks can originate loans, which they keep on their balance sheet, and their balance sheet capacity is limited by their capitalization. We differ from standard models by allowing banks to adjust their business models on the balance sheet retention margin: banks can choose how many loans to retain versus sell. Shadow banks benefit from a lower regulatory burden (Gete and Reher (2018); Buchak et al. (2018)) and compete with banks in originating loans, but can only finance loans by selling them. Additionally, in line with the empirical facts and relative ease of entry and exit for shadow banks, we allow for entry and exit of non-fintech shadow banks.

We model demand using a modified discrete-choice framework featuring rich heterogeneity (Berry et al. 1995; Nevo 2000). Consumers with heterogeneous preferences over price, quality, and mortgage size choose among a menu of mortgages offered by various types of originators. This heterogeneity is important to accommodate realistic consumer substitution patterns and, especially, to capture the redistributive consequences of policies (see Stroebel and Vavra (2019) and Wong (2018)). Because markets are segmented, policy interventions have redistributive consequences. For example, if capital requirements decrease the supply of on-balance-sheet lending, then this policy will likely be costlier for wealthier borrowers, who are more likely to take jumbo mortgages. We depart from discretechoice models by also allowing consumers to choose their mortgage size and, consequently, decide whether they want a conforming or jumbo mortgage (see Benetton (2019) for an alternative way to model discrete-continuous choices in the mortgage market).

We estimate demand and supply separately. To identify standard demand parameters, we need to instrument for price endogeneity. We exploit geographic differences in financing cost of GSEconforming mortgages, which arise through political economy considerations and are unrelated to mortgage demand (see Hurst et al. (2016) for extensive documentation of that fact). Second, we 
exploit bunching at the conforming-jumbo cutoff to help estimate consumer preferences for mortgage size. Intuitively, consumers who bunch at the conforming loan limit choose a smaller than ideal mortgage. The higher the disutility from taking on a smaller than ideal mortgage, the less bunching we observe. Having estimated demand, we estimate supply-side parameters using intermediary price setting and financing decisions.

Our model captures the salient features of the data, such as the market shares of banks and shadow banks, as well as pricing of mortgages. The model estimates match the extent of bunching at the conforming discontinuity across markets and price elasticity estimates from the literature (see DeFusco and Paciorek (2017)). As out-of-sample validation of our model, we study model performance following policy changes in conforming loan limits. Our model predicts changes that are quantitatively very close to the realized changes. Moreover, we find that consumers are very price elastic, with lower price elasticity in the jumbo market. Since this market faces less competition from shadow banks, it is a source of rents for banks.

On the supply side, our estimates suggest that financing jumbo mortgages is more expensive than financing conforming mortgages, even when the latter are retained on the balance sheet. The difference declines with bank capitalization and even reverses for very well-capitalized banks. Moreover, post-2012 increases in the regulatory burden of traditional banks substantially constrained their mortgage origination. This suggests that noncapital requirement-related regulatory constraints, such as risk of enforcement actions and lawsuits, provided a large advantage to shadow banks and contributed more to shadow bank migration than the increased capital requirements.

Next, we use our estimated model to consider three policy relevant counterfactuals: changing capital requirements (Acharya et al. 2011; Benetton 2019); unconventional monetary policy such as QE or GSE interventions (see Wong (2018), Di Maggio et al. (2020), Luck and Zimmermann (2020), Agarwal et al. (2020)); and changing the access to a secondary loan market through the GSEconforming limit. These policies lead to changes in the quantity, pricing, and distribution of mortgage credit, as well as where the credit is held in the intermediation sector.

One overarching insight from the counterfactuals is that adjustments on the shadow bank migration margin and the balance sheet retention margin are both critical to understanding quantitative consequences of policies. For example, the tradeoff between bank stability and lending is much less severe than anticipated by models that feature only on-balance-sheet lending. Our model predicts that increasing bank capital requirements from current levels to $9 \%$ reduces bank balance sheet lending by $88 \%$, but overall mortgage lending declines by only $10 \%$. The critical margin of adjustment in this case is the balance sheet retention margin: while balance sheet lending declines by $88 \%$, total bank lending declines by only $25 \%$ as banks move their lending from retention to selling. Accounting for migration of lending to shadow banks fills the remainder of the gap. Both margins are equally important in quantitatively shaping responses to other policies. These findings connect to the literature, which argues that high capital requirements associated with credit crunches, induce constrained banks to sell loans (see Pennacchi (1988) and Peek and Rosengren (1995)). In contrast, we show that due to the secondary market a capital regulation-induced credit crunch is less likely even in the absence of shadow banks, due to banks switching their business model. A model of 
financial intermediation must therefore account for both the highlighted margins when evaluating policies.

The second general insight is that the overall adjustment depends on whether policy interventions target traditional banks or secondary markets. When tighter regulation only targets traditional banks (e.g., increased capital requirements), solely focusing on bank balance sheets overstates the adverse effect of such polices on overall lending volume. The adjustments on the shadow bank migration margin and the balance sheet retention margin work to offset the adverse impact. For policies which tighten the secondary loan market, the shadow bank migration margin exacerbates the effect: lending contracts for shadow banks leading to a large overall decline in lending. For example, if quantitative easing increases GSE financing costs by 100 basis points, bank lending actually increases by $\$ 106$ billion while shadow bank lending decreases by $\$ 600$ billion. Thus policy analysis, which ignores the role of bank balance sheet adjustment and shadow bank lending, would result in incorrect qualitative and quantitative predictions.

The third insight is that interventions aimed at bank stability differ in their redistributive consequences. For example, increasing capital requirements achieves bank stability by decreasing onbalance-sheet lending, i.e., reducing jumbo mortgages. Therefore, the cost of bank stability is mainly borne by higher-income borrowers. An expansion of GSE funding increases the appeal of securitization, also shifting loans from bank balance sheets and increases bank stability. It does so while expanding lending and benefiting consumers across the income spectrum, but it comes at the cost of taxpayers subsidizing GSE lending.

These insights generate implications for regulation that go beyond the U.S. market. For instance, the Basel regulatory framework proposes a uniform treatment of capital requirements across countries. The U.K., for example, does not have a large and liquid secondary market for mortgages (Benetton 2019). Our analysis suggests that increasing capital requirements in the U.K. would result in a substantially higher contraction in lending than in the U.S. due to the absence of bank retention margin. More generally, regulatory policy response in different economies needs to consider the two margins of adjustment we highlight above.

More broadly, our work speaks to the theories of banking in the presence of shadow banks (see Sunderam (2015) and Koijen and Yogo (2016)). The traditional view of banks is that they use deposits to make loans, which they retain on their balance sheet. Our paper suggests that banks' choice of business model depends on both their capitalization and their equilibrium interaction with shadow banks. On one end of the spectrum are well capitalized banks, which dominate the market for loans that are retained on the balance sheet. At the other end are shadow banks, which originate to distribute (OTD). In the middle are poorly capitalized banks with limited balance sheet capacity, whose participation in the market for retained loans is limited. Thus, we argue that a complete policy analysis must incorporate the industrial organization of the credit market and the equilibrium interaction of banks and shadow banks. 


\section{Section II: Institutional Setting and Data}

\section{II.A U.S. Residential Mortgage Market}

The residential mortgage market is the largest consumer finance market in the U.S. As of 2017 there have been more than 50 million residential properties that have a mortgage with a combined outstanding debt of about $\$ 10$ trillion (Source: Corelogic Data). In the U.S., the process by which a mortgage is secured by a borrower is called origination. This involves the borrower submitting a loan application and documentation related to his or her financial history and/or credit history to the lender. We discuss below the main segments of the U.S. residential mortgage market and the associated lenders active in these markets.

\section{II.A.1 Banks, Shadow Banks, and Loan Origination Business Models}

The two main groups of mortgage originators in the U.S. are banks and shadow banks (nonbank lenders). Buchak et al. (2018) document a decline in traditional bank originations and the growth of shadow banks, with the shadow bank market share growing from less than $30 \%$ to more than $50 \%$ by 2015. These originators differ on at least three dimensions. First, banks (traditional banks and credit unions) partially fund their lending through insured deposits. Shadow banks do not take deposits. Second, they differ in terms of their business models. There are two business models a loan originator can follow: portfolio lending or originate-to-distribute. Portfolio lending implies the originator retains the loan on their balance sheet. Conversely, in the originate-to-distribute model, originators can sell the loan as well as service rights. Banks engage in both models, with portfolio loans comprising about $40 \%$ of their originations during our sample period. Shadow banks, on the other hand, almost exclusively originate to distribute (see Buchak et al. (2018)). The third difference is in regulation. Banks face a substantially higher regulatory burden than shadow banks, including capital requirements; enhanced supervision from a wide set of regulators, such as the FDIC, FED, OCC, and state regulators; as well as extensive compliance and rules.

\section{II.A.2 Mortgage Products}

We focus on two main residential mortgage market segments in the U.S.: the conforming loan market and the jumbo loan market. Together these two segments account for more than $80 \%$ of all U.S. residential mortgages originated during our sample period (based on the Home Mortgage Disclosure Act). The largest residential market segment in the U.S. consists of conforming loans. These are usually extended to borrowers with relatively high credit scores, with loan-to-value (LTV) ratios typically up to $80 \%$, and fully documented incomes and assets. Conforming mortgages must be below the conforming loan limit, which grew from $\$ 417,000$ in 2007 to $\$ 424,000$ in 2017 for a one-unit, single-family dwelling in a low-cost area, and from $\$ 625,000$ to $\$ 636,000$ for the same unit type in a high-cost area. In addition, the American Recovery and Reinvestment Act of 2009 temporarily increased these limits in certain high-cost areas to up to $\$ 729,500$. Mortgages that exceed the conforming limit are termed "jumbo."

Government-sponsored enterprises (GSEs) allow for substantially easier securitization of conforming mortgages. For example, Fannie Mae and Freddie Mac, the two most prominent GSEs, purchase conforming mortgages and package them into mortgage-backed securities (MBS), insuring default 
risk. These MBS are particularly attractive to investors interested in relatively safe assets. In 2017, conforming loans in mortgage-backed securities guaranteed by Fannie Mae and Freddie Mac comprised about $50 \%$ of the outstanding residential loans (Source: Securities Industry and Financial Markets Association Data). Because jumbo mortgages are ineligible for GSE financing, they are issued without government guarantees. Consequently, these mortgages are significantly more difficult to securitize, and the vast majority are retained by the originators.

\section{II.B Description of Datasets}

Our paper brings together a number of datasets which we describe below:

HMDA: Mortgage-level application data from 2007 to 2017 is the main source for market shares across lender and product types. The Home Mortgage Disclosure Act (HMDA) collects the vast majority of mortgage applications in the U.S., along with their approval status. The dataset includes loan type, purpose, amount, year of origination, and location information down to the applicant's census tract as well as applicant income. Important for this analysis, it includes the originator's identity, which we link manually across years. Finally, it documents whether the originator sells the loan to a third party within the calendar year, and if so, whether the loan purchaser is a GSE. If the originator sells the loan in the subsequent year, it is recorded in HMDA as a non-sale. ${ }^{4}$

Fannie Mae and Freddie Mac Single-Family Loan Origination Data: These datasets, provided by Fannie Mae and Freddie Mac, contain origination data from the GSEs' thirty-year, fully amortizing, full-documentation, single-family, conforming fixed-rate mortgage purchases. ${ }^{5}$ The loan-level data contain information on the loan, property, and borrower, including loan size, interest rate, loan purpose, property location, borrower credit score, loan-to-value ratio, and, importantly, the identity of the lender that sold the loan to the GSE. We use these data to calculate average interest rates by lender type and market.

Black Knight McDash Loan-Level Mortgage Performance Dataset: Black Knight is a private company that provides a comprehensive, dynamic loan-level dataset on mortgages, including loans serviced by the ten largest U.S. mortgage servicers, accounting for approximately $75 \%$ of all mortgages in the U.S. as of year-end 2010 (data vendor estimate). Importantly, Black Knight includes information on jumbo and GSE loans and loans retained on banks' balance sheets. It contains interest rates and a large number of borrower- and loan-specific characteristics, including FICO score at origination, loan-to-value ratio, five-digit zip code of origination, loan purpose, and whether the loan is fixed or adjustable-rate. The Black Knight McDash data also include dynamic data on monthly payments, mortgage balances, and delinquency status.

\footnotetext{
${ }^{4}$ Buchak et al. (2018) find that among conforming loans, the time-to-sale is roughly 40 days. This implies that our measure of balance-sheet retention is overstated across all lenders by roughly $10 \%$. Because most of our results are about differences across banks and shadow banks and banks by capitalization, this level effect is largely differenced out.

${ }^{5}$ The dataset does not include adjustable-rate mortgage loans, balloon loans, interest-only mortgages, mortgages with prepayment penalties, government-insured mortgage loans such as Federal Housing Authority loans, Home Affordable Refinance Program mortgage loans, Refi Plus ${ }^{\mathrm{TM}}$ mortgage loans, or nonstandard mortgage loans. The dataset also excludes loans that do not reflect current underwriting guidelines, such as loans with originating LTVs over $97 \%$ and mortgage loans subject to long-term standby commitments, those sold with lender recourse or subject to other third-party risk-sharing arrangements, or those acquired by Fannie Mae on a negotiated bulk basis.
} 
U.S. Census Data: We use metropolitan statistical area-level data on incomes, homeownership rates, and home values from the U.S. Census and American Community Survey between 2010 and 2017.

Federal Reserve Bank Data: We use banking regulatory call reports to measure bank capital ratios, ${ }^{6}$ assets, deposits, and other data from bank balance sheets spanning 2007 through 2017.

\section{II.C Lender Classification}

We classify lenders as in Buchak et al. (2018). ${ }^{7}$ Briefly, a "bank" is a depository institution and a "shadow bank" is not. This definition parallels that of the Financial Stability Board, which defines banks as "all deposit-taking corporations" and shadow banking as "credit intermediation involving entities and activities outside of the regular banking system." Additionally, we classify shadow bank lenders as "fintech" or "non-fintech" according to Buchak et al. (2018).

\section{Section III: Empirical Analysis}

We present a set of empirical facts regarding price, quantity, and composition of mortgage credit, and industrial organization of the market. These facts motivate our analysis and model, shedding light on the drivers of the comparative advantage of banks and shadow banks. Table 1 shows summary statistics for the main datasets used in our analysis.

\section{III.A Aggregate Facts}

\section{III.A.1 Bank Balance Sheet Supply Shock: On-Balance Sheet Lending Volumes and Prices}

We start by documenting three related aggregate trends in Figure 1. As the capitalization of the banking sector declined from 2007 to 2009, the share of on-balance sheet (jumbo) mortgage originations declined and their relative price increased. From 2009 onwards these trends reversed: as the capitalization of the banking sector increases, balance sheet (jumbo) mortgage originations increased and their relative price declined. We argue that these trends suggest that a decline in the balance sheet capacity of the banking sector serves as a supply shock to on-balance-sheet lending. We next discuss these trends in more detail.

Figure 1A presents the relative share of the jumbo market in the overall origination volume. This share declined sharply from $28 \%$ in 2007 to about 9\% in 2009. From 2009 onwards, the jumbo share experienced a substantial increase, reaching about 30\% in the 2014 to 2017 period. Figure 1B, which shows total origination volumes, illustrates that this trend was driven by changes in the jumbo market: the jumbo market collapsed before recovering to earlier levels.

Figure 1C shows that these contractions in the jumbo market share were accompanied by increases in the relative interest rates of jumbo mortgages to conforming mortgages, the "jumbo spread," and vice versa. Before the crisis, the aggregate data showed virtually no aggregate jumbo spread. As the quantity of jumbo mortgages contracted towards 2009, their relative price increased by almost 40 basis points, and as much as 70 basis points in early 2009. As the market share of jumbo mortgages recovered, the jumbo spread decreased by up to 60 basis points. The positive correlation between

\footnotetext{
${ }^{6}$ In particular, tier-one risk weighted capital ratios.

${ }^{7}$ A complete lender classification is available at https://sites.google.com/view/fintech-and-shadow-banks.
} 
aggregate price and quantity suggests that supply shocks may be partially responsible for driving the aggregate trends. If the contraction in jumbo quantity was solely driven by demand for jumbos (e.g., due to a decline in house prices), we should also observe a decrease in the pricing of jumbo mortgages.

We next show that changes in the capitalization of the banking sector are a candidate source of these supply shocks. Figure 1D illustrates that the banking sector capitalization was at a low point going into the crisis in 2007, remained low in 2008, and began increasing thereafter. Overall, these patterns suggest that as traditional bank capitalization declines, the amount of on-balance sheet (jumbo) lending declines and their relative pricing increases. In other words, these aggregate facts are consistent with the idea that a decline in the balance sheet capacity of the banking sector serves as a supply shock to on-balance-sheet lending, at least relative to lending, which can be securitized.

\section{III.A.2 Shadow Bank Migration and Banks'Business Model Adjustment}

The jumbo and conforming market segments experienced large changes in their market structure, which can be captured in two trends. The first trend is related to the migration of residential mortgage origination activity to shadow banks. Prior work shows that during this period, $25 \mathrm{pp}$ of market share migrated to shadow banks (Buchak et al. 2018). Central to this paper, we show that the migration of shadow banks did not take place in balance-sheet intensive jumbo lending. Bank market share in the jumbo market has remained fairly stable, varying between $80 \%$ and $95 \%$. This contrasts with the conforming mortgage market, in which bank market share declined by over one third, from slightly under $70 \%$ in 2007 to about 40\% in 2016 (Figure 2A). In other words, the contraction and later expansion in the amount of jumbo lending is mainly driven by changes in originations by traditional banks. The changes in the conforming market, on the other hand, are driven by changes in both shadow and traditional bank originations.

Figure 2B shows traditional banks adjusted their business models, which coincided with changes in their capitalization. One possible way to interpret the facts above is that traditional banks uniformly contracted their lending across markets as their capitalization decreased, but shadow banks chose to only expand in the conforming market. This was not the case. Figure 2B shows that as banks' capitalization $^{8}$ declined during the financial crisis, the share of jumbo mortgages in their lending declined from $30 \%$ to $10 \%$--they shifted their lending to easy to sell conforming mortgages. As bank capitalization increased, they shifted their originations back to on-balance-sheet lending with jumbo mortgages comprising more than $45 \%$ of their originations by 2017 . In other words, banks appear to adjust to capitalization and other regulatory shocks by switching between the classic banking model (originating and retaining loans) and the originate-to-distribute model (shadow bank model). We call this margin on which banks can adjust the "balance sheet retention margin."

\section{III.A.3 Summary of Aggregate Facts}

The aggregate facts we document are consistent with the idea that banks and shadow banks differ in their ability to extend on balance sheet (jumbo) and easy to sell (conforming) mortgages, resulting in

\footnotetext{
${ }^{8}$ We measure capital using the variable "Total Tier-1 Risk-Based Capital to Adjusted Risk-Weighted Assets and Adjusted for Financial Subsidiaries if Reported” from call reports.
} 
market segmentation. Because shadow banks do not have much balance sheet capacity, they mainly originate to distribute, which is limited to the conforming market. This market segmentation implies that a decline in the balance sheet capacity of the banking system leads to a relatively larger contraction in traditional on balance sheet mortgage supply through two channels. First, shadow banks, lacking balance sheet capacity, respond to rising bank constraints by expanding in the conforming market, but cannot do so in the jumbo market. Second, traditional banks, lacking balance sheet capacity, tilt their activity towards easy to sell conforming originations and away from retaining loans on balance sheet. The larger contraction in the supply of jumbo mortgages leads to an increase in their relative price, i.e., an increase in the jumbo-conforming spread.

\section{III.B Micro Evidence}

In this section, we provide micro-level evidence consistent with the aggregate facts, which narrows down the potential interpretations of the forces driving the aggregate data.

\section{III.B.1 Market Segmentation at the Conforming Loan Limit}

We exploit the conforming loan size limit discontinuity to narrow the scope of possible explanations. One set of alternative explanations centers on economic shocks, which simultaneously change the demand for jumbo mortgages and bank capitalization. For example, suppose that wealthy borrowers who are more likely to take up jumbo mortgages also have larger demand for other banking services. In other words, the alternative explanation is that banks specialize in large loans, which also happen to be jumbo loans. During the crises, housing demand of the wealthy contracted, for example, because of house price shocks, leading to a decrease in demand for jumbo. As we argue above, this should have led to a decrease in jumbo prices, so demand side explanations alone are not sufficient to explain aggregate patterns. Here we provide additional evidence exploiting the sharp loan amount cutoff to qualify as a conforming loan which we discussed in Section II. Borrowers' demand for banking services or exposure to economic shocks should increase somewhat continuously with mortgage size, rather than jump exactly at the conforming cutoff. The ability to securitize a mortgage, on the other hand, discontinuously drops at the conforming loan amount. Thus, observing a discontinuous jump in the bank market share at the conforming limit would reject the demand alternative.

We first confirm that the probability of a loan being retained on balance sheet indeed discretely jumps at the conforming loan limit. As Figure 3A shows, the fraction of loans retained on lenders' balance sheets discontinuously jumps from about $20 \%$ just below the conforming loan limit to almost $80 \%$ just above the conforming loan limit.

To test whether banks specialize in large loans or in jumbo loans, we confirm that their market share discretely increases at the conforming loan limit in Figure 3B. Banks' market share of loans just below the cutoff is roughly $55 \%$, whereas bank market share above the cutoff is roughly $80 \%$. The results suggest that banks have a comparative advantage in originating jumbo loans because these loans are difficult to sell.

We next more formally test whether balance sheet financing share and bank market share discretely jump at the conforming loan limit discontinuity. We focus on mortgages within $1 \%$ of the conforming 
cutoff and estimate the extent of the discontinuity at the conforming loan limit using the following regression discontinuity specification:

$$
\text { Bank }_{i l t}=\beta \times \operatorname{Jumbo}_{i}+X_{i}^{\prime} \Gamma+\gamma_{l t}+\epsilon_{i l t},
$$

where Bank $_{i l t}$ is a $\{0,1\}$ indicator variable for whether the loan $i$ in census tract $l$ originated in year $t$ is financed on the balance sheet or originated at a bank, respectively. Jumbo $i$ is an indicator for whether the loan size is above the conforming loan limit in the time-county of origination, and the corresponding coefficient $\beta$ is the object of interest. $X_{i}^{\prime}$ is a vector of loan-level controls including log loan size, log applicant income, and dummy variables for race, ethnicity, sex, loan type, loan purpose, occupancy, and property type. $\gamma_{l t}$ is a census tract-origination year fixed effect, which absorbs any variation in local conditions over time, as well as regulatory differences. In other words, we examine the effect by comparing loans from the same census tract and year around the conforming limit, adjusting for observable borrower differences. For robustness, we also experiment with larger samples, those within $5 \%, 10 \%$, and $25 \%$ of the conforming loan limit.

Table 2A shows that loans directly above the conforming loan limit experience about $60 \mathrm{pp}$ increase in the share of loans financed on the balance sheet. Increasing the bandwidth above $1 \%$ produces similar results, as shown in columns 2-4. In 2017, the most recent year in our sample with complete data coverage, this association is even stronger: the share of loans financed on the balance sheet jumps by about $63 \mathrm{pp}$ above the conforming loan limit (column 5).

Table 2B shows that loans directly above the conforming loan limit are nearly $32 \mathrm{pp}$ more likely to have been originated by a traditional bank, as opposed to a shadow bank. As above, when considering only loans originated in 2017, this difference grows to $47 \mathrm{pp}$ (column 5). Increasing the bandwidth above $1 \%$ produces similar results, as shown in columns $2-4$ and $6-8$. The results around the discontinuity illustrate that traditional banks specialize in originating mortgages, which have to be retained on the balance sheet, and not simply mortgages, which are large.

\section{III.B.2 Within-Bank Analysis: Balance Sheet Capacity and the Balance Sheet Retention Margin}

In the previous section, we look at market segmentation between banks and shadow banks. In this section, we look within banks. We do so for two reasons. First, we use within-bank analysis to show that balance sheet capacity is driving banks' comparative advantage in the jumbo market, rather than other regulatory differences with shadow banks. Second, we provide micro evidence for the balance sheet retention margin within banks: as a bank's capitalization declines, it shifts its activity away from on balance sheet lending.

\section{Market Segmentation and Balance Sheet Capacity: Conforming Loan Limit Discontinuity}

Our findings above are consistent with the idea that banks' ability to finance loans with their balance sheets generates a strong comparative advantage in the segment for difficult-to-sell loans-i.e., jumbo loans. However, balance sheet capacity is not the only differentiating factor between banks and shadow banks; for example, shadow banks are subject to a very different regulatory burden than traditional banks (see Buchak et al. (2018)). If low balance-sheet capacity is the source of market 
segmentation between banks and shadow banks, then we should observe similar segmentation between well-capitalized and poorly capitalized banks.

In aggregate evidence in Section III.A, we present raw measures of bank capitalization. Shifting to micro data, we want to account for the possibility that optimal capital ratios differ across banks, so the level of capital that is adequate for one bank, may in fact result in another bank being undercapitalized, because of different banking activities on the asset or liability side may require different capital structure (Jiang et al. 2021). ${ }^{9}$ We therefore compute a bank's capital ratio gap, the difference between a banks' capital, and its target capital ratio (see Plosser and Santos 2018 for a recent work using target capital ratios). We first estimate the target capital ratio of bank $b$ at time $t$, $\widehat{C R_{b t}}$, as follows:

$$
C R_{b t}=X_{b t}^{\prime} \mathrm{B}+\epsilon_{b t}
$$

The vector of bank controls, $X_{b t}^{\prime}$, includes log number of originations, log bank assets, deposits to liabilities, log of the average loan size and applicant income of the bank's originations. The object of interest is the deviation of a banks' capital from its' capital requirement, the bank's capital ratio gap:

$$
\Delta C R_{b t}=C R_{b t}-\widehat{X_{b t}^{\prime}} \mathrm{B}=\epsilon_{b t}
$$

i.e. the residual from the target capitalization regression.

We define a bank to be well capitalized if its capital ratio gap is positive, $\Delta C R_{b t}>0$. Figure $3 \mathrm{C}$ shows that the well capitalized banks' market share jumps discontinuously by about 5 pp at conforming loan cutoff, suggesting that these banks possess a comparative advantage in jumbo mortgage lending. We formally test for the discontinuity in Table 3. First, within the sample of loans originated by banks, the likelihood of loan to be retained on the balance sheet significantly jumps at the conforming loan limit (Table 3A). Second, the fraction of loans originated by the well-capitalized banks substantially increases at the conforming loan limit (Table 3B). These results suggest that the balance sheet capacity of well-capitalized banks gives them a comparative advantage in the jumbo sector relative to both shadow banks and poorly capitalized traditional banks, leading to market segmentation.

\section{Balance Sheet Retention Margin}

In the aggregate data we document that banks' business models adjust to shocks in balance sheet capacity. They shift away from originating balance-sheet intensive loans (jumbo), and towards loans they can sell (conforming) when their capitalization declines. Here, we provide micro evidence of the balance sheet retention margin.

Figure 4A shows a scatter plot of banks' shares of loans retained on the balance sheet (adjusted for observable characteristics as in eq. 2) as a function of their capital ratio gap. The plot illustrates a strong positive relationship between bank capitalization and the share of loans they choose to retain

\footnotetext{
${ }^{9}$ We thank the referee for suggesting adjusted capital ratios. The results are robust to using raw capital rations. See Appendix B2.
} 
versus sell. Figure 4B shows that this is the case within a bank as well. Banks, which experience a decrease in balance sheet capacity are more likely to sell loans, rather than retain them on the balance sheet. In other words, banks change their business models in response to changes in their balance sheet capacity. As banks' balance sheet capacity declines, they shift towards the originate-todistribute model and then move back towards portfolio lending as their balance sheet capacity improves.

We more formally investigate whether traditional banks are more likely to retain a larger share of originated mortgages on their balance sheet if they are better capitalized using the following specification:

$$
\operatorname{Retain}_{i x b t}=\beta \Delta C R_{b t}+\gamma_{t x}+\gamma_{b}+X_{b t}^{\prime} \Gamma+\epsilon_{b t}
$$

Where Retain $_{\mathrm{ibxt}}$ is the dummy variable that takes value of one if a loan $i$ originated in location $x$ (census tract) is retained on the balance sheet by bank $b$ in year $t, \Delta C R_{b t}$ is a bank's capital ratio gap; $\gamma_{\mathrm{b}}$ are bank fixed effects, controlling for differences in banks' propensities towards portfolio lending, as well other time invariant differences in business models; $\gamma_{\mathrm{tx}}$ are time-location fixed effects, which absorb any aggregate and regional changes that would affect the business model of banks, including aggregate demand or supply fluctuations and local economic conditions such as house prices that would affect the propensity to retain loans on the balance sheet; $X_{b t}$ contains bank controls, including $\log$ number of originations, log bank assets, deposits to liabilities, log of the average loan size and applicant income of the bank's originations, and log of the number of unique census tracts in which the bank lends, fraction of non-core funding and fraction of core deposits to total deposits. ${ }^{10}$ These specifications are estimated for with and without bank fixed effects, $\gamma_{b}$.

Table 4 shows that as a bank's capital ratio gap increases by $1 \mathrm{pp}$, the propensity to retain its loans on balance sheets increases by $2.2 \mathrm{pp}$ (Column 2). Column 4 shows that increases in banks' capitalization are correlated with increased origination of jumbo loans. Column 6 shows that the main within-bank balance sheet retention margin occurs on the dimension of conforming loans. In other words, as banks capitalization increases, they increase the share of conforming loans they retain on the balance sheet. Because the secondary market for jumbo loans is limited, banks can only adjust their balance sheet effect by adjusting originations, which is costly. The large response on retention of conforming loans suggests this is the easiest margin of adjustment, which banks can make without adjusting their originations substantially. ${ }^{11}$ These micro-level results support the aggregate evidence, which suggested that banks vary their business models on the conforming side in response to changes in their own capitalization.

\footnotetext{
${ }^{10}$ Mian and Sufi (2018) show that non-core deposit liability financing played a role in the run-up to the financial crisis.

${ }^{11}$ Due to differences in risk weighting due to regulation, jumbo origination requires more capital than conforming loans. An alternative explanation of our findings could be that some banks have a desire to originate more jumbo loans and, because of regulatory reasons, such banks have to increase their capitalization. This is unlikely to be driving our findings. The reason is that we find this relationship also holds for conforming loans.
} 


\section{III.B.3 Relative Product Pricing}

The aggregate results indicate that balance sheet contraction of traditional banks leads them to contract supply of jumbo mortgages, increasing the jumbo spread. The aggregate jumbo spread may partially reflect the differences in the mortgage composition, for example, if different types of consumers sort to jumbo or conforming mortgages over time. To shed more light on conforming and jumbo loan pricing, we first residualize them against loan characteristics, and then compare them around the conforming loan limit in Figure 5. We compare the period during which the bank capitalization was low (2008) in Panel (b) with the period in which bank capitalization was high, (2017). Similar to aggregate data, there is a sharp discontinuity of about 30 to 40 basis points at the conforming loan cutoff in 2008 (Figure 5B). By 2017 (Figure 5C), on the other hand, we observe that the spread had reversed.

As we discussed above, the positive correlation between aggregate price and quantity and bank capitalization suggests that supply shocks were at least partially responsible for driving the aggregate trends. If the contraction in jumbo lending in the 2007-2009 period was solely driven by demand for jumbos (e.g., due to a decline in house prices), we should also observe a decrease in the pricing of jumbo mortgages. Instead we find the opposite effect: jumbos are relatively more expensive in times of low jumbo-market share.

\section{III.B.4 Consumer "Bunching" at the Conforming Loan Cutoff}

There is well-known bunching at the conforming limit-i.e., there is a mass of borrowers right below the conforming loan cutoff (e.g., DeFusco and Paciorek (2017)). A consumer who would, all else equal, prefer a jumbo mortgage may therefore prefer to choose a cheaper conforming mortgage instead. Presumably such consumers would choose the largest possible mortgage that is still conforming. We confirm this bunching in Figure 6A. As we note above the spread turns negative by 2017, but borrowers still bunch under the conforming loan limit as shown in Figure 6C. The negative spread suggests that some borrowers prefer conforming mortgages even when they are more expensive, because they have favorable non-price characteristics, such as a more streamlined origination and approval process.

We also document a spike in borrower income below the conforming loan limit (Figure 6B). Larger mortgages are, on average, taken out by people with larger incomes. This implies that the bunching at the discontinuity draws from a higher-income population than what the mortgage size would suggest. A large spike in income would suggest that even very wealthy borrowers are willing to take up a smaller mortgage in exchange for lower rates. We formalize this intuition in the model and exploit the moments related to this bunching to estimate the model.

\section{Section IV: Model of Mortgage Demand and Supply}

Motivated by the evidence from the previous sections, we build and estimate a structural model of the U.S. residential mortgage market, which features banks competing with shadow banks for consumers. The model has several goals. First, we want to understand how the industrial organization of financial intermediation and the choice of bank business model determine who originates which types of mortgages and at which interest rates. Second, we then use the estimated model to 
quantitatively analyze the consequences of capital requirements, access to secondary loan markets, and unconventional monetary policy on lending volume and pricing, risk, bank stability, and the distribution of consumer surplus across rich and poor households. Moreover, we quantify the importance of the shadow bank migration and balance sheet retention margins for policy analysis.

Our model builds on Buchak et al. (2018) but is substantially richer in several dimensions on both the demand and supply sides. Most importantly, our model accounts for the market segmentation between products which can easily be sold, and those that cannot (conforming versus jumbo mortgages), both on the demand and supply sides. We briefly discuss some salient features of the supply and demand sides before describing the model in detail.

On the supply side we explicitly model different financing choices across intermediaries. The supply side of the market consists of banks and shadow banks. ${ }^{12}$ Financial intermediaries engage in two activities: loan origination and financing. They can finance mortgages two different ways: portfolio (balance-sheet) lending or originate-to-distribute. In portfolio lending the intermediary finances the mortgage from its own funds. Therefore, differences in lenders' internal funds-i.e., balance sheet capacity - will change their willingness to engage in this activity. Alternatively, intermediaries can originate to distribute: they finance the mortgage by selling it to a third-party financier through GSEs. Following the current institutional setup of the U.S. mortgage market, a central distinction between jumbo and conforming mortgages is that only conforming mortgages can be financed by originating to distribute; jumbo loans are portfolio loans. Banks' ability to shift from balance sheet to GSE financing on conforming loans allows them to endogenously transition between two ways of financing.

Banks can access deposits, which give them the ability to finance portfolio loans. ${ }^{13}$ Shadow banks, on the other hand, have no balance sheet capacity, so they can only originate-to-distribute. The ability to lend on balance sheet comes with several regulatory restrictions. First, banks are subject to capital requirements, which limit their balance sheet capacity. While capital requirements constrain banks' funding advantage, they do not eliminate it. Banks also face regulatory pressures beyond capital requirements. These can arise from legal or regulatory enforcement actions, or the anticipation of future actions on the part of regulators or prosecutors. Rather than affecting the marginal cost of lending, which banks would pass through to consumers, these restrictions prevent lending on the extensive margin by making, e.g., some customers too risky to lend to at all. These regulatory pressures constrain banks' lending activity even if banks are well capitalized. To analyze medium run policy consequences, we also allow for entry and exit to shape the industrial structure. In Section V.E, we relax the assumption that balance sheet capacity is fixed. We allow banks to increase their balance sheet capacity through equity issuance and asset sales.

\footnotetext{
12 To better fit the data, we further distinguish between non-fintech shadow banks and fintech shadow banks, who differ in terms of which types of mortgages they predominantly originate, as well as in the quality of services they provide. (see Buchak et al. (2018)).

${ }^{13}$ Because banks have access to a subsidized funding of their balance sheet through insured deposits, one can model the shadow bank decision not to engage in balance sheet lending as a competitive outcome with a corner solution.
} 
With this setup, our model generates endogenous market segmentation between traditional and shadow banks and within the banking sector between well-capitalized and poorly capitalized banks. In Section V.E we extend our analysis to allow jumbo mortgage securitization.

On the demand side, we build a rich discrete-continuous choice framework with an application to the mortgage market. Importantly, we allow preferences of borrowers to be correlated with their income and house prices. These differences in preferences, especially for larger mortgages, play a critical role in studying the distributional aspects of policies. We also allow for differences in risk across borrowers; unlike preferences, risk is observable to intermediaries, which account for it in pricing of their loans.

\section{IV.A Demand}

Borrowers differ in three dimensions: whether they need the mortgage to finance a purchase or a refinance (mortgage type); whether they are low or high risk; and preferences over mortgages. Lenders observe mortgage type and risk, so we can treat borrowers of different risk and mortgage type as belonging to distinct markets in which lenders charge distinct prices. For example, all potential low risk borrowers in the New York City MSA attempting to refinance their mortgages represent one market. Formally, each market has $i=1, \ldots, I_{c t}$ consumers and $j=1, \ldots, J$ lenders. A market $c$ in year $t$ is defined at geography, loan purpose (refinance or purchase) and risk level. For computational tractability, we have two dimensions of risk: low and high.

Lenders can offer up to two types of products in each market: conforming and jumbo mortgages. All mortgages must satisfy the individual-specific LTV constraint, ${ }^{14} \overline{L T V}$, such that the chosen mortgage size $F_{i}^{*}$ given house price $P_{i}$ is $F_{i}^{*} \leq \overline{L T V} \times P_{i}$. A conforming mortgage, in addition, has to satisfy the market-specific conforming loan limit $\overline{F_{c t}}$, which is $\$ 417,000$ in most markets during our estimation period. Then the individual's maximum conforming loan size $\overline{F_{i c t}}$ is the minimum of the market-level conforming level, and the LTV constraint:

$$
\overline{F_{i c t}}=\min \left\{\overline{F_{c t}}, \overline{L T V} \times P_{i}\right\}
$$

A mortgage that satisfies the LTV condition, but not the conforming limit is a jumbo mortgage. Let $g \in\{C, N C\}$ denote whether the mortgage is conforming $(C)$ or jumbo $(N C)$. Conditional on an offered rate, consumers can choose any loan size subject to the limits described above.

Each consumer has an ideal mortgage size $F_{i}$. Her utility from a mortgage depends on the mortgage interest rate $r_{j c t g}$, the chosen mortgage size $F_{i}^{*}$, which can differ from the ideal mortgage size $F_{i}$, and the convenience or quality of the service provided by the lender:

\footnotetext{
14 Actual LTV constraints vary by contract, borrower. See, e.g., Fannie Mae loan specifications from 2017 here: https://singlefamily.fanniemae.com/media/4736/display, varying between $75 \%$ and $97 \%$ for a principal residence. For tractability purposes, we impose a single LTV constraint of $90 \%$, which falls roughly in the middle of the distribution.
} 


$$
\begin{aligned}
u_{i j c t g}= & \underbrace{-\alpha_{i} r_{j c t g}}_{\text {rate }} . \\
& -\underbrace{\beta_{i}\left(I\left(F_{i}^{*}<F_{i}\right)\right.}_{\text {size }} \\
& +\underbrace{\gamma_{i} I\left(F_{i}^{*}<\overline{F_{i c t}}\right)}_{\text {conforming convenience }}+\underbrace{q_{j t}+\xi_{j c t}+\epsilon_{i j c t g}}_{\text {service and convenience }}
\end{aligned}
$$

A consumer's utility declines in the mortgage rate $\alpha_{i} r_{j c t g}$, with $\alpha_{i}$ measuring the consumer-specific sensitivity to interest rates.

Borrower $i$ 's mortgage amount $F_{i}^{*}$ can be smaller than her ideal mortgage size, $F_{i}$. If that is the case, she suffers a disutility $\beta_{i} I\left(F_{i}^{*}<F_{i}\right)$, ${ }^{15}$ where the borrower-specific coefficient $\beta_{i}$ measures the extent of disutility and $I$ is the indicator function. ${ }^{16}$ Switching to a smaller loan could be interpreted as either buying a smaller house that is less desirable, or buying the same house but having to put up more money down at the time of origination (perhaps through an expensive outside loan). The parameter $\beta_{i}$ captures the utility cost of either of these avenues. This can occur when the borrower's ideal mortgage is a jumbo $F_{i}>\overline{F_{i c t}}$, but the borrower chooses a mortgage under the conforming limit $I\left(F_{i}^{*}<\overline{F_{i c t}}\right) I\left(F_{i}>\overline{F_{i c t}}\right)$, or when a binding LTV constraint prevents the borrower from obtaining their ideal jumbo mortgage $I\left(F_{i}^{*}>\overline{F_{i c t}}\right) I\left(F_{i}>\overline{L T V} \times P_{i}\right) .{ }^{17}$

Consumers also value mortgages on dimensions other than size and price. For example, conforming mortgage approval and administrative procedures are less convenient than those of jumbo mortgages. ${ }^{18}$ We allow consumers to have different preferences over these non-rate attributes of conforming relative to jumbo mortgages, captured by $\gamma_{i}$. These preferences also rationalize consumers' preferences for conforming mortgages even when jumbo mortgages are cheaper later in the sample.

Consumers also value lenders' convenience and/or service quality. Intuitively, consumers like to borrow from fintech shadow banks such as Quicken Loans because they offer a convenient way to interact online. $q_{j t}+\xi_{j c t}$ measures convenience differences between lenders. $q_{j t}$ is the year-lender type invariant quality difference, ${ }^{19}$ and $\xi_{j c t}$ is a year-lender market-specific unobservable. $q_{j t}$ is estimated as a year-lender type fixed effect, and is thus observable by the researcher, while $\xi_{j c t}$ is not. Last, borrowers' preferences over lenders differ idiosyncratically, which is captured in the i.i.d.

\footnotetext{
${ }^{15}$ A consumer will never choose a mortgage which is too large.

${ }^{16}$ Fixed adjustment cost rationalize a mass of borrowers directly to the right of the conforming loan limit in the data.

${ }^{17}$ Observe that although the consumer has an optimal loan size, her optimal decision is still a discrete choice problem where, for a consumer desiring a non-conforming loan, her choice set includes loans at the conforming loan limit and her idiosyncratic optimal size.

${ }^{18}$ For example, approval rates significantly decrease once the loans becomes jumbo (Appendix B4), suggesting that the loan application process is more onerous.

${ }^{19}$ Because of large changes in the quality of fintech providers over time, we allow the quality of fintech shadow banks to evolve over time as well.
} 
T1EV borrower-specific utility shock $\epsilon_{i j c t g}$ (e.g., some borrowers prefer to borrow from JPMorgan Chase over Quicken because they have a bank account with the former, making it easier to transact).

The ideal mortgage size, interest rate sensitivity, relative preference for a conforming loan, as well as the cost of departing from the ideal mortgage size are consumer specific. Consumers' preferences are drawn from a distribution, where the distribution is a function of income and house prices in a market. Specifically, let $\mathrm{B}_{i} \equiv\left(\alpha_{i}, \beta_{i}, \gamma_{i}, F_{i}\right)^{\prime}$ describe consumer preferences, then:

$$
\mathrm{B}_{i}=\overline{\mathrm{B}}+\Pi\left(D_{i c t}-\bar{D}\right)+\Sigma v_{i}
$$

Where $\bar{B}$ is the vector of mean consumer preferences and $\Pi$ maps demeaned consumer demographic characteristics such as income and house prices $\left(D_{i c t}-\bar{D}\right)$ to individual consumer preferences. For example, higher-income borrowers can have different price sensitivities than lower-income borrowers, and their preferences over mortgage size can differ. $\Sigma$ scales normal i.i.d. shocks $v_{i} \sim N(0, I)$. Thus, even borrowers with the same observable characteristics, such as income, can differ in their price elasticity or ideal mortgage size. The demand parameters to be estimated are then $\theta_{d}=$ $(\overline{\mathrm{B}}, \Pi, \Sigma) .20$

Consumers choose the mortgage that maximizes their utility by choosing between offered mortgages in their choice set, ${ }^{21}$ subject to an LTV constraint. If they do not choose a mortgage, they choose an outside good with a fixed utility, $u_{i 0}$. In other words, given product characteristics for each mortgage offered in the market jctg (including interest rate, mortgage type, risk, lender type, statutory size limits, and service quality), and demand parameters $\theta_{d}$, the set of borrower characteristics (including product-borrower match utilities $\epsilon_{i j c}$. ), such that borrowers with these characteristics in market $c t$ choose a mortgage of type $g$ from lender $j$ is:

$$
\begin{aligned}
A_{j c t g}\left(r_{\cdot c t .}, g_{\cdot c t .}, \bar{F}_{c t}, q_{\cdot t}, \xi_{c c t} ; \theta_{d}\right) \\
=\left\{\left(D_{i}, \epsilon_{i 0 c t g}, \ldots, \epsilon_{i j c t g}\right) \mid u_{i j c t g} \geq u_{i k c t l}, \forall k, l\right\}
\end{aligned}
$$

$A_{j c t g}(\cdot)$ denotes the set of demographic characteristics $D_{i}$ and idiosyncratic shocks $\epsilon_{i \cdot c t g}$ such that given loan characteristics $\left(r_{. c t .}, g_{. c t .}, \bar{F}_{c t}, q_{\cdot t}, \xi_{\cdot c t}\right)$ and parameters $\theta_{d}$, consumers with those demographics and preference shocks obtain more utility from choosing the loan from lender $j$ of type $g$, $u_{i j c t g}$, than from all other lenders and loan types, $u_{i k c t l}$ among loans satisfying the borrowerspecific LTV constraint. Integrating over demographics and shocks yields the market share of mortgage lender $j$ offering product $g$ in market $c t$ :

$$
s_{j c t g}\left(r_{\cdot c t .}, g_{\cdot c t,}, \bar{F}_{c t}, q_{\cdot t}, \xi_{\cdot c t} ; \theta_{d}\right)=\int_{A_{j c t g}} \frac{\exp \left(u_{i j c t g}\left(\mathrm{~B}_{i}\right)\right)}{\sum_{k, l} \exp \left(u_{i k c t l}\left(\mathrm{~B}_{i}\right)\right)} d B\left(B_{i}\right)
$$

\footnotetext{
${ }^{20}$ We directly draw $\log F_{i}$, log house prices and log income from normal distributions. In consequence, the distribution of $\log F_{i}$ is normal, so $F_{i}$ is lognormal.

${ }^{21}$ We assume that borrowers within a market-risk-bucket have the same choice set. For example, all high-risk borrowers within a MSA-year choose from the same set of offered mortgages.
} 
Note that the size of mortgages a consumer chooses is implicitly captured in expression D.4. If a consumer prefers a jumbo-sized mortgage and chooses a jumbo mortgage, she does so at the ideal size or at the LTV constraint. If instead this consumer chooses a conforming mortgage, she will choose the largest conforming mortgage possible subject to the LTV constraint, which implies bunching at the conforming loan limit.

\section{IV.B Mortgage Supply}

Potential lenders first choose which markets to enter and pay sunk cost of entry. Upon entry they simultaneously set mortgage rates, and decide how to finance the mortgages they originate. Because fixed costs are sunk, they do not affect lenders' pricing decisions. We therefore first describe the supply side taking the number of lenders as given, and then describe lenders' entry decisions.

A lender sets mortgage rates and has to decide how many loans to retain as portfolio loans on the balance sheet and how many to finance through GSE securitization. Each bank has only one balance sheet across all markets in which it participates. Consider a lender $j$ who originates $m_{j c t g}$ dollars of mortgage type $g$ in market $c t$, and denote by $m_{j c t g}^{b}$ the mortgages retained on the balance sheet. The remainder is financed through GSE securitization $m_{j c t g}-m_{j c t g}^{b}$. Jumbo mortgages cannot be securitized and are retained on the balance sheet $m_{j c t N C}=m_{j c t N C}^{b}$. From the financing perspective, only the total amount of balance sheet financing, $m_{j t}^{b}=\sum_{c t g} m_{j c t g}^{b}$, is relevant for a lender. In other words, the total balance sheet impact is the same whether a lender originates one jumbo loan in the New York City or one in the Houston MSAs.

\section{IV.B.1 Origination}

Mortgage origination is costly, beyond the mere financing cost of a mortgage. Lenders incur nonfinancing costs such as costs of an appraisal and title check, document processing, and loan closure, which involve labor and equipment. We designate the per-dollar origination cost of lender $j$ of mortgage type $g$ as $w_{j g}$, and the total origination cost in market $c t$ is:

$$
\sum_{g} m_{j c t g} w_{j g}
$$

This specification allows for different origination costs across banks, non-fintech shadow banks, and fintech shadow banks. For example, this heterogeneity allows us to capture potential cost savings from technology employed by fintech shadow banks who use less labor in lending.

\section{IV.B.2 Financing, Risk, and Regulatory Burden}

Recall that mortgages can be financed two ways. Conforming mortgages can be sold to GSEs, i.e., OTD. Alternatively, conforming and jumbo mortgages can be financed by using a bank's internal funds as portfolio loans. These two types of financing can have different costs. 


\section{Originate-to-Distribute Financing}

Lenders can securitize conforming mortgages though GSEs. Since GSEs purchase mortgages at predetermined risk adjusted prices, all lenders face the same originate-to-distribute financing cost in a given market. We model securitization as an ability to obtain funding for a conforming mortgage at a rate $\sigma_{t}^{G S E}=\sigma_{t}^{b}+\sigma_{c}^{\mathrm{GSE}}+\sigma_{c}^{\Delta, \mathrm{GSE}}$, which depends on market level funding costs and riskiness of the loan. $\sigma_{t}^{b}$ represents the underlying financing costs of funding absent any costs arising from intermediation and captures the current risk-free interest rate environment in the macroeconomy. ${ }^{22}$ $\sigma^{G S E}$ captures additional costs coming from the lender using GSE financing, which can include the guarantee fee (g-fee) charged by the GSEs for coverage of projected credit losses from borrower defaults in the securitized pools. ${ }^{23} \sigma_{c}^{\Delta, \mathrm{GSE}}$ represents the additional cost that GSEs charge for lending to high-risk borrowers. Intuitively, lenders and GSEs observe whether the borrower is a high or low risk type, i.e. if they have a high or low credit score, and GSEs account for these observable course differences in risk in the g-fee. In other words, when the firm originates-to-distribute a mortgage, it earns the spread on the mortgage rate minus the financing and non-financing origination costs $r_{j c t g}-$ $\sigma_{t}^{G S E}-w_{j g}$ for every dollar of the mortgage. Reflecting the post-crisis period, which we study, we assume that securitization is only available for conforming loans; jumbo loans must be retained on balance sheet. One could easily account for a jumbo securitization in the same way (see Section V.E).

\section{Costs of Portfolio Lending}

The cost of portfolio lending depends on the composition of the lender's balance sheet, the amount of tier one equity capital $e_{j t}$, and on the riskiness of the borrower pool indexed by $c$ (recall that $\mathrm{c}$ indexes both loan purpose, riskiness, and location). A lender sources financing at the firm level and has one balance sheet comprising mortgage assets across markets. There are two types of assets held on a lender's balance sheet: mortgages - the amount of which is chosen by the lender in each market - and other assets such as government bonds or commercial loans in the amount $m_{j t o}^{b}$. Lenders also differ in the amount of equity capital $e_{j t}$. The amount of equity and the asset composition of the balance sheet jointly determine the cost of portfolio lending for an intermediary.

A lender's risk-adjusted capital ratio $\rho_{j t}$, i.e. balance sheet capacity, depends on the bank's tier-one equity capital $e_{j t}$ and banks' risk-adjusted assets $\xi_{o} m_{j t o}^{b}+\sum_{c t g} \xi_{g} m_{j c t g}^{b}$ :

$$
\rho_{j t}=\frac{e_{j t}}{\xi_{o} m_{j t o}^{b}+\sum_{c t g} \xi_{g} m_{j c t g}^{b}}
$$

\footnotetext{
${ }^{22}$ Our estimation period (2010-2017) covers the rounds of quantitative easing (QE2 and QE3) that predominantly affected the overall level of interest rates but not the relative pricing of jumbo vs conforming loans. This contrasts with QE1 (ended in the first quarter of 2010), which changed the relative pricing of jumbo and conforming loans at announcement in 2008 (DiMaggio et al. 2020; Luck and Zimmerman 2020). Our specification captures the level effects of QE2 and QE3 through a time-varying common interest rate component $\sigma_{t}^{b}$, which affects all loans.

${ }^{23}$ The GSE's Credit Risk Transfer (CRT) program, which offloads mortgage default risk to capital markets, is an example of a program that could alter $\sigma^{G S E}$. While we do not study the potential impacts of CRT, they would enter our model through this parameter.
} 
Where $\xi_{g}$ represents the risk weight of mortgages of type $g$ and $\xi_{o}$ represents the risk weight of other assets the bank holds. Since jumbo mortgages have higher risk weights, they use up more statutory capital per dollar of actual lending. A bank's risk-adjusted capital needs to be below its statutory riskadjusted capital requirement $\bar{\rho}$ if it wants to lend on its balance sheet. We take banks' balance sheet capacity as fixed in the baseline model. As the equation suggests, there are two ways for a bank to expand this capacity, issue equity_increase $e_{j t}$ —or sell other non-mortgage assets-decrease $m_{j t o}^{b}$. We explore these possibilities in Section in Section V.E.

The per-dollar cost of financing a portfolio loan of lender $j$ depends on its capitalization and on the riskiness of the loan:

$$
\sigma_{j t}^{p}=\sigma_{t}^{b}+\sigma_{c}^{\Delta}+\sigma^{b 1}\left(\rho_{j t}-\bar{\rho}\right)^{-\phi}
$$

As before, $\sigma_{t}^{b}$ represents the underlying financing costs of funding in the macroeconomy. $\sigma_{c}^{\Delta}$ represents the additional marginal (expected) cost of lending to high-risk borrowers, both from the perspective of expected default as well as administrative costs of dealing with delinquent borrowers. We normalize this cost relative to low-risk conforming mortgages, for whom $\sigma_{c}^{\Delta} \equiv 0$. $\sigma^{b 1}\left(\rho_{j t}-\bar{\rho}\right)^{-\phi}$ is the shadow cost of balance-sheet funding above this base rate. The closer a bank's risk-adjusted capital ratio is to the statutory requirement, i.e., the smaller $\left(\rho_{j t}-\bar{\rho}\right)$, the larger the cost of portfolio loan financing. $\phi$ and $\sigma^{b 1}$ parameterize the extent of this cost. This formulation captures the fact that banks choose a capital buffer above the hard capital requirement. The microfoundations of such a buffer can be generated in a dynamic setting but are not the central interest in this paper (see Corbae and D'Erasmo (2019)). We assume that balance sheet lending by shadow banks is prohibitively expensive. This assumption captures in reduced form the notion that shadow banks do not have access to a subsidized deposit funding and must use external financing instead.

\section{Regulatory Burden}

Banks face regulatory pressures beyond capital requirements. For example, risk constraints, liquidity regulations, and fear of enforcement or lawsuits are correlated with the decline of bank lending and the rise of shadow banks since the Great Recession (see, e.g., Buchak et al. 2018; Gete and Reher 2018). Critically, these regulatory pressures do not seem to directly affect the marginal cost of lending in the same way as capital requirements. Intuitively, marginal cost increases will be reflected in interest rates, but in our data, interest rates alone are unable to explain declines in bank market shares since the Great Recession. We follow Buchak et al. (2018) and capture this type of regulatory burden through parameter $1 / \zeta_{t g}$, which reduces traditional banks' activity on the extensive margin. For banks, the probability of lending to a specific borrower of mortgage $g$ in market $c t$ is scaled by a factor $\zeta_{t g}$. A higher $1 / \zeta_{t g}$ (lower $\zeta_{t g}$ ) captures a relatively constrained bank; a lower $1 / \zeta_{t g}$ (higher $\zeta_{t g}$ ) captures a relatively unconstrained bank. Intuitively, these regulatory constraints account for the loss in market share of banks, which is due to the regulatory burden beyond capital requirements. These shocks are i.i.d. across lender-borrower pairs, which accounts for the uncertainty that a bank faces with respect to which loans may be subject to these issues ex post. 


\section{IV.B.3 Choosing Mortgage Rates and Financing}

Taking other lenders' actions as given, an individual lender maximizes its profits by setting interest rates for all products across they markets they entered simultaneously and chooses how many mortgages to retain on its consolidated balance sheet. Denote by $\boldsymbol{r}_{j t}$ the set of interest rates of all products, conforming and jumbo, across all markets for lender $j$ at time $t, \boldsymbol{r}_{j t}=\left\{r_{j c t g}: \forall c, g\right\}$, and recall that $m_{j t}^{b}=\sum_{c t g} m_{j c t g}^{b}$ is the total amount of balance sheet lending by lender $j$ at time $t$. Then the lenders choose interest rates and the amount of conforming mortgages to retain on the balance sheet by maximizing profits:

$$
\Pi_{j t}=\max _{r_{j t}, m_{j t}^{b}} \underbrace{\sum_{\text {ctg }} r_{j c t g} m_{j c t g}}_{\text {rate income }}-\underbrace{\sum_{\text {ctg }} m_{j c t g} w_{j g}}_{\text {origination cost }}-\underbrace{\left(m_{j t}^{G S E} \sigma_{t}^{G S E}+m_{j t}^{b} \sigma_{j t}^{p}\right)}_{\text {financing cost }}
$$

Intermediaries' profits comprise interest rate income (either collected by themselves or through servicing rights), origination costs, and financing costs. The first term, labeled rate income, is the yearly income that the lender earns from the loans that it has made, equal to the sum of interest rates times mortgage volumes across all loan types and markets. The second term, labeled origination cost, is the costs the lender occurs in originating the loans, such as the wages of mortgage brokers, advertising, and administrative expense. The third term, labeled financing cost, is the financing cost of the mortgage, reflecting the costs of either GSE or balance-sheet financing, depending on the lender's optimal financing cost.

The quantity of lending in each market by a lender $m_{j c t g}$ is only a function of the interest rate on that product, $r_{j c t g}$, the interest rates of other products, $r_{-j c t g}$, and the regulatory burden $\zeta_{t g}$ if the intermediary is a bank: $m_{j c t g}\left(r_{j c t g}, r_{-j c t g}, \zeta_{t g}\right)$. The only choice linking intermediary decisions across markets is balance sheet capacity of the institution, and the associated financing cost. Because shadow banks have no balance sheet capacity, their pricing decisions across markets are de-coupled.

A bank, on the other hand, must decide how many mortgages to originate on the balance sheet, which links its interest rate decisions across all markets. For example, decreasing the interest rate on jumbo mortgages in a specific market will increase quantity of jumbos in that market, which will take up balance sheet capacity and thus increase the cost of originating jumbo mortgages across all markets. In other words, pricing decisions on portfolio loans are linked across markets though the shadow cost of balance sheet capacity.

\section{Entry}

Prior to setting prices, financial intermediaries decide which markets to enter. Empirically, the entry exit margin is most significant among non-fintech shadow banks and there is very little entry and exit of banks during the time of our sample (Figure A5 in the Appendix). We therefore limit the entry decision to these intermediaries and take the number of banks in the market as exogenous. We do so 
for tractability in computing counterfactual equilibria, and because, empirically, our ability to estimate the distribution of fixed cost for banks is limited due to variation in the data.

We model entry as a two-stage game (Syverson 2004; Meliz 2003, Buchak et al. 2018). In the first stage intermediaries pay a fixed cost to operate in a market, and in the second stage intermediaries compete. Formally, in a market $m$ there are $N_{m}$ potential shadow bank entrants. Each potential entrant $j$ has a fixed cost of operation, distributed iid as $f_{j t} \sim F(f ; \Theta)$, where $\Theta$ parameterizes $F$. Potential entrant $j$ realizes its fixed cost draw $f_{j}$ before deciding whether to enter, and chooses to enter if the equilibrium profit exceeds the fixed cost:

$$
\begin{aligned}
& \Pi_{j t} \geq f_{j t}: \text { enter } \\
& \Pi_{j t}<f_{j t}: \text { do not enter }
\end{aligned}
$$

Therefore, the marginal intermediary who enters earns zero economic profit, but infra-marginal entrants earn positive rents. ${ }^{24}$

\section{IV.B.4 Equilibrium}

An equilibrium is a set of mortgage rates $\boldsymbol{r}_{\boldsymbol{j} t}$, financing decisions $m_{j t}^{b}$, and set of shadow banks, such that

1) Demand: Consumers maximize utility-taking interest rates and lender characteristics as given. Demand is characterized by consumers' choice of mortgages and market share equations (D.5 holds for each market).

2) Supply: Intermediaries maximize profits by setting mortgage rates across all markets in which they participate and banks also choose the size of their balance sheet. Supply is characterized by intermediaries' maximizing profits conditional on entry (S.4 holds for each intermediary)

3) Free Shadow Bank Entry: Shadow banks enter if doing so is profitable (S.5 holds for each potential entrant).

\section{IV.C Estimation}

We estimate the demand, and supply, and entry separately. To estimate the model, we aggregate the loan-level data to market-lender-type observations. A market is defined as an MSA-year-loan purpose, e.g., refinances in New York City in 2013. In each MSA-year, we measure demographic data including means and standard deviations of log incomes and log house prices from the ACS data. Within MSA-years, we separate markets into mortgages originated for new purchases and mortgages originated for refinances, the idea being that a borrower looking for one type of loan is not in the market for another type. Additionally, we separate markets into low FICO $(<740)$ and high FICO $(>$ 740) buckets. Choice sets are constructed by looking at the set of realized originations for a given market-purpose-risk category.

\footnotetext{
${ }^{24}$ This differs from homogenous entry cost in Buchak et al (2018), in which all intermediaries earn 0 profits.
} 
We compute risk-adjusted interest rates in a market by projecting out FICO and LTV differences. We then project each loan's actual interest rate to its predicted interest rate differences so that each loan in the market has the risk-category-wide average FICO score. This adjustment ensures that across markets and lenders we are comparing interest rates of similarly risky borrowers. Next, we aggregate from the loan level to the time and market level by taking the average of these residualized interest rates across product and lender types.

We obtain the number of unique lenders $\left(N_{b c t}, N_{f c t}\right.$, and $\left.N_{n c t}\right)$ by taking the median number of lenders per census tract within the MSA. This captures the typical number of loan offerings from each type of lender that a borrower faces. Market size is defined as one-tenth of the total number of households in the case of new originations - under the assumption that one-tenth of households are potentially in the market for a new home per year-and as the total number of outstanding mortgages in the case of refinances. We estimate the model using data between 2010 and 2017 to avoid overlap with the worst of the financial crisis and subsequent market structure and regulatory changes that are not modeled. ${ }^{25}$

\section{IV.C.1 Demand Estimation}

Our estimation roughly follows Berry et al. (1995) and Nevo (2000), with several differences. The first important difference is that borrowers choose loan quantity, in addition to choosing whether to take up a mortgage. In other words, while Berry et al. (1995) is a discrete-choice model, our model is discrete-continuous. Therefore, in addition to estimating standard preferences for interest rates (governed by $\alpha_{i}$ ) and non-price attributes of mortgages (governed by $\gamma_{i}$ and $q_{j t}+\xi_{j c t}$ ), we have to estimate the preferences for mortgage size. These are governed by a borrower's (unobserved) ideal mortgage size $F_{i}$, and the disutility of choosing a mortgage which is too small, $\beta_{i}$. The most significant departure from the standard Berry et al. (1995) and Nevo (2000) type of estimation is the use of the discontinuity at the conforming loan limit in addition to aggregate data. In other words, we introduce bunching-style identification into a structural model.

To identify consumer preferences, we need to instrument for prices. We exploit an institutional feature of how GSEs set interest rates of conforming mortgages from Hurst et al. (2016). The loan purchase prices of GSE only reflect borrowers' LTV ratios and FICO scores, but do not incorporate other riskbased information such as geography. ${ }^{26}$ Thus, lenders originating conforming loans face marginal costs that do not vary with market-level risk. In contrast, lenders face the risk of jumbo loans, so their marginal costs vary with geographical risk (Hurst et al. 2016). Our instrument levers this observation, using past mortgage default to generate within-market variation in jumbo and conforming origination costs, and thus prices. In other words, the risk adjusted financing cost of a conforming mortgage relative to a jumbo mortgage is higher in some areas than in other areas and is unrelated to mortgage demand. Accordingly, we use the variation in mortgage pricing across regions to obtain relative

\footnotetext{
${ }^{25}$ Including, e.g., bank bailouts, government liquidity support, and recapitalizations, the existence and subsequent evaporation of markets for non-agency mortgage-backed securities, and regulatory changes around bank capital requirements

${ }^{26}$ See https://singlefamily.fanniemae.com/media/9391/display.
} 
variation in conforming and jumbo interest rates that is driven by GSE institutional constraints and not by borrower demand.

In addition to aggregate data, we also exploit novel micro-level data moments. First, we use the mean and standard deviation of realized loan sizes for jumbo and conforming loans within a market. Second, we use two moments around the conforming limit discontinuity: the market share of borrowers who obtain conforming loans exactly at the conforming loan limit (Figure 6A) and the income difference between borrowers exactly at the conforming loan limit and those nearby (Figure 6B).

\section{Identification Discussion:}

While all moments jointly identify the parameters of the model, here we provide an informal discussion of how different moments in the data relate to the identification of different parameters. To formalize the intuition for which moments inform which parameter estimates, we perform the parameter sensitivity analysis described in Andrews, Gentzkow, and Shapiro (2017). As in Berry et al. (1995) and Nevo (2000), the aggregate market shares allow us to identify the distribution of preferences for interest rates and non-price attributes of mortgages once we instrument for price. The price variation induced by the GSE cost shocks allows us to identify the price sensitivity for consumers, $\alpha_{i}$. Variation in market shares for a given interest rate across lenders allows us to estimate consumer preferences over non-price attributes, $q_{j t}+\xi_{j c t}$. Intuitively, if Quicken has a larger market share for mortgages for a given interest rate, it must be because consumers value Quicken's convenient mortgage screening and documentation system.

Jointly with the aggregate moments, the micro-moments allow us to estimate the preferences for other parameters of the model. Intuitively, consumers who choose a jumbo mortgage choose the mortgage at their ideal size (subject to the consumer-specific LTV constraint). Similarly, consumers who choose a conforming mortgage below the conforming limit choose a mortgage at their ideal size (subject to LTV constraint). Intuitively, the mean and standard deviation of realized loan sizes for jumbo and conforming loans within a market are very informative about the distribution of ideal loan sizes $F_{i}$, once we account for the behavior at the discontinuity.

The parameter $\beta_{i}$ governs behavior at the discontinuity, and consequently the distribution of loan sizes around the discontinuity are highly informative in identifying these parameters. Recall that a consumer choosing a smaller-than-ideal mortgage suffers disutility $\beta_{i}$. Consider a consumer whose ideal mortgage size is greater than the conforming limit. She has three choices: obtain a jumbo mortgage at the ideal size, obtain a conforming mortgage that is too small—perhaps at a lower rate, or exit the market entirely. When $\beta_{i}$ is large, she will be unlikely to take a smaller conforming loan unless the interest rate differential and her price sensitivity are large. In contrast, when $\beta_{i}$ is small she is more likely to take a conforming mortgage exactly at the conforming loan cutoff. Therefore, all else equal, $\beta_{i}$ governs the amount of bunching at the conforming loan cutoff. Large $\beta_{i}$ leads to less bunching and small $\beta_{i}$ leads to more bunching. Consequently, the average level of $\beta_{i}$ is identified from the observed bunching in the data, and $\beta_{i}$ 's covariance with income and house price is identified by how bunching varies with income and house prices in the data. 
Besides taking a smaller conforming loan, the consumer has the option to obtain a jumbo loan or exit the market entirely. If $\gamma_{i}$ is high, holding the conforming market share fixed, then jumbo loans are highly inconvenient and the consumer is more likely to exit the market entirely rather than obtain a jumbo loan. In contrast, when $\gamma_{i}$ is low, jumbo loans are relatively convenient and the consumer is more likely to remain in the market. That is, $\gamma_{i}$ governs the missing mass of borrowers whose ideal loan size is jumbo, but because jumbo loans are inconvenient and conforming loans are too small, decide to exit the market entirely. Observe from Figure 6A that there is indeed a missing mass of jumbo borrowers: the density of mortgages drops discontinuously above the conforming loan limit in excess of the bunching at the limit. That is, consumers value the convenience of conforming mortgages. Put another way, holding market size constant on the extensive margin, $\gamma_{i}$ governs the relative market shares of conforming and jumbo mortgages, with a high $\gamma_{i}$ leading to relatively more conforming loans. Consequently, the average level of $\gamma_{i}$ is identified from the relative market shares of conforming and jumbo loans holding overall market shares fixed, while $\gamma_{i}$ 's covariance with income and house price is identified based on how these relative market shares vary with wage and house prices in the data.

The last micro-moment we match is the income difference between borrowers exactly at the conforming loan limit and those nearby (see Figure 6B). Intuitively, the larger the income spike at the discontinuity, the less sensitive the higher-income population is to taking a mortgage which is smaller than ideal. This moment aids in identifying the correlation between income and preferences for a jumbo mortgage, i.e., the structure of the correlation in the random coefficients.

\section{Model Fit: Targeted Moments and Simulated Responses to Real Policy Changes}

We estimate the model over the period 2010-2017. The demand parameter estimates are shown in Table 5. By construction, the model fits market shares data. The model also fits the size distribution of mortgages in the data quite well. Figure 7B shows the model replicates the average amount of bunching at the conforming loan limit generated by our model. Figure 7A shows that the model can replicate the qualitatively bunching patterns across markets and does well in quantitatively matching the extent of bunching. We overestimate the extent of bunching in the markets with the most bunching. Intuitively, these are markets with the highest demand for jumbo mortgages. The difference between data and model estimates is likely due to approximating the desired loan size with a lognormal distribution. Markets in which desired loan sizes are large will also be high variance, so the log-normal distribution will put a lot of mass to the right.

We also examine the fit of the model by confronting it with actual policy changes. We exploit changes to conforming loan limits over time in the U.S. mortgage market between 2007 and 2016. We compute market outcomes using model estimates, and compare model-predicted changes to those from the data. The main variables of interest at the level of county and origination year are jumbo origination share (\%Jumbo), bank origination share (\%Bank), and the mass of borrowers at conforming limit cutoff ( $\%$ AtCutoff). The main explanatory variable captures the change in conforming limit in a given county in a given year. We measure increases as the percentage difference between the conforming loan limit in year $t$ in county $c$ and the conforming loan limit in 2007 for the same county $c$ : 


$$
\text { LimitIncrease }_{c t}=\frac{\text { Limit }_{c t}}{\text { Limit }_{c 2007}}-1
$$

The origination amount weighted mean of LimitIncrease $e_{c t}$ is $10.2 \%$ and the median is 0 . The specifications to test the impact of these limit increases on jumbo and bank share are as follows:

$$
\begin{aligned}
& \text { \%Jumbo }_{c t}=\text { BLimitIncrease }_{c t}+\gamma_{c}+\gamma_{t}+\epsilon_{c t} \\
& \% \text { AtCutoff }_{c t}=\text { BLimitIncrease }_{c t}+\gamma_{c}+\gamma_{t}+\epsilon_{c t} \\
& \% \text { Bank }_{c t}=\beta \text { LimitIncrease }_{c t}+\gamma_{c}+\gamma_{t}+\epsilon_{c t}
\end{aligned}
$$

Where $\gamma_{c}$ and $\gamma_{t}$ are county and year fixed effects, respectively.

Specification (4) investigates whether jumbo share of originations declines along with conforming loan limit increases. Column 1 of Table 6 shows that increasing the conforming loan limit by $1 \%$ leads to an approximately $0.23 \%$ reduction in the jumbo share in the county. These estimates from actual data compare well with model counterfactual estimates where we simulate a similar change in conforming limits and assess the response. Table 11 finds a similar reduction of $0.18 \%$. As the conforming loan limit increases, there is a significant shift towards conforming loans.

Specification (5) tests the extent of declines in bunching, which is measured as the number of conforming originations within 5\% of the conforming loan limit. Column 2 of Table 6 shows that when the conforming loan limit increases the mass of borrowers exactly at the conforming loan cutoff decreases, suggesting that many of these borrowers would have selected larger loans had the conforming loan limits not been in place, and now that the limit has been relaxed, they are able to select larger, now conforming loans. As Figure 7B shows, the model closely captures the market shares of borrowers within a $5 \%$ band both above and below the conforming loan limit.

Specification (6) tests whether bank market share declines. Column 3 of Table 6 shows that a 1\% increase in the conforming loan limit decreases bank market share by roughly $0.02 \%$ percentage points. Again, this estimate from actual data is broadly consistent with that produced by our model (see counterfactual in Table 11), which finds that a $1 \%$ increase in the jumbo loan limit leads to roughly a $0.13 \%$ decrease in bank market share around the limit. ${ }^{27}$

\section{Price Sensitivity}

Our estimates of mean price sensitivity in Table 5 suggest that borrowers are quite price elastic, and the differences in price elasticity are small. The mean parameter $\bar{\alpha}=1.65$ from Table 5A implies a price elasticity of roughly 6.5. This estimate is close to DeFusco and Paciorek (2017), who estimate the elasticity from the conforming loan discontinuity using a different approach. The estimate of $\sigma_{\alpha}^{2}=$

\footnotetext{
${ }^{27} \mathrm{We}$ also measure the change in bank market share as more jumbo loans are originated by using the following specification: BankShare Bt $=\beta$ JumboShare ct $+\gamma_{c}+\gamma_{t}+\epsilon_{c t}$. The results in Table 6, Column 4 find a positive and significant association between bank share and jumbo share. This coefficient, here estimated as roughly 0.26 , is roughly in line with the relationship suggested in the model from Tables 9,10 , and 11, which finds that bank share increases by roughly 0.50 percentage points per percent increase in jumbo market share. Note that variation in jumbo share from the regression above obtains from all sources, such as variation in demand, supply, and policy, whereas the cross-validating variation in the model comes entirely from policy variation where one would expect a stronger relationship between jumbo share and bank share.
} 
0.1 in Table 5C suggests moderate borrower differences in price elasticity, ranging from 5.8 to 7.4 for borrowers two standard deviations above and below the mean in price sensitivity. Second, for a given level of income, borrowers who buy more expensive houses are less price elastic with respect to mortgages. This makes sense: customers who are willing to purchase a larger house are also more willing to pay a higher interest rate. Conditional on the house price, on the other hand, higher-income households are more price elastic. In other words, the household which bought a more frugal home relative to its income is also more price elastic when choosing a mortgage. Since jumbo mortgages cater to borrowers in high house-price areas, this implies that they cater to a less price-elastic part of the borrower population, allowing, all else equal, higher markups earned on these mortgages.

\section{Distribution of Ideal Mortgage Sizes}

The preference for mortgage size is a central driver of consumers choosing jumbo versus conforming mortgages. As Table 5B shows, the ideal mortgage size is larger for wealthier individuals, with an elasticity of 0.39 : as income rises by $1 \%$, the desired mortgage size increases by $0.39 \%$. Desired loan size also increases with house prices, with an elasticity of approximately 0.34 .

Consumers borrow below their ideal size either due to LTV constraints or because they choose a cheaper and more convenient conforming mortgage instead of the desired jumbo. Borrowers find departures from their ideal mortgage size costly. For borrowers who would otherwise prefer a jumbo mortgage, we estimate a mean disutility of taking a smaller loan to be $\bar{\beta}=4.34$, which is equivalent to roughly a $2.6 \%$ higher interest rate. This estimate reflects the fact that consumers are on average very price elastic, but jumbo borrowers are still willing to take a more expensive jumbo mortgage. Therefore, these borrowers must place a high value on the additional funds provided by a jumbo mortgage. That is intuitive: taking out a smaller conforming mortgage may prevent the borrower from purchasing a home or result in purchasing a substantially smaller home than they desire.

Borrowers with high income are less sensitive to taking smaller loans, while borrowers with high house prices are more sensitive to taking smaller loans. This is not surprising: High-income borrowers are likely to be able to adjust to smaller loan sizes by putting up more of their own money. Borrowers buying high-price homes, on the other hand, are more dependent on larger loan sizes and consequently are less willing to substitute a small conforming loan for a large jumbo loan. Finally, we find a small positive preference for conforming loans overall as opposed to jumbo loans, possibly reflecting the costs of qualifying for and obtaining a jumbo loan (e.g., increased screening/loan documentation requirements, additional time and effort needed to obtain a jumbo loan relative to conforming loan).

\section{IV.C.2 Supply Estimation and Results}

We estimate the supply-side parameters in two steps. We first estimate intermediaries' behavior conditional on entry. We describe the estimation of fixed cost in the next section. We use revealed preference to estimate parameters governing the costs of origination for the three types of intermediaries we observe, the financing cost of balance sheet lending, and the costs of originate-todistribute. Intuitively, using demand estimates, we can compute the markups that intermediaries earn. We use lenders' pricing decisions, combined with these markups, to infer the costs of lending. For example, if an intermediary is charging higher prices for a given markup, this implies that the 
intermediary is facing higher lending costs, which the lender passes on to consumers. Recall that for a bank, the cost of portfolio lending depends on its current risk-adjusted capital ratio $\rho_{j}$, the statutory risk-adjusted capital requirement $\bar{\rho}$, other parameters such as the risk weights $\xi_{g}$ and $\xi_{j}$, and the type of mortgage. To the extent that low capitalization indeed causes a higher cost of portfolio lending, the model implies how these higher costs should be passed through to different types of mortgages given estimated demand.

The bank regulatory burden parameter, rather than working through price, directly prevents banks from originating some mortgages. To identify this parameter in the model, we observe deviations in bank market shares at the yearly level that cannot be explained by observed product characteristics such as price, whether the loan is conforming, or whether the loan is smaller than the consumer's desired size. In a year where the predicted bank market share would otherwise be high yet in the data is low, our model explains this gap with a high bank regulatory burden. In the following discussion, we map this parameter to a number of unmodeled bank regulatory changes such as legacy lawsuits arising out of the financial crisis, a shift towards stricter regulators, and the adoption of unfavorable rules regarding the treatment of mortgage servicing rights. For a more detailed discussion, see Buchak et al. (2018).

Table 7 shows the estimated parameters. Because we estimate costs using intermediaries' pricing decisions, we cannot separate the baseline origination and financing costs. Intuitively, if a bank's baseline financing costs increase by $0.5 \%$ (50 basis points), but origination costs decline by $0.5 \%$, the costs of making a loan do not change. Since mortgage demand is quite price elastic the markups are quite moderate, with an average markup of $0.64 \mathrm{pp}$.

As banks' capitalization declines, their financing costs rise. To better understand the different costs of mortgages, Figure 8 plots total marginal costs for different levels of excess bank capitalization, defined as the difference between the bank's capital ratio and the statutory requirement, $\rho-\hat{\rho}$. Several aspects are worth discussing. First, well-capitalized banks have a cost advantage over poorly capitalized banks because they can lend with lower-cost balance sheet financing. Even poorly capitalized banks have a cost advantage over shadow banks. While all intermediaries can finance mortgages through GSEs, the model estimates that banks can do so more cheaply than shadow banks. This estimate likely reflects the advantage of banks in originating mortgages: the existing pool of bank customers means they have a lower customer acquisition cost, and the existing relationship with the customer may make document processing and screening for irregularities in mortgage applications easier. The baseline costs of originating and financing a mortgage varies from 3.8\%-4.8\%, reflecting the low markups in this market. This represents the cost of financing and originating a new purchase mortgage if a bank were flush with capital.

Second, while financing jumbo mortgages is more expensive than financing conforming mortgages, even when the latter are retained on the balance sheet, the total cost of jumbo mortgages can be lower once the non-financing costs are accounted for. Jumbo mortgages' risk weight is 2.5 that of conforming mortgages, i.e., a dollar in a jumbo mortgage tightens the capital constraint more than a 
dollar of conforming mortgages, resulting in higher financing cost. ${ }^{28}$ This difference declines with bank capitalization. In other words, if the capital constraint is loose, then a higher risk weight has a small cost. For a bank whose capital exceeds the statutory capital by $2 \%$, the additional financing cost is around $13 \mathrm{bps}$; at 10\% of capital above the statutory limit the cost difference declines to $3 \mathrm{bps}$.

Quantitatively, these numbers are reasonable. In 2009, a time period outside of the estimation window, the typical bank originator of a jumbo loan had an excess capital ratio of roughly $7 \%$. According to our model, this corresponds to a roughly $3.90 \%$ marginal cost. At the same time, the typical bank origination of a conforming loan had an excess capital ratio of roughly $6.0 \%$, which corresponds to roughly a $4.25 \%$ marginal cost. This implies a negative conforming-jumbo marginal cost spread, which is roughly in line with patterns in Figure 1C.

Finally, the model suggests that originating mortgages to higher-risk (lower FICO) borrowers has a higher marginal cost of roughly 20-30 basis points for conforming loans and jumbo loans, consistent with the GSE pricing grid, which assigns higher g-fees to lower-FICO loans, and with the fact that borrowers with lower FICO have higher marginal costs for loans retained on balance sheet through worse expected performance.

\section{IV.C.3 Bank Regulatory Burden and Fintech Quality}

Table 8 shows two primary reasons why banks have been losing market share during the period from 2010 to 2015: an increase in the regulatory burden from 2012 onwards and the entrance of new fintech competitors. Part of the reason why banks have lost market share during the period is an increase in capital requirements, which has increased their costs of funding, as we discuss above. On the other hand, the period following the crisis has been profitable, increasing banks' capitalization and undoing some of the capital requirement increases. Despite that, banks have lost substantial market share in the conforming market. Table 8 explains these trends.

The regulatory burden measures the noncapital requirement-related regulatory constraints faced by the banking sector relative to shadow banks, such as risk of enforcement actions and lawsuits, which constrain bank origination. The estimates show that the banking sector regulatory burden increased steadily, particularly from 2012 onwards. This is the period of implementation of the Dodd-Frank Act, the establishment of the Consumer Financial Protection Bureau, and increased mortgage lawsuit activity targeted at traditional banks. These results are consistent with those of Buchak et al. (2018), who estimate the regulatory burden in a simpler model, but on a sample going further back in time, and show reduced-form evidence on the different aspects of the regulatory burden such as tougher regulatory enforcement and lawsuits leveled against banks. The substantial changes in the regulatory burden emphasize that the singular focus on capital requirements misses a large degree of regulatory and enforcement changes in the banking sector following the crisis, which a model has to account for.

The second reason that banks have been losing market share over this period is the entrance of new fintech lenders. These fintech lenders entered on the promise of providing a better user experience,

\footnotetext{
${ }^{28}$ Exposures to U.S. government-sponsored enterprises receive 20\% risk weights; exposure to first-lien mortgages on owner-occupied single-family houses receive a 50\% risk weight. See: https://www.mercatus.org/system/files/mercatusbarth-primer-capital-standards-v1.pdf.
} 
with a more consumer-convenient online interface. Table 8 suggests that fintech were successful in this regard in the market for mortgage refinancing, which constitutes their main activity. This result is consistent with consumer survey evidence, which consistently measure high consumer satisfaction associated with borrowing from Quicken Loans, the largest fintech lender, during our sample period. ${ }^{29}$ The model estimates also suggest that non-bank fintech lenders were initially at a disadvantage in the market for purchase loans, i.e., when the borrower is using a loan to purchase a house. These borrowers on average prefer non-fintech shadow banks over the whole sample, although by 2015 this preference has reversed. This result is consistent with the idea that the online origination has not been as well-suited to originating purchase mortgages, which require on-the-ground activities such as a structural examination (Stroebel 2016).

\section{IV.C.3 Fixed Cost Estimation and Results}

Last, we estimate the distribution of fixed cost, $F(f ; \Theta)$. Having estimated demand and supply parameters we can compute the expected profits for each lender in each market configuration. The intuition for the estimation is simple: each entrants' profits must have exceeded the fixed cost of entry and the entry of an additional lender would not have been profitable given their fixed cost draw (eq. S.5). The ex-ante probability that lender $j$ enter a market is the probability that it drew a lower fixed cost than its profits: $\operatorname{Pr}\left(f_{j} \leq \Pi_{m}^{v}\right)=F\left(\Pi_{m}^{v} ; \Theta\right)$, with $\Theta$ parameterizing the distribution of fixed costs. The number of entrants is then binomially distributed with probability of success $F\left(\Pi_{m}^{v} ; \Theta\right)$ and number of entrants $n_{m}$ where the number of potential entrants in a market is $N_{m}$. The log likelihood of observing a market configuration is as follows:

$$
\begin{aligned}
\ell(\Theta)=\sum_{m} \log \left(\begin{array}{l}
N_{m} \\
n_{m}
\end{array}\right)+n_{m} \log F\left(\pi_{m}^{v} ; \Theta\right) \\
+\left(N_{m}-n_{m}\right) \log \left(1-F\left(\pi_{m}^{v} ; \Theta\right)\right)
\end{aligned}
$$

We estimate the distribution of fixed costs using maximum likelihood and parameterize the distribution of fixed costs with a $\log$ normal distribution: $\log f_{j} \sim N\left(\mu, \sigma^{2}\right)$. We estimate the distribution using across market variation, assuming that the potential number of entrants in each market is identical, i.e., that $N_{m}=N$. We set $N$ equal to the total number of unique non-fintech shadow bank lenders in a given year, which far exceeds the number of shadow banks in any market, or in even the most severe counterfactuals. ${ }^{30}$ Our estimates in Table 7 Panel D suggest that the fixed cost of a marginal shadow bank entrant is roughly $\$ 7$ thousand per year per market. These costs represent licensing costs, which are on the order of $\$ 1$ thousand, ${ }^{31}$ as well as other setup costs. This is consistent with the fairly modest markups and small size of a typical shadow bank lender.

\footnotetext{
${ }^{29} \mathrm{https} / / / \mathrm{www} . j d$ power.com/business/press-releases/2019-us-primary-mortgage-servicer-satisfaction-study [Retrieved September 19, 2019].

${ }^{30}$ In our data, $\mathrm{N}=815$.

${ }^{31} \mathrm{https} / /$ integritymortgagelicensing.com/pricing-for-state-licensing/
} 


\section{Section V: Counterfactual Policy Analysis}

In this section, we use the estimated model to study the consequences of several policy changes. Because we allow for entry of shadow banks but assume no changes in the entry or exit of banks, these are probably best seen as medium run counterfactuals. Our baseline scenario is based on 2017 lending volumes, as reported in HMDA, together with 2017 regulatory policies. ${ }^{32}$ We evaluate the effects of policies on the amount, distribution, and pricing of loans, as well as the resulting market structure. Broadly, we analyze the consequences of policy changes along two dimensions. The first is mortgage origination and redistribution, which analyzes the policy from the perspective of potential borrowers: how many mortgages of each type are originated, at which prices, and to which borrowers. Because policies have a differential impact across borrowers of different incomes, they have distributional consequences and affect inequality. The second dimension is implications for bank stability. Because policies impact bank profits and balance-sheet loan retention, they have implications for bank stability. These counterfactuals also allow us to evaluate how predictions of policy consequences change once we account for the impact of the balance sheet retention margin and the shadow bank migration margin. The individual counterfactuals are useful because they analyze the consequences of specific policies. We summarize the robust patterns and insights we obtain across counterfactuals in Section V.D.

\section{V.A Changes to Bank Capital Requirements}

We first study the consequences of changing capital requirements. The level of the capital requirement is one of the main tools used by policymakers to regulate banks. Taking the 2017 market as given, we counterfactually study the impact of increasing and decreasing tier-one risk-adjusted capital requirements relative to the $6 \%$ baseline. Table 9 and Figure 9 show the results. Because capital requirements effectively raise the marginal cost of portfolio lending, we can interpret this counterfactual more broadly as studying regulatory interventions, which increase the cost of portfolio lending such as liquidity requirements or other capital structure regulations.

We first preview the results, which we describe in more detail below. Intuitively, capital requirements tighten the capital constraint, increasing banks' cost of lending on the balance sheet. Therefore, bank balance sheet lending increases stability in the banking sector at a cost of substantially fewer portfolio loans. The central insight is that the change in overall lending is much smaller than suggested by balance sheet contraction. First, on the balance sheet retention margin banks switch from on-balancesheet jumbo to conforming loans that they do not retain on the balance sheet. Second, shadow bank migration also offsets some of the decline in originations. The extent of shadow bank migration in response to capital requirements is now acknowledged as an important margin to consider in policy proposals..$^{33}$ Our counterfactuals quantifies this force, and suggest that the balance sheet migration

\footnotetext{
${ }^{32}$ Note that our baseline shadow bank market share (55\%) is the fraction of loans originated by shadow banks in the combined conforming and jumbo issuance volume.

${ }^{33}$ For instance, the "Minneapolis Plan" of the Minneapolis Federal Reserve proposes substantially increased capital ratios, above $20 \%$. One of the critical inputs involves projections on the amount of activity that could migrate to the shadow banking sector (https://www.minneapolisfed.org/publications/special-studies/endingtbtf/final-proposal/summary-of-theminneapolis-plan-to-end-too-big-to-fail).
} 
margin is at least as, if not more, quantitatively important, especially when lowering capital requirements. The welfare cost of capital requirements is a decline in bank profits and in the consumer surplus of higher-income individuals. In other words, tightening capital requirements trades off bank stability with welfare of high-income consumers and bank profits. Across capital requirements, we find large responses in the prices of jumbo loans, but small changes in the conforming rates, which mainly reflect changes in marginal costs of lending. This suggests that the number of lenders makes the mortgage market quite competitive across segments, leading to significant pass-through, despite product differentiation and imperfect competition, consistent with Bresnahan and Reiss (1991).

\section{Mortgage Origination and Redistribution}

The two margins described drive a large wedge between overall lending and portfolio lending in response to capital requirement changes. Cutting capital requirements by half, to $3 \%$, would result in $145 \%$ increase in balance sheet lending. Total lending, on the other hand, would increase by a much more modest $7.6 \%$. The difference is primarily due to the balance sheet retention margin, though which traditional banks increase the share of conforming mortgages on their balance sheets. The main change in overall lending comes from an increase in the quantity of jumbo mortgages and a $41 \mathrm{bp}$ decline in jumbo rates. The benefits from relaxing capital requirements are small, with consumer surplus increasing by $\$ 9$ billion to predominantly high income borrowers, ${ }^{34}$ and with lender profits increasing by $\$ 7$ billion.

Increasing capital requirements from $6 \%$ to $9 \%$, on the other hand, dramatically decreases balance sheet lending, by $\$ 336$ billion, or $88 \%$. Total mortgage originations, on the other hand, only decline somewhat, by $\$ 182$ billion, or $11 \%$. In other words, the dramatic decrease in balance sheet lending substantially overestimates the consequences of increasing capital requirements on total lending. As the aggregate number suggest, the balance sheet migration margin plays an important role in offsetting the decline in lending: banks shift about $\$ 140$ billion of balance sheet lending off balance sheet. Shadow banks migration accounts for another $\$ 14$ billion. This counterfactual also illustrates that shadow banks have limited ability to offset the decline in portfolio lending, which cannot be securitized. Overall, due to the secondary market, a capital regulation-induced credit crunch is less likely for conforming loans, even in the absence of shadow banks, due to banks switching their business model.

The contraction in lending is largest in the jumbo market, which serves high income individuals. Total consumer surplus declines by roughly $\$ 1$ billion. Top quartile income borrowers see their annual consumer surplus decline by roughly $\$ 84$, while bottom quartile income borrowers see theirs decline by only $\$ 10$. The decline in consumer surplus occurs along two margins: (i) the borrowers who still borrow jumbo loans now pay almost 3 pp higher rates and (ii) the borrowers who do not borrow the optimal amount either because they switched to conforming mortgages, or exited the market, with exit being the predominant force.

\footnotetext{
${ }^{34}$ We compute consumer surplus as a lifetime present-value dollar equivalent measure of expected utility (integrated over consumer specific shocks $\epsilon_{i j c t g}$ ), assuming a subjective discount rate of $4.00 \%$ over a period of 10 years.
} 
Given the capital requirement of $9 \%$, bank profits decrease by roughly $\$ 10$ billion. These increases in interest rates are driven almost entirely by increases in banks' marginal costs of originating jumbo loans on balance sheet rather than changes in markups, and these marginal costs increase by roughly $2.9 \mathrm{pp}$ over the baseline markup of $0.64 \mathrm{pp}$. Shadow bank profits are essentially unchanged. This suggests that the number of lenders makes the mortgage market quite competitive despite product differentiation and imperfect competition.

\section{Bank Stability}

Finally, it is important to note that losses in bank profits have to be weighed against possible welfare gains of moving risk from bank balance sheets (e.g., Egan et al. 2017). Capital requirements operate primarily on the balance sheet retention margin. These large adjustments starkly illustrate the importance of the bank balance sheet retention margin in responding to increases in capital requirements. This risk is instead shifted to GSEs and indirectly to taxpayers, who insure these mortgages. Offsetting somewhat the decrease in risk is also a decrease in expected bank profits, which decline with tighter capital requirements.

\section{V.B Secondary Market Interventions: Quantitative Easing}

Instead of targeting banks, financial intermediation policies can target secondary markets for loans. One set of such major policies during the last financial crisis was referred to as quantitative easing (QE). The Federal Reserve intervened in the securitization market by purchasing large amounts of GSE-guaranteed mortgages, hoping to decrease the rates at which GSEs purchased mortgages from originators, and, in turn, reducing mortgage rates (relative to other rates, such as the cost of balance sheet financing) and increasing easing access to mortgages in particular. Estimates suggest mortgage rates declined between $20-100$ bps across different QE operations. ${ }^{35}$ We model QE as a decrease in the GSE financing costs, which was also the stated intent of the policy. To better understand the implications of secondary market interventions, we also experiment with increasing GSE rates. Such an increase could reflect the reversal of the QE policy or increase in the guarantee fees charged by the GSEs for coverage of projected credit losses from defaults in the securitized pools. The results are shown in Table 10 and Figure 10.

One can compare secondary market interventions with a relaxing of capital requirements, since QE was used in part to encourage lending by banks who had experienced a contraction in capital. Our results suggest that both policy interventions result in more mortgages, but impact different parts of the market. Therefore, they have dramatically different distributional consequences across the income spectrum and result in markedly different allocations of mortgage risk in the economy.

\section{Mortgage Origination and Redistribution}

Our counterfactuals suggest that the main effect of QE is to decrease conforming loan rates and increase conforming mortgage lending volumes significantly: a 25 bp decrease in GSE rates leads to an essentially one-to-one decrease in conforming loan rates and roughly $\$ 377$ billion of new

\footnotetext{
${ }^{35}$ See, among others, Krishnamurthy and Vissing-Jorgensen (2011) and Di Maggio, Kermani, and Palmer (2019).
} 
conforming mortgage origination. Jumbo interest rates and volumes are largely unaffected. Aggregate consumer surplus increases by roughly $\$ 15$ billion, driven by both increased lending and lower interest rates for existing borrowers.

An increase in GSE financing costs has a relatively smaller impact on interest rates and on lending volumes because banks adjust on the balance sheet retention margin. A $25 \mathrm{bp}$ increase in the cost of a securitized conforming mortgage only leads to a 16 bp increase in conforming loan rates. As GSE financing costs increase, banks make significant adjustments along the bank balance sheet retention margin and substitute away from GSE financing and towards cheaper balance sheet financing. In this scenario, conforming mortgage origination declines by only $\$ 220$ billion, in comparison to the $\$ 377$ billion increase caused by an equivalent GSE rate decrease. Jumbo origination volumes decrease slightly because the increased conforming loan balance sheet financing crowds out jumbo lending and increases jumbo origination costs slightly.

This asymmetry in response to rate increases and decreases is more apparent in more extreme scenarios. A $100 \mathrm{bp}$ decline in GSE financing costs leads to roughly a $100 \mathrm{bp}$ decline in conforming interest rates. In contrast, a $100 \mathrm{bp}$ increase in GSE financing costs leads to only a $31 \mathrm{bp}$ increase in conforming interest rates. This asymmetric response of interest rates again reflects the importance of the bank balance sheet retention margin. As banks retain more loans on the balance sheet, the sensitivity of mortgage interest rates to GSE rates decreases. The implications for lending volumes are similarly asymmetric, with a $100 \mathrm{bp}$ decrease leading to origination volume increases of roughly $\$ 2,233$ billion, compared to origination volume decreases of $\$ 540$ billion for a $100 \mathrm{bp}$ increase.

Unlike banks, shadow banks are very sensitive to changes in the securitization market: a $100 \mathrm{bp}$ increase in the GSE financing costs leads to a 30 percentage point decline in the overall shadow bank market share and a 32 percentage point decline in the shadow bank share of conforming loans. Shadow bank lending volume shrinks substantially by around $69 \%$, and the number of shadow banks operating in the typical market decreases by $22 \%$ as formerly profitable shadow banks lose market share and exit due to fixed costs that are too high. Banks' ability to shift to balance-sheet conforming loans gives them a comparative advantage when GSE rates rise.

\section{Bank Stability}

In the baseline scenario, conforming loans comprise roughly 41 percent ( $\$ 156$ billion) of balance sheet lending, but even a slight decline in GSE funding costs creates large enough incentives to move these loans from bank balance sheets to be sold. A 10bp reduction in GSE funding costs causes conforming loans to comprise only 7.3 percent $^{36}$ ( $\$ 18$ billion) as banks endogenously sell these loans to the GSEs. In other words, banks respond to QE by shifting conforming loans off the balance sheet along the balance sheet retention margin. This endogenous shift explains why conforming interest rates are so sensitive in particular to decreases in GSE financing costs: when GSE financing is cheaper, all conforming originations are GSE financed, and so further changes to GSE rates are passed

\footnotetext{
${ }^{36}$ Counterfactual total conforming volume is $\$ 1,622$ of which $1 \%$ is originated on bank balance sheet.
} 
through roughly one-to-one to conforming loan rates. QE also expands traditional bank profits, increasing them by $\$ 6$ billion for a 25 basis points decrease in GSE rates.

In contrast, banks are able to respond to increases in GSE financing costs by shifting originations onto their balance sheets. In response to the $100 \mathrm{bp}$ GSE cost increases, the balance sheet financing share increases substantially, from $22 \%$ to $75 \%$, which mutes the effect on rates and aggregate lending volumes. Once GSE financing costs increase, the cheap on-balance sheet funding of banks gives them a large comparative advantage and banks adjust on the balance sheet retention margin. Bank profits are initially unaffected as GSE costs increase because lending volumes decrease overall, which is offset by increases in more profitable balance sheet lending. However, for larger increases in GSE costs, the latter effects dominate as borrowers substitute more and more towards loans financed on bank balance sheets, and bank profits increase by a small amount.

This counterfactual illustrates how the effects of QE differ substantially from capital requirements. Both increases to capital requirements and increases to GSE financing costs have the effect of contracting mortgage origination. However, an increase in GSE financing cost leads to much larger contraction of aggregate lending volume compared to the increases in capital requirements. This is because an increase in the GSE financing costs directly affects the lending ability of both banks and shadow banks and ends up contracting lending substantially. On the other hand, increases in the capital requirements target only banks. As a result, shadow banks end up alleviating the adverse effects of an increase in the capital requirements on aggregate lending volume by increasing their lending though the migration margin.

\section{V.C GSE Reform: Changes to Conforming Loan Limits}

We next consider changing conforming loan limits, which has been actively debated in the context of GSE policy reform (see Hurst et al. (2016)). This policy has been actively changed since the beginning of the crisis, with the explicit purpose of intervening in the mortgage market. During the 2006-2016 period, conforming loans were generally limited to a $\$ 417,000$ cap. As we illustrate in Figure 1 , at the beginning of the crisis the jumbo market experienced a contraction, which was particularly relevant for high housing-cost markets. In order to increase lending in these areas, the Economic Stimulus Act of 2008 temporarily increased the conforming loan limit in high-cost areas by as much as $\$ 729,750$. The policy of higher limits has persisted since then, although the limit for high-cost areas was subsequently reduced to $\$ 625,000 .{ }^{37}$ The limit is subject to an ongoing policy debate regarding the potential downsizing of the GSE role by progressively lowering conforming loan limits. ${ }^{38}$ Moreover, because the policy caps loan amounts, its consequences differ substantially across markets with different house prices and households with different mortgage demands. We experiment with several scenarios and show the results in Table 11 and Figure 11.

\section{Mortgage Origination and Redistribution}

\footnotetext{
${ }^{37}$ Due to progressive increases in conforming loan limits from 2017 onwards, by 2019 the conforming loan limit reached $\$ 484,350$ in most markets and up to $\$ 726,525$ in high-cost areas.

38 See, for example: https://www.housingwire.com/articles/27344-affordability-concerns-surface-in-conforming-loanlimit-debate [accessed October 2, 2018].
} 
We first consider expanding GSE coverage by increasing the conforming loan limit by $25 \%$. For most markets, this means increasing it from $\$ 417,000$ to roughly $\$ 520,000$. This counterfactual highlights the redistributive impact of expanding GSE coverage because of the changed market structure. Increasing conforming loan limits leads to increases in overall and conforming volume, decreases in jumbo volume, and increases in consumer welfare, especially in high house-price areas. Total origination volumes increase by roughly $\$ 44$ billion, with conforming origination volumes increasing by roughly $\$ 120$ billion and jumbo originations decreasing by roughly $\$ 75$ billion. This expansion of GSE coverage leads to increases in shadow bank market share by roughly $3.3 \mathrm{pp}$. Consumer surplus increases by roughly $\$ 3$ billion in the highest-income markets, while it is roughly unchanged in the lowest-income markets. Borrowers in high-income areas gain most, since more loans at the ideal mortgage size are now conforming, which are cheaper and more convenient.

Finally, it is interesting to consider the two scenarios of unifying conforming loan limits across counties, reverting to pre-crisis policies. Column 5 of Table 11 considers setting all limits to the $\$ 417,000$ lower limit; Column 6 considers setting all limits to the $\$ 625,000$ higher limit. While lowering the limit decreases lending volumes overall and raising the limit increases lending volumes overall, these gains are not evenly distributed. Decreasing limits in all markets to $\$ 417,000$ has essentially no impact on low-income area consumer surplus, while reduces high-income area consumer surplus by roughly $\$ 2$ billion relative to the baseline scenario. On the other hand, increasing limits across all markets to $\$ 625,000$ increases consumer surplus in high-income areas. Borrowers in high-income areas see consumer welfare increase by $\$ 3$ billion, while borrowers in low-income areas see consumer welfare essentially unchanged.

\section{Bank Stability}

While changes to the conforming loan limit mechanically have a large impact on conforming loan volumes, interestingly the impact on loan retention is less direct. Decreasing the conforming loan limit by $25 \%$ raises the share of loans financed on balance sheet by 8 percentage points. This increase is driven largely by increased jumbo lending as a share of overall lending, which increases by 9 percentage points. Increasing the conforming loan limit has a muted effect on the share of balance sheet financing, which declines from $22 \%$ to $18 \%$. While a substantially greater share of mortgage originations is conforming, banks continue to retain a significant share of these originations on balance sheet rather than selling them. They replace jumbo on-balance-sheet lending with conforming on-balance-sheet lending. That is, banks' response along the balance sheet retention margin is small even though their ability to sell loans increases. Increasing conforming loan limits does impact the distribution of profits between banks and shadow banks, with banks' profits decreasing and those of shadow banks' increasing as the latter now originate and distribute to a larger segment of the market where banks once dominated.

There is an interesting difference between the effects of lowering conforming loan limit (Table 11 and Figure 11) versus increasing capital requirements (Table 9 and Figure 9) on aggregate lending volumes. Both polices decrease aggregate lending volumes. However, in the case of increased capital requirements, both shadow bank migration and changes to bank balance sheet retention alleviate the adverse effect of policy on the aggregate lending volume. In other words, in the case of tighter capital 
requirements, solely focusing on bank balance sheet data would overstate the adverse effect of such policy on overall lending volume. On the other hand, in the case of lowering the conforming loan limit, the shadow banking sector amplifies the adverse impact on aggregate lending volume as this policy also causes a contraction of shadow bank lending.

To summarize, the conforming loan limit has significant effects not only on overall lending volumes and lender market shares, but especially on the distribution of welfare and profits in the mortgage market. Extending conforming loan limits beyond their current level increases consumer surplus, but these gains are primarily felt in the highest-income areas, as is the impact of the current policy of having higher limits in high-cost MSAs. The consequences of this policy for the distribution of mortgage risk in the economy are relatively limited, with banks retaining substantial amounts of mortgages on their balance sheets.

\section{V.D Summary from Counterfactuals and Robustness.}

\section{Large Effect of Shadow Bank Migration Margin and the Balance Sheet Retention Margin}

One overarching insight from the counterfactuals is that both adjustments on the shadow bank migration margin and the balance sheet retention margin are critical to understanding policy consequences. For example, we show that the tradeoff between bank stability and lending is much less severe than anticipated by models that focus only on balance sheet lending. Figure $12 \mathrm{~A}$ illustrates this visually by showing a change in the aggregate mortgage origination volume (in billions of dollars) across various bank capital ratio requirements (in percentages) relative to the baseline scenario. Roughly, the difference between total bank lending response and on-balance sheet bank lending response - indicated by the dashed arrow - captures the importance of the balance sheet retention margin, while the difference between aggregate lending response, including shadow banks and the total bank lending response-indicated by the solid arrow — captures the importance of the shadow bank migration margin.

While higher capital requirements lead to a substantial decline in the bank balance sheet lending volume, the overall decline in the bank lending volume is considerably smaller because banks expand off-balance-sheet lending through loan sales. The shadow bank migration margin further moderates the adverse impact of bank capital requirements aggregate lending. For example, our model predicts that increasing bank capital requirements from current levels to $9 \%$ (Table 9 and Figure 9) reduces bank balance sheet lending by $88 \%$, but overall mortgage lending declines by only $10 \%$. One margin of adjustment that is important is the balance sheet retention margin: total bank lending declines by only $25 \%$ as banks adjust their lending from retention to selling. Further accounting for shadow banks and the migration towards them means the net decline is only $2.5 \%$.

It is clear from this example as well as other counterfactuals that a model of financial intermediation must carefully account for both of these margins when evaluating policies. This insight extends well beyond the U.S. market. For instance, the U.K. does not have a large and liquid secondary market for mortgages. Therefore, the impact of financial regulation will differ substantially from the perspective of consumers as well as bank stability. The current Basel regulatory framework proposes a uniform treatment of capital requirements across countries. Our framework suggests that increasing capital 
requirements in the U.K. would result in a substantially higher contraction in overall lending since the bank retention margin in absent in the U.K. Thus, the consequences of imposing similar regulations across countries could result in dramatically different responses depending on the market.

\section{Policy Intervention Targeting: Banks or Secondary Markets?}

The second general insight is that the adjustment depends on whether policy interventions target traditional banks or secondary markets. The concrete examples we analyze are capital requirements versus secondary market interventions such as the GSE premium (QE), conforming loan limits, or, as in extensions below (Section V.E), having a jumbo securitization market. When tighter regulation only targets traditional banks, as is the case with increased capital requirements, solely focusing on bank balance sheets overstates the adverse effect of such polices on overall lending volume. The adjustments on the shadow bank migration margin and the balance sheet retention margin work to offset the adverse impact of tightening. For policies that tighten the secondary market, such as increasing the GSE financing cost or lowering the conforming loan limit, the balance sheet retention margin still offsets some of the adverse effect as shown in Figure 12B and 12C. The shadow bank migration margin, however, exacerbates the effect by lending contracts for shadow banks, leading to a large overall decline in lending. Ignoring the role of shadow banks can yield not only the wrong magnitude of the aggregate effect, but also the wrong direction (see Figure 12B, which compares both the bank-to-bank and shadow bank responses). ${ }^{39}$

This insight has direct consequences for how empirical researchers approach measuring policy consequences and modeling the intermediation sector. When financial regulations and policies change, researchers typically use bank balance sheet data to measure the consequences. Our counterfactuals suggest that drawing quantitative conclusions solely based on bank balance sheet data can be extremely problematic, and difficult to debias without an explicit model of bank retention and shadow bank migration margins.

\section{Bank Stability and Income Redistribution}

The third insight is that interventions to achieve bank stability differ in their redistributive consequences. For example, increasing capital requirements achieves bank stability by decreasing onbalance-sheet lending, i.e., reducing jumbo mortgages. Therefore, the cost of bank stability is mainly borne by higher-income borrowers. An expansion of GSE funding increases the appeal of selling loans, also shifting loans from bank balance sheets and increasing bank stability. It does so while expanding lending and benefiting consumers across the income spectrum, but comes at the cost of taxpayers subsidizing GSE lending.

\section{Robustness}

Our parameters are estimated with noise, and so we produce standard errors around our counterfactual predictions. To calculate these standard errors, we bootstrap the counterfactual predictions by drawing

\footnotetext{
${ }^{39}$ Notably, the equilibrium response of the shadow bank sector is quite important in explaining the aggregate lending response to various policies. For example, lowering the conforming loan limit by $25 \%$ results in $\$ 122$ billion decline in lending (Table 11 and Figure 12C). The contraction of lending by shadow banks ( $\$ 164$ billion), exceeds the aggregate decline as lending shits from conforming to jumbo loans.
} 
new sets of parameter values using the estimated values and standard errors. We then plot $95 \%$ confidence intervals for four of the key outcome variables: total lending volumes, the jumboconforming interest rate spread, the shadow bank market share, and the balance sheet financing share. Appendix Figures A6-A8, Panels A-C show these results for the capital requirement, unconventional monetary policy, and conforming loan limit counterfactuals, respectively. At a high level, these results show that the qualitative results discussed earlier are robust to noise in the parameter estimates.

\section{V.E Model Extensions: Raising Equity, Asset Sales, and Jumbo Securitization}

Our baseline model is already rich, accounting for equilibrium interactions between banks and shadow banks across several markets, as well as allowing banks to adjust their business models on the balance sheet retention margin. Nevertheless, we limit the model complexity to components which are necessary to match the patterns in the data. In this section, we extend the model on several dimensions. We allow banks to issue equity and sell existing assets so they can adjust their balance sheet capacity endogenously. Second, we investigate whether our conclusions would change if a securitization market for jumbo mortgages were to arise in the future.

\section{Endogenous Balance Sheet Capacity: Bank Equity Issuance and Asset Sales}

In the baseline model we assume that issuing loans on the balance sheet becomes increasingly more expensive because banks have a fixed balance sheet capacity. We first extend the model to allow banks to issue equity in order to finance their originations. If a bank wants to keep a mortgage on the balance sheet at a fixed risk-adjusted capital ratio, the cost of external funding is a fixed premium over GSE financing costs. This approach nests banks choosing any desired debt-to-equity ratio: If a bank has chosen a certain (arbitrary, not necessarily the current) debt-to-equity ratio, financing an additional mortgage requires only the issuance of enough equity to keep the debt-to-equity ratio constant at the same cost.

Another way banks can obtain additional balance sheet capacity is to sell existing assets. Recall that banks hold assets other than mortgages on its balance sheet. In the baseline model, the quantity of these assets is fixed. Since adding mortgages on the balance sheet is increasingly more expensive, the bank could choose to sell its assets and substitute these for mortgages. We assume these other assets have a fixed opportunity cost (return). For ease of modeling, we assume that these assets yield a premium over GSE-securitized mortgages that the bank could instead hold.

Intuitively, allowing banks to choose balance sheet capacity changes the model the following way. When a bank is close to its capital requirement, balance sheet lending becomes very expensive. At that point, banks have the option to finance new jumbo originations by raising external financing or selling assets. The advantage of doing this, from the bank's perspective, is that it does not raise the financing costs on its inframarginal assets. Since equity issuance is more expensive than GSE financing, banks will always finance conforming mortgages through GSE financing or existing balance sheet equity, rather than through new equity issuance.

To understand the effect of endogenous balance sheet capacity, we study the impact of raising capital requirements. We set the cost of issuing external funds and the opportunity cost of holding 
nonmortgage assets at 25 bps above GSE funding. Note that this is not the cost of equity financingit is the cost of external financing holding leverage ratios fixed. The results are shown in Appendix Table A1. As one would expect, endogenous balance sheet capacity mutes the effects of raising capital requirements. Raising capital requirements to $9 \%$ decreases lending volumes by only $\$ 7$ billion and increases jumbo interest rates by 1 basis point. The effects on consumer welfare are also muted. The large adjustment occurs on the share of loans that are financed through expanded balance sheet capacity. With the baseline capital requirements of $6 \%$, banks immediately raise equity and finance roughly $14 \%$ of loans through equity issuance. Increasing capital requirements to $9 \%$ increases this further to $15 \%$. As shown in Figure A3, when capital requirements are 3\% no jumbo loans are financed through new issuance; with capital requirements at $9 \%$, nearly all jumbo loans are financed with new capital.

\section{Jumbo Mortgage Securitization Market}

We conduct our policy analysis using the institutional environment from 2017: while conforming mortgages can either be securitized or retained on the balance sheet, there is no securitization market for jumbo mortgages. ${ }^{40}$ As our model suggests, if bank balance sheets become significantly impaired, the premium on jumbo mortgages rises. If the effect is persistent, one might imagine that a securitization market for jumbo mortgages would arise, as they did pre-financial crisis. We introduce a securitization market for jumbo mortgages by allowing jumbo mortgages to be sold on a secondary market. Similar to how conforming securitization has a fixed $\operatorname{cost} \sigma_{t}^{g s e}$, we assume that jumbo securitization has a fixed cost $\sigma_{t}^{\text {jum }}$.

The introduction of jumbo securitization has two effects. First, traditional banks now face a tradeoff between financing jumbo mortgages on balance sheet versus financing jumbo mortgages through securitization. When bank capital is closer to the capital requirement, on-balance sheet financing costs for jumbo mortgages rise. When these costs are sufficiently high, banks choose to switch to external financing through securitization. Second, the introduction of jumbo securitization allows shadow banks to engage in jumbo loan origination. In other words, shadow banks now compete with traditional banks also in the jumbo lending market.

To understand the effect of introducing jumbo securitization markets, we assume that jumbo securitization would be 25 bps more expensive than conforming securitization, since it is not supported by GSE. The results are shown in Appendix Table A2. The introduction of a jumbo securitization market would change the equilibrium significantly even at the baseline $6 \%$ capital requirement. This occurs for two reasons: first, traditional banks who were previously using (potentially expensive) balance sheet financing to originate jumbo loans can switch to a (potentially less expensive) originate to distribute model. Second, shadow banks can enter the jumbo loan origination market. Jumbo lending would increase by $\$ 374$ billion, with conforming lending largely unaffected. Shadow banks' origination would increase by $\$ 440$ billion, $\$ 60$ billion of which would

\footnotetext{
${ }^{40}$ This is conceptually similar to the introduction of the GSE Credit Risk Transfer programs, in which the GSEs sell tranched GSE mortgage exposure to the capital markets.
} 
come at the expense of traditional banks. Banks lose market share because additional shadow banks enter to originate and securitize jumbo loans, which take bank jumbo market share as well as further reducing bank conforming share

After the introduction of jumbo securitization markets, changes to capital requirements have muted effects on overall lending volumes and welfare. In other words, the tradeoff between bank stability and mortgage origination becomes even less severe than our baseline model would suggest. This is because the bank balance sheet retention margin and the shadow bank migration margin now apply to jumbo loans in addition to conforming loans.

Increasing capital requirements to $9 \%$ decreases lending volumes by only $\$ 6$ billion, in comparison to the decrease of $\$ 182$ billion when there are no jumbo securitization markets. Without jumbo securitization markets, increasing capital requirements increases jumbo origination costs because these mortgages must be retained on balance sheet. With jumbo securitization, in contrast, as higher capital requirements increase balance sheet lending costs, banks can adjust on the retention margin. Figure A4 illustrates these dynamics. Panel A shows that while origination volume falls slightly as capital requirements are raised, the effects of higher capital requirements are much smaller. Panel B shows that there is a large margin of adjustment along the share of jumbo mortgages that are securitized. Even with the baseline $6 \%$ capital requirement, the addition of the jumbo securitization market means nearly all jumbo originations are securitized. With a $9 \%$ capital requirement, all jumbo loans are financed through securitization. Additionally, shadow banks can now originate jumbo mortgages, and so the shadow bank migration margin functions in all segments of the market.

These extensions suggest that the importance of the shadow bank migration margin and the balance sheet retention margin play an important role when it comes to policy. The existence of securitization markets - conforming, jumbo, or both — gives lenders considerable flexibility in mortgage financing. Analyses that overlook this and focus on, for example, only bank balance sheet lending, miss significant economic forces and lead to misleading policy analyses.

\section{Effects Due to House Price Changes}

In our counterfactuals, we abstract away from general equilibrium effects on house prices due to tractability. It is possible that by changing access to credit, house prices will endogenously change. While important to consider, we argue that the feedback effects onto house prices are likely to be small in the majority of our counterfactuals. First, in the case of capital requirements, we find that the overall impact on lending volumes is small due to the shadow bank migration and balance sheet retention channels. Because the effect on the overall amount of credit is small, house price responses are likely to be small. Quantitatively, Adelino et al. (2013) study changes to the conforming loan limit and find that houses constrained by the conforming loan limit see prices declines of only $0.5 \%$. In our model, house prices feed back into desired loan size. Our estimates predict that a $0.5 \%$ reduction in house prices is associated with roughly a $0.2 \%$, or $\$ 400$, decrease in desired loan size on average. This is a small decrease relative to the average desired loan size of $\$ 220,000$, as well as the large variation in estimated desired loan size across markets and borrowers. Finally, in the case of unconventional monetary policy, credit expansion in GSE lending would tend to increase house 
prices, thereby acting to mute the overall impact of the counterfactual policy. This would not, however, impact our broader point concerning how lending growth is allocated among bank balance sheets, bank securitization, and shadow banks.

\section{Section VI: Related Literature and Conclusion}

\section{VI.A Related Literature}

The increased amount of bank-like activity taking place outside the traditional banking system has attracted increased attention. Buchak et al. (2018) analyze the recent dramatic growth of shadow banks and fintech lenders in the residential mortgage market and find that the regulatory burden faced by traditional banks and growth of financial technology can account for a large part of the recent shadow bank growth. Fuster et al. (2018) provide complementary evidence that suggests fintech lenders adjust supply more elastically than other lenders in response to exogenous mortgage demand shocks, thereby alleviating capacity constraints associated with traditional mortgage lending. Kim et al. (2018) discuss potential liquidity risks faced by shadow bank lenders. Irani et al. (2018) focus on corporate loans and study the role of bank capital regulation in the growth of shadow banks. Our paper focuses on the limits of shadow banks, which arise from their lack of balance sheet capacity, and points out that banks' ability to adjust their business models to balance sheet capacity shocks makes them similar to shadow banks. We explore the consequences of these two features on the structure of the mortgage market both in segments where originate-to-distribute is common and in segments where it is less common. In addition, our structural model allows us to assess the role of capital requirements, government credit subsidies, and unconventional monetary policy on the overall distribution of mortgage credit across borrowers, as well as on bank stability.

Our paper is also related to a growing literature that uses structural models to study industrial organization in the context of consumer finance. Egan, Hortaçsu, and Matvos (2017), for example, study banking competition and financial fragility through the context of a structural model of demand for bank deposits, and Egan, Lewellen, and Sunderam (2017) structurally decompose the sources of bank value. ${ }^{41}$ Similarly, Aguirregabiria, Clark, and Wang (2019) structurally estimate the economies of scope between bank deposits and loans. Buchak et al. (2018) use a structural framework to analyze the drivers of the recent growth of shadow bank and fintech lenders in the U.S. mortgage market. Corbae and D'Erasmo (2019) build a structural model of bank entry and exit to study the impact of capital and liquidity regulations, focusing on bank size and market structure. Allen, Clark, and Houde (2019) structurally estimate the role of search and brand loyalty in the Canadian mortgage market.

Benetton (2019), the closest paper to ours, uses a structural framework to analyze the impact of bank capital regulation on the U.K. residential mortgage market. Similar to this papers, our demand model follows models like Berry et al. (1995) and Nevo (2000) and applies these modeling techniques to answer regulatory and policy questions in finance. We depart from discrete-choice demand models in several ways. Our model, as well as Benetton (2019), extends the discrete-choice model to include continuous choice, although using different modeling techniques. Continuous choice of mortgage size

\footnotetext{
${ }^{41}$ See also Cox (2017) who develops a structural model of the borrowers' repayment preferences in the student loan market and uses it to measure the overall gains in consumer surplus from risk-based pricing.
} 
is critical in a market segmented on size. We also depart from the standard identification of demand models by introducing the microeconometric bunching estimation into a structural demand model.

The critical modeling departure from the existing literature is on the supply side of financial intermediation. As in Buchak et al. (2018) we model competition between banks and shadow banks. Most structural models of financial intermediation assume balance sheet lending. We strongly depart from this view and allow banks to choose whether to originate on balance sheet or originate to distribute-i.e., the balance sheet adjustment margin. As we emphasize in the paper, modeling this feature critically changes insights from important policy counterfactuals.

Our paper is related to studies that have examined the changing nature of mortgage origination in the United States. The wake of the financial crisis saw increased interest in the functioning of the originate-to-distribute model and its impact on the recent housing crisis. In particular, papers have focused on the originate-to-distribute model and its costs and benefits. See, for example, Mian and Sufi (2009), Keys et al. (2010) and Purnanandam (2011). We contribute to this literature on several dimensions. We model banks' choice of OTD origination in a structural model and examine the equilibrium choice of OTD and balance sheet lending.

Our paper is also related to the literature on GSEs. Many papers, e.g., Acharya et al. (2011), Bhutta (2012), Hurst et al. (2016), and Elenev et al. (2016), have studied how successful GSEs have been in effecting these goals, and have found mixed results. We focus particularly on the role of GSE financing and its interaction with recent regulatory and bank capital changes in explaining the growth of shadow banks. We study how market segmentation arises out of a GSE-financed market interacting with bank balance sheet capacity and bank capital regulation, and how it affects overall origination volume, distribution of credit across borrowers, and relative pricing of products.

Our paper also connects to a large literature that examines the impact of government regulations and various policy interventions on banking and credit markets adopted during and after the financial crisis. See, for example, Mayer et al. (2014); Agarwal et al. (2014, 2017, 2020); Auclert et al. (2019); Lucca et. al. (2014); Piskorski et al. (2015); Egan, Hortaçsu, and Matvos (2017); Granja and Leuz (2017); Di Maggio et al. (2017, 2020) and Scharfstein and Sunderam (2017). Our paper focuses instead on the growth of shadow banks and their interplay with traditional banks after the crisis.

Our paper is also connected to recent quantitative equilibrium models of mortgage and housing markets with heterogonous agents (e.g., Favilukis, Ludvigson, and Van Nieuwerburgh (2017); Kaplan, Mitman, and Violante (2016); Greenwald, Landvoigt, and Van Nieuwerburgh (2018); Guren, Krishnamurthy, and McQuade (2018); and Wong (2018)). Such models can provide many valuable insights, including the quantitative assessment of various effects. Unlike these papers that use computational tools developed in the quantitative macroeconomics literature, we follow the structural industrial organization literature. The advantage of macroeconomic models is that they capture general equilibrium effects, which are absent from our model. On the other hand, we build a credit market framework with supply and demand functions that can be directly estimated using microdata. Moreover, we allow for substantially richer heterogeneity across consumers which can be directly linked to microdata. This rich heterogeneity allows us to speak to the distribution consequences of 
different policies. On the supply side our approach allows for rich strategic choices of banks and shadow banks, as well as their strategic interactions in the market.

Finally, our paper is related to recent work focusing on various forms of bank-like activities taking place outside the traditional banking system and studying the implications of such shifts (e.g., Gennaioli, Shleifer, and Vishny (2013); Adrian and Ashcraft (2016); Moreira and Savov (2017); Ordonez (2018); and Begenau and Landvoigt (2018)). Among this recent work, Koijen and Yogo (2016) analyze the implications of the reinsurance market, which allows regulated insurance companies to move some of their liabilities to shadow reinsurers. Drechsler et al. (2017) and Xiao (2018) show that when the federal funds rate rises, banks widen the spreads they charge on deposits and deposits flow out of the banking system towards the uninsured shadow banking sector, thereby affecting the transmission of monetary policy. Unlike these papers, which focus on the consequences of deposits flowing between the traditional and shadow banks, we study the consequences of capital requirements, conforming credit limits, and unconventional monetary policy that operate independently from the deposit channel. In doing so, we study the impact of equilibrium interaction of shadow banks with traditional banks on quantity, price, and allocation of mortgage credit, as well as on bank stability.

\section{VI.B Conclusion}

Our findings have a number of implications. First, policy analysis of financial intermediation critically requires simultaneously analyzing the impact of the policy on both banks and shadow banks, and accounting for their equilibrium interaction. Any regulation that affects a part of the intermediation market spills over to other markets through competition, and affects which products are offered by which firms and which part of the household income distribution is impacted, as well as equilibrium prices. This observation does not only apply to the residential mortgage market- the focus our study - but to any credit market with a large presence or possible entry of shadow banks with off-balance-sheet lending options. Policy analysis has been moving in this direction somewhat (e.g., the Minneapolis Plan). Unlike these current approaches, we develop one based on a comprehensive model which accounts for the industrial organization of financial intermediation, as well as the changing business models of banks. This framework serves as a starting point for even richer policy analysis.

Second, our paper highlights that the line between traditional and shadow banks from a functional perspective is not clearly demarcated. Well-capitalized banks indeed behave as traditional models of banking suggest: they take deposits and use them to make loans, which they hold to maturity. Poorly capitalized banks, on the other hand, do not have balance sheet capacity and behave like shadow banks, originating loans and selling them off. The ability to do so allows these banks to originate loans despite depressed capital, offsetting some of the effects of capital tightening. Thus, without considering banks' responses on the balance sheet retention margin-deciding to sell instead of retaining loans on the balance sheet - traditional policy tools, including capital ratios and other bank capital regulatory requirements, may have limited effectiveness. On the other hand, disruptions in secondary loan markets have significant impacts on aggregate lending volume and pricing as they adversely affect the ability to lend for both shadow banks and poorly capitalized traditional banks. 
More broadly, we suggest taking a broad view of government insurance subsidies and regulation in order to understand their impacts on the financial intermediation system. On one hand, traditional banks have access to insured deposit financing. On the other hand, shadow banks and poorly capitalized banks predominantly rely on GSE mortgage guarantees. Our results suggest that as subsidies for banks in one sector decline, for example because of restrictive capital requirements, they tilt their activity toward other sources of taxpayer financed subsidies. Understanding the web of subsidies and regulations that pervade the financial system, their equilibrium interactions, and their impact on systematic risk and welfare remains a fruitful area for future research.

\section{References}

Acharya, Viral V., Matthew Richardson, Stijn Van Nieuwerburgh, and Lawrence J. White, 2011, Guaranteed to fail: Fannie Mae, Freddie Mac, and the debacle of mortgage finance. Princeton University Press.

Auclert, Adrien, Will Dobbie and Paul Goldsmith-Pinkham, 2019, Macroeconomic effects of debt relief: Consumer bankruptcy protections in the Great Recession, working paper.

Adrian, Tobias, and Adam B. Ashcraft, 2016, "Shadow banking: A review of the literature." In Banking Crises, pp. 282-315. Palgrave Macmillan UK.

Adelino, Manuel, Antoinette Schoar, and Felipe Severino 2013, Credit supply and house prices: evidence from mortgage market segmentation, working paper.

Agarwal, Sumit, David Lucca, Amit Seru, and Francesco Trebbi, 2014, Inconsistent regulators: Evidence from banking, Quarterly Journal of Economics 129, 889-938.

Agarwal, Sumit, Gene Amromin, Itzhak Ben-David, Souphala Chomsisengphet, Tomasz Piskorski, Amit Seru, 2017, Policy intervention in debt renegotiation: Evidence from Home Affordable Modification Program, Journal of Political Economy 125, 654-712.

Agarwal, Sumit, Gene Amromin, Souphala Chomsisengphet, Tim Landvoigt, Tomasz Piskorski, Amit Seru, and Vincent Yao, 2020, Mortgage refinancing, consumer spending, and competition: Evidence from the Home Affordable Refinancing Program, NBER working paper 21512.

Aguirregabiria, Victor, Clark, Robert, and Hui Wang. 2019, The geographic flow of bank funding and access to credit: Branch networks and local-market competition, working paper.

Allen, Jason, Robert Clark, and Jean-François Houde, 2019, Search frictions and market power in negotiated-price markets, Journal of Political Economy 127, 1550-1598.

Benetton, Matteo, 2019, Leverage regulation and market structure: An empirical model of the UK mortgage market, working paper.

Begenau, Juliane, and Tim Landvoigt, 2018, Financial regulation in a quantitative model of the modern banking system, working paper.

Beraja, Martin, Andreas Fuster, Erik Hurst, and Joseph Vavra, 2019, Regional heterogeneity and monetary policy, Quarterly Journal of Economics, 134, 109-183.

Berry, Steven, James Levinsohn, and Ariel Pakes, 1995, Automobile prices in market equilibrium, Econometrica 63, 841-890. 
Bhutta, Neil, 2012, GSE activity and mortgage supply in lower-income and minority neighborhoods: The effect of the affordable housing goals, Journal of Real Estate Finance and Economics 45, 238261.

Buchak, Greg, Gregor Matvos, Tomasz Piskorski, and Amit Seru, 2018, Fintech, regulatory arbitrage, and the rise of shadow banks, Journal of Financial Economics 130, 453-692.

Corbae, Dean, and Pablo D'Erasmo, 2019, Capital requirements in a quantitative model of banking industry dynamics, NBER working paper 25424.

Cox, Natalie, 2017, Pricing, selection, and welfare in the student loan market: Evidence from borrower repayment decisions, working paper.

DeFusco, Anthony A., and Andrew Paciorek, 2017, The interest rate elasticity of mortgage demand: Evidence from bunching at the conforming loan limit, American Economic Journal: Economic Policy 9, 210-40.

Di Maggio, Marco, Amir Kermani, and Christopher Palmer, 2020, How Quantitative easing works: Evidence on the refinancing channel, Review of Economic Studies 87, 1498-1528.

Di Maggio, Marco, Amir Kermani, Benjamin J. Keys, Tomasz Piskorski, Rodney Ramcharan, Amit Seru, and Vincent Yao, 2017, Interest rate pass-through: Mortgage rates, household consumption and voluntary deleveraging, American Economic Review 107, 3550-88.

Drechsler, Itamar, Alexi Savov, and Philipp Schnabl, 2017, The deposits channel of monetary policy, Quarterly Journal of Economics 132, 1819-1876.

Egan, Mark, Ali Hortaçsu, and Gregor Matvos, 2017, Deposit competition and financial fragility: Evidence from the us banking sector, American Economic Review 107, 169-216.

Egan, Mark, Stefan Lewellen, and Adi Sunderam, 2017, The cross section of bank value., NBER working paper 23291.

Elenev, Vadim, Tim Landvoigt, and Stijn Van Nieuwerburgh, 2016, Phasing out the GSEs, Journal of Monetary Economics 81, 111-132.

Favilukis, Jack, Sydney C. Ludvigson, and Stijn Van Nieuwerburgh, 2017, The macroeconomic effects of housing wealth, housing finance, and limited risk sharing in general equilibrium, Journal of Political Economy 125, 140-223.

Fuster, Andreas, Matthew C. Plosser, Philip Schnabl, James I. Vickery, 2018, The role of technology in mortgage lending, working paper.

Gennaioli, Nicola, Andrei Shleifer, and Robert W. Vishny, 2013, A model of shadow banking, Journal of Finance 68, 1331-1363.

Granja, João, and Christian Leuz, 2017 The death of a regulator: Strict supervision, bank lending and business activity, working paper.

Greenwald, Daniel, Tim Landvoigt, Stijn Van Nieuwerburgh, 2018, Financial fragility with SAM?, MIT Sloan Research Paper 5261-17.

Greenwood, Robin, and David Scharfstein, 2013, The growth of finance, Journal of Economic Perspectives 27, 3-28.

Guren, Adam M., Arvind Krishnamurthy, and Timothy J. McQuade, 2018, Mortgage design in an equilibrium model of the housing market, NBER working paper 24446. 
Hurst, Erik, Benjamin J. Keys, Amit Seru, and Joseph Vavra, 2016, Regional redistribution through the US mortgage market, American Economic Review 106, 2982-3028.

Irani, Rustom, Raj Iyer, Ralf Meisenzahl and Jose-Luis Peydro, 2018, The rise of shadow banking: Evidence from capital regulation, working paper.

Kaplan, Greg, Kurt Mitman, and Giovanni L. Violante, 2016, Non-durable consumption and housing net worth in the great recession: Evidence from easily accessible data. NBER working paper 22232.

Keys, Benjamin J., Tanmoy Mukherjee, Amit Seru, and Vikrant Vig, 2010, Did securitization lead to lax screening? Evidence from subprime loans, Quarterly Journal of Economics 125, 307-362.

Kim, You Suk, Steven M. Laufer, Karen Pence, Richard Stanton, 2018, Liquidity crisis in the mortgage market, working paper.

Koijen, Ralph S.J. and Motohiro Yogo, 2016, Shadow insurance, Econometrica 84, 1265-1287.

Krishnamurthy, Arvind, and Annette Vissing-Jorgensen, 2011, The effects of quantitative easing on interest rates: channels and implications for policy, Brookings Papers on Economic Activity 43, 215 265.

Lucca, David, Amit Seru, and Francesco Trebbi, 2014, The revolving door and worker flows in banking regulation, Journal of Monetary Economics 65, 17-32.

Luck, S., and T. Zimmermann, 2020, Employment effects of unconventional monetary policy: Evidence from QE, Journal of Financial Economics 144, 908-932.

Mayer, Christopher, Edward Morrison, Tomasz Piskorski, and Arpit Gupta, 2014, Mortgage modification and strategic behavior: Evidence from a legal settlement with Countrywide, American Economic Review 104, 2830-2857.

Mian, Atif, and Amir Sufi, 2009, The consequences of mortgage credit expansion: Evidence from the U.S. mortgage default crisis, Quarterly Journal of Economics 124, 1449-96.

Mian, Atif, and Amir Sufi, 2018, Credit supply and housing speculation, working paper.

Moreira, Alan, and Savov, Alexi, 2017, The macroeconomics of shadow banking, The Journal of Finance 72, 2381-2432.

Nevo, Aviv, 2000, Mergers with differentiated products: The case of the ready-to-eat cereal industry, The RAND Journal of Economics 31, 395-421.

Ordonez, Guillermo, 2018, Sustainable shadow banking, American Economic Journal: Macroeconomics, 10, 1-25.

Palmer Christopher, 2015, Why did so many subprime borrowers default during the crisis: Loose credit or plummeting prices?", working paper.

Peek, Joe, and Eric S. Rosengren, 1995. Bank lending and the transmission of monetary policy. In:

Peek, J., Rosengren, E.S., (Eds.), Is Bank Lending Important for the Transmission of Monetary

Policy? Federal Reserve Bank of Boston Conference Series No. 39, pp. 47-68.

Pennacchi, George, 1988, Loan sales and the cost of bank capital, Journal of Finance 43, 375-396.

Plosser, Matthew C., and João A. C. Santos, 2018, Banks incentives and inconsistent risk models, Review of Financial Studies 31, 2080-2112. 
Piskorski, Tomasz, Amit Seru, James Witkin, 2015, Asset quality misrepresentation by financial intermediaries: Evidence from the RMBS market, Journal of Finance 70, 2635-2678.

Purnanandam, Amiyatosh, 2011, Originate-to-distribute model and the subprime mortgage crisis, Review of Financial Studies 24, 1881-1915.

Scharfstein, David, and Adi Sunderam, 2017, Market power in mortgage lending and the transmission of monetary policy, working paper

Seru, Amit, 2019, "Regulating banks in the era of fintech shadow banks", Andrew Crockett Memorial Lecture, Bank for International Settlements.

Stroebel, Johannes, 2016, Asymmetric information and collateral values, Journal of Finance 71(2), 1071-1112

Stroebel Johannes and Joseph Vavra, 2019, House prices, local demand, and retail prices, Journal of Political Economy, 127(3), 1391-1436

Sunderam, Adi, 2015, Money creation and the shadow banking system, Review of Financial Studies, 28(4), 939-977

Syverson, Chad, 2004,Market structure and productivity: A concrete example, Journal of Political Economy, 112(6), 1181-1222.

Wong, Arelene, 2018, Refinancing and transmission of monetary policy to consumption”, working paper

Xiao, Kairong, 2018, Monetary transmission through shadow banks, working paper. 


\section{Table 1: Summary Statistics}

Table 1 shows summary statistics for the datasets used in the reduced-form section of the paper. The sample is mortgages for single-family homes. Panel A shows summary statistics from the HMDA loan-level dataset. Reduced form evidence uses HMDA data between 2007 and 2017; for the structural estimation we use data between 2010 and 2017 to avoid overlap with the financial crisis. Panel B shows summary statistics from the bank-year level dataset constructed from HMDA and call report data, which is used in the regressions for Table 4 and spans 2007-2017.

Panel A: HMDA Loan-Level Summary Dataset over Estimation Period, 2007-2017

\begin{tabular}{rccc}
\hline \hline & All Lenders & Shadow Banks & Traditional Banks \\
\hline Total Originations & $50,585,486$ & $17,278,663$ & $33,306,823$ \\
\% Retained on Balance Sheet or Affiliate & $30 \%$ & $10 \%$ & $41 \%$ \\
\% Sold to Commercial Bank & $10 \%$ & $18 \%$ & $6 \%$ \\
\% Sold to GSE & $47 \%$ & $46 \%$ & $48 \%$ \\
\% Sold to Other & $13 \%$ & $26 \%$ & $6 \%$ \\
\hline \hline
\end{tabular}

Panel B: Bank-Year Dataset

\begin{tabular}{rrrrrrr}
\hline \hline & 2007 & 2008 & 2009 & 2010 & 2011 & 2012 \\
\hline Unique Banks & 3847 & 3879 & 3845 & 3717 & 3601 & 3527 \\
Tier one Risk-adjusted Capital Ratio & $9 \%$ & $9 \%$ & $10 \%$ & $12 \%$ & $12 \%$ & $12 \%$ \\
\% Loans Retained on Balance Sheet & $54 \%$ & $47 \%$ & $31 \%$ & $40 \%$ & $44 \%$ & $42 \%$ \\
\% Jumbo Loans & $31 \%$ & $20 \%$ & $11 \%$ & $14 \%$ & $22 \%$ & $24 \%$ \\
\% Jumbo Loans Retained on Balance Sheet & $77 \%$ & $85 \%$ & $85 \%$ & $88 \%$ & $88 \%$ & $92 \%$ \\
\hline \hline Conforming Loans Retained on Balance Sheet & $44 \%$ & $38 \%$ & $24 \%$ & $32 \%$ & $32 \%$ & $27 \%$ \\
\hline \hline & & & & & & \\
\hline Unique Banks & 3440 & 3366 & 3257 & 3148 & 2539 \\
\% Loans Retained on Balance Sheet & $48 \%$ & $60 \%$ & $60 \%$ & $60 \%$ & $61 \%$ \\
\% Jumbo Loans & $31 \%$ & $43 \%$ & $45 \%$ & $46 \%$ & $48 \%$ \\
\% Conforming Loans Retained on Balance Sheet & $30 \%$ & $38 \%$ & $35 \%$ & $34 \%$ & $36 \%$ \\
\hline \hline
\end{tabular}




\section{Table 2: Financing on Balance Sheet and Originator Type (Bank vs. Shadow Bank) around the Conforming Loan Limit}

This table assesses the discontinuity of financing on balance sheet and originator type around the conforming loan limit for all (bank and shadow bank) originations. Panel A considers balance sheet lending versus outside financing. The left-hand side variable is an indicator for whether the loan is retained on the balance sheet or sold. Panel B considers bank originators versus shadow bank originators. The left-hand side variable is an indicator for whether the originator is a traditional bank. In both panels, Jumbo is an indicator for whether the loan size is above the conforming loan limit in the time-county of origination rendering it ineligible for securitization through GSEs. In both panels, columns (1)-(4) use years 2007-2017, while (5)-(8) use 2017 originations only. Columns (1)-(4) and (5)-(8) consider discontinuity bandwidths from +/$1 \%, 5 \%, 10 \%$, and $25 \%$ around the conforming loan limit. Controls include log loan amount, log applicant income, dummy variables for applicant race, ethnicity, sex, loan type, loan purpose, occupancy, and property type, and census tract-year fixed effects. Standard errors in parentheses are clustered at the lender-year-state level.

Panel A: Loan Retained on Balance Sheet or Sold?

\begin{tabular}{|c|c|c|c|c|c|c|c|c|}
\hline \multirow[b]{3}{*}{ Bandwidth +/- } & \multicolumn{4}{|c|}{ All Sample } & \multicolumn{4}{|c|}{2017 Originations } \\
\hline & (1) & (2) & (3) & (4) & (5) & (6) & (7) & (8) \\
\hline & $1 \%$ & $5 \%$ & $10 \%$ & $25 \%$ & $1 \%$ & $5 \%$ & $10 \%$ & $25 \%$ \\
\hline Jumbo & $\begin{array}{c}0.591 \\
(0.019)\end{array}$ & $\begin{array}{c}0.570 \\
(0.016)\end{array}$ & $\begin{array}{c}0.542 \\
(0.015)\end{array}$ & $\begin{array}{c}0.505 \\
(0.014)\end{array}$ & $\begin{array}{c}0.626 \\
(0.023)\end{array}$ & $\begin{array}{c}0.580 \\
(0.032)\end{array}$ & $\begin{array}{c}0.550 \\
(0.029)\end{array}$ & $\begin{array}{c}0.490 \\
(0.025)\end{array}$ \\
\hline Loan-Level Controls & Yes & Yes & Yes & Yes & Yes & Yes & Yes & Yes \\
\hline Tract-Year FE & Yes & Yes & Yes & Yes & Yes & Yes & Yes & Yes \\
\hline Observations & $1,039,220$ & $1,823,247$ & $2,732,767$ & $6,227,076$ & 93,872 & 173,747 & 277,201 & 647,617 \\
\hline $\mathrm{R}^{2}$ & 0.277 & 0.286 & 0.282 & 0.254 & 0.341 & 0.362 & 0.341 & 0.301 \\
\hline
\end{tabular}

Panel B: Loan Originated by Bank?

\begin{tabular}{|c|c|c|c|c|c|c|c|c|}
\hline \multirow[b]{3}{*}{ Bandwidth +/- } & \multicolumn{4}{|c|}{ All Sample } & \multicolumn{4}{|c|}{2017 Originations } \\
\hline & (1) & (2) & (3) & (4) & (5) & (6) & (7) & (8) \\
\hline & $1 \%$ & $5 \%$ & $10 \%$ & $25 \%$ & $1 \%$ & $5 \%$ & $10 \%$ & $25 \%$ \\
\hline Jumbo & $\begin{array}{c}0.318 \\
(0.026) \\
\end{array}$ & $\begin{array}{r}0.319 \\
(0.021) \\
\end{array}$ & $\begin{array}{c}0.290 \\
(0.019) \\
\end{array}$ & $\begin{array}{c}0.252 \\
(0.016) \\
\end{array}$ & $\begin{array}{c}0.472 \\
(0.038) \\
\end{array}$ & $\begin{array}{c}0.416 \\
(0.024) \\
\end{array}$ & $\begin{array}{c}0.382 \\
(0.019) \\
\end{array}$ & $\begin{array}{c}0.326 \\
(0.016) \\
\end{array}$ \\
\hline Loan-Level Controls & Yes & Yes & Yes & Yes & Yes & Yes & Yes & Yes \\
\hline Tract-Year FE & Yes & Yes & Yes & Yes & Yes & Yes & Yes & Yes \\
\hline Observations & $1,039,220$ & $1,823,247$ & $2,732,767$ & $6,227,076$ & 93,872 & 173,747 & 277,201 & 647,617 \\
\hline $\mathrm{R}^{2}$ & 0.355 & 0.296 & 0.261 & 0.219 & 0.357 & 0.308 & 0.273 & 0.228 \\
\hline
\end{tabular}




\section{Table 3: Financing on Balance Sheet and Capitalization of Traditional Banks around Conforming Loan Limit}

This table assesses the discontinuity of financing on balance sheet and capitalization of traditional banks around the conforming loan limit for only traditional bank originations, with shadow bank originations excluded. Panel A considers balance sheet lending versus outside financing. The left-hand side variable is an indicator for whether the loan is retained on balance sheet or sold. Panel B considers well versus poorly capitalized banks. The left-hand side variable is a dummy that takes the value of 1 if the gap between actual and target capital ratio is positive. The target capital ratio is estimated based on bank specific factors. In both panels, Jumbo is an indicator for whether the loan size is above the conforming loan limit in the time-county of origination rending it ineligible for securitization through GSEs. In both panels, columns (1)-(4) use years 2007-2017; (5)-(8) use 2017 originations only. Columns (1)-(4) and (5)-(8) consider discontinuity widths from $+/-1 \%, 5 \%, 10 \%$, and $25 \%$ around the conforming loan limit. Controls include log loan amount, log applicant income, dummy variables for applicant race, ethnicity, sex, loan type, loan purpose, occupancy, and property type, and census tract-year fixed effects. Standard errors in parentheses are clustered at the lender-year-state level.

Panel A: Loan Retained on Balance Sheet or Sold?

\begin{tabular}{|c|c|c|c|c|c|c|c|c|}
\hline \multirow[b]{3}{*}{ Bandwidth +/- } & \multicolumn{4}{|c|}{ All Sample } & \multicolumn{4}{|c|}{2017 Originations } \\
\hline & (1) & $(2)$ & (3) & (4) & $(5)$ & (6) & (7) & $(8)$ \\
\hline & $1 \%$ & $5 \%$ & $10 \%$ & $25 \%$ & $1 \%$ & $5 \%$ & $10 \%$ & $25 \%$ \\
\hline Jumbo & $\begin{array}{c}0.574 \\
(0.015) \\
\end{array}$ & $\begin{array}{c}0.571 \\
(0.012)\end{array}$ & $\begin{array}{c}0.550 \\
(0.011)\end{array}$ & $\begin{array}{c}0.518 \\
(0.010) \\
\end{array}$ & $\begin{array}{c}0.529 \\
(0.044) \\
\end{array}$ & $\begin{array}{c}0.574 \\
(0.034)\end{array}$ & $\begin{array}{c}0.546 \\
(0.030) \\
\end{array}$ & $\begin{array}{c}0.488 \\
(0.028) \\
\end{array}$ \\
\hline Loan-Level Controls & Yes & Yes & Yes & Yes & Yes & Yes & Yes & Yes \\
\hline Tract-Year FE & Yes & Yes & Yes & Yes & Yes & Yes & Yes & Yes \\
\hline Observations & 596,107 & $1,065,055$ & $1,601,705$ & $3,603,686$ & 33,531 & 69,766 & 118,432 & 281,484 \\
\hline $\mathrm{R}^{2}$ & 0.366 & 0.376 & 0.372 & 0.332 & 0.553 & 0.527 & 0.484 & 0.428 \\
\hline
\end{tabular}

Panel B: Loan Originated by a Well Capitalized Bank?

\begin{tabular}{|c|c|c|c|c|c|c|c|c|}
\hline \multirow[b]{3}{*}{ Bandwidth +/- } & \multicolumn{4}{|c|}{ All Sample } & \multicolumn{4}{|c|}{2017 Originations } \\
\hline & (1) & (2) & (3) & (4) & (5) & (6) & (7) & (8) \\
\hline & $1 \%$ & $5 \%$ & $10 \%$ & $25 \%$ & $1 \%$ & $5 \%$ & $10 \%$ & $25 \%$ \\
\hline \multirow[t]{2}{*}{ Jumbo } & 0.084 & 0.086 & 0.085 & 0.072 & 0.172 & 0.188 & 0.173 & 0.146 \\
\hline & $(0.013)$ & $(0.011)$ & $(0.010)$ & $(0.008)$ & $(0.045)$ & $(0.032)$ & $(0.027)$ & $(0.021)$ \\
\hline Loan-Level Controls & Yes & Yes & Yes & Yes & Yes & Yes & Yes & Yes \\
\hline Tract-Year FE & Yes & Yes & Yes & Yes & Yes & Yes & Yes & Yes \\
\hline Observations & 594,739 & $1,062,638$ & $1,598,236$ & $3,596,177$ & 33,531 & 69,765 & 118,428 & 281,479 \\
\hline $\mathrm{R}^{2}$ & 0.381 & 0.314 & 0.271 & 0.211 & 0.492 & 0.381 & 0.311 & 0.229 \\
\hline
\end{tabular}




\section{Table 4: Balance Sheet Retention and Bank Capitalization}

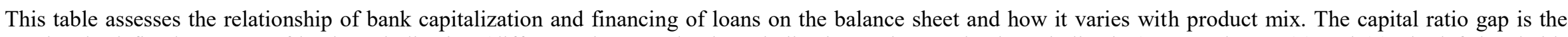

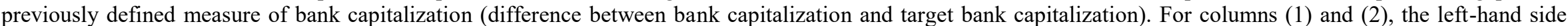

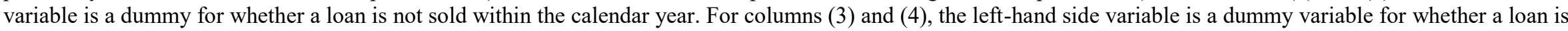

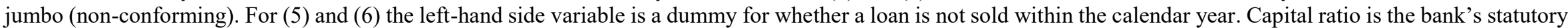

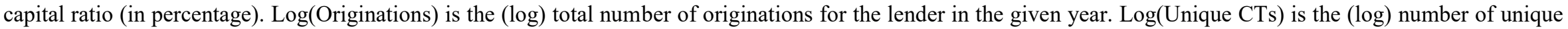

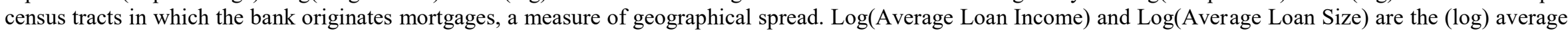

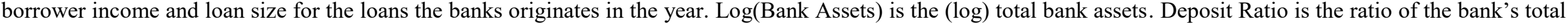

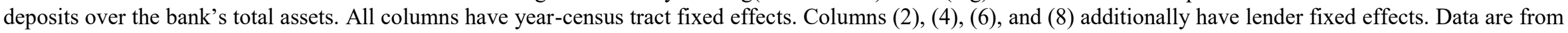
HMDA and the Federal Reserve call reports and cover 2007 to 2017. Standard errors in parentheses are clustered at the lender-year-state level.

\begin{tabular}{|c|c|c|c|c|c|c|}
\hline & \multicolumn{2}{|c|}{$\begin{array}{l}\text { Retained Indicator } \\
\text { (All loans) }\end{array}$} & \multicolumn{2}{|c|}{$\begin{array}{c}\text { Jumbo Indicator } \\
\text { (All loans) }\end{array}$} & \multicolumn{2}{|c|}{$\begin{array}{l}\text { Retained Indicator } \\
\text { (Conforming) }\end{array}$} \\
\hline & $(1)$ & $(2)$ & $(3)$ & $(4)$ & $(5)$ & $(6)$ \\
\hline \multirow[t]{2}{*}{ Capital Ratio Gap } & 0.024 & 0.022 & 0.002 & 0.002 & 0.025 & 0.023 \\
\hline & $(0.003)$ & $(0.005)$ & $(0.0004)$ & $(0.001)$ & $(0.003)$ & $(0.005)$ \\
\hline \multirow[t]{2}{*}{ Log(Income) } & 0.059 & 0.074 & 0.011 & 0.008 & 0.062 & 0.080 \\
\hline & $(0.004)$ & $(0.005)$ & $(0.001)$ & $(0.001)$ & $(0.004)$ & $(0.006)$ \\
\hline \multirow[t]{2}{*}{$\log ($ LoanSize $)$} & -0.112 & -0.054 & 0.020 & 0.033 & -0.127 & -0.068 \\
\hline & $(0.005)$ & $(0.007)$ & $(0.001)$ & $(0.001)$ & $(0.005)$ & $(0.008)$ \\
\hline \multirow[t]{2}{*}{ Log(Originations) } & -0.346 & -0.123 & -0.029 & 0.001 & -0.348 & -0.084 \\
\hline & $(0.016)$ & $(0.044)$ & $(0.002)$ & $(0.005)$ & $(0.016)$ & $(0.046)$ \\
\hline \multirow[t]{2}{*}{ Log(Unique CTs) } & -0.045 & -0.068 & -0.029 & -0.038 & -0.018 & -0.075 \\
\hline & $(0.016)$ & $(0.042)$ & $(0.002)$ & $(0.005)$ & $(0.016)$ & $(0.044)$ \\
\hline \multirow[t]{2}{*}{ Log(Assets) } & 0.323 & 0.161 & 0.041 & 0.011 & 0.300 & 0.140 \\
\hline & $(0.009)$ & $(0.047)$ & $(0.002)$ & $(0.006)$ & $(0.009)$ & $(0.050)$ \\
\hline \multirow[t]{2}{*}{ Deposit Ratio } & -0.0005 & 0.116 & -0.007 & -0.003 & 0.005 & 0.120 \\
\hline & $(0.010)$ & $(0.015)$ & $(0.001)$ & $(0.001)$ & $(0.011)$ & $(0.016)$ \\
\hline \multirow[t]{2}{*}{ Non-core Funding } & -0.004 & 0.053 & 0.008 & 0.004 & -0.009 & 0.052 \\
\hline & $(0.008)$ & $(0.010)$ & $(0.001)$ & $(0.001)$ & $(0.008)$ & $(0.011)$ \\
\hline \multirow[t]{2}{*}{ Core Deposits } & -0.111 & -0.027 & 0.009 & 0.010 & -0.124 & -0.033 \\
\hline & $(0.013)$ & $(0.016)$ & $(0.001)$ & $(0.002)$ & $(0.014)$ & $(0.016)$ \\
\hline Year * Census Tract FE & Yes & Yes & Yes & Yes & Yes & Yes \\
\hline Lender FE & No & Yes & No & Yes & No & Yes \\
\hline Observations & $33,254,621$ & $33,254,621$ & $33,254,621$ & $33,254,621$ & $33,254,621$ & $33,254,621$ \\
\hline $\mathrm{R}^{2}$ & 0.238 & 0.333 & 0.330 & 0.340 & 0.233 & 0.334 \\
\hline
\end{tabular}




\section{Table 5: Structural Estimation - Key Demand Parameters}

This table shows the estimated demand parameters. Consumer preferences are given by the equation $\mathrm{B}_{i}=\overline{\mathrm{B}}+\Pi\left(D_{i c}-\bar{D}\right)+\Sigma v_{i}$, where $\overline{\mathrm{B}}$ is the vector of parameter means, $\Pi$ is the mapping between demographic characteristics, and $\Sigma$ scales random shocks. Panels A, B, and C show the results for $\overline{\mathrm{B}}, \Pi$, and $\Sigma$, respectively. $\alpha$ is the consumer's price sensitivity, i.e., how much her utility decreases from a $1 \%$ higher interest rate. $\beta$ is the consumer's disutility from obtaining a smaller loan. $\gamma$ is the consumer's utility from obtaining a conforming loan rather than a jumbo loan, regardless of loan size. A detailed description of the economic meaning of these parameters and how they are estimated can be found in Sections IV.A and IV.C.1, respectively.

Panel A: Mean Preference Parameters

\begin{tabular}{ccc}
\hline \hline & $\overline{\mathrm{B}}$ & \\
\hline Parameter & Description & Estimate (SE) \\
\hline $\bar{\alpha}$ & Price & $1.65(0.27)$ \\
$\bar{\beta}$ & Disutility from smaller loan & $4.34(0.14)$ \\
$\bar{\gamma}$ & Conforming convenience & $0.83(0.13)$ \\
$\log \bar{F}$ & Log loan size & $13.05(0.03)$ \\
\hline \hline
\end{tabular}

Panel B: Demographic-Preference Relationships

\begin{tabular}{cccc}
\hline \multicolumn{4}{c}{ Panel B: Demographic-Preference Relationships } \\
\hline Parameter & Description & Estimate (log Income) (SE) & Estimate (log Price) (SE) \\
\hline$\alpha_{i}$ & Price & $0.675(0.0017)$ & $-0.454(0.0014)$ \\
$\beta_{i}$ & Disutility from smaller loan & $-1.806(0.0019)$ & $0.594(0.0018)$ \\
$\gamma_{i}$ & Conforming preference & $-3.787(0.0004)$ & $2.311(0.0005)$ \\
$\log F_{i}$ & Log loan size & $0.387(0.0037)$ & $0.343(0.0035)$ \\
\hline \hline
\end{tabular}

Panel C: Shocks

\begin{tabular}{ccc}
\multicolumn{3}{c}{ Panel C: Shocks } \\
\hline \hline Parameter & Description & Estimate $(\mathrm{SE})$ \\
\hline$\sigma_{\alpha}^{2}$ & Price & $0.1(0.0005)$ \\
$\sigma_{\beta}^{2}$ & Disutility from smaller loan & $1.3(0.0001)$ \\
$\sigma_{\gamma}^{2}$ & Conforming preference & $0.05(0.0001)$ \\
$\sigma_{\log F}^{2}$ & Log loan size & $0.89(0.0112)$ \\
\hline \hline
\end{tabular}




\section{Table 6: Validation of Counterfactual Results using Conforming Loan Limit Changes}

This table studies the response of jumbo market share, conforming loan bunching, and bank market share to changes in conforming loan limits at the year-county level. Limit Increase is the percentage increase in the conforming loan limit in a county between 2007 and year $t$, which runs to 2017. Column (1) regresses jumbo share on this increase. The left-hand side is the county-year level jumbo loan market share in percentage terms. Column (2) regresses the bunched market share of borrowers within a $5 \%$ band around the conforming loan cutoff. Column (3) is the reduced form of bank market share on the limit increase. Column (4) is the OLS of bank share on jumbo origination share. The left-hand side variable in columns (3) and (4) is the county-year level bank market share in percentage terms. All columns include year and county fixed effects. Standard errors are in parentheses.

\begin{tabular}{lcccc}
\hline \hline & Jumbo Share & Cutoff Share & \multicolumn{2}{c}{ Bank Share } \\
\cline { 2 - 5 } & $(1)$ & $(2)$ & $(3)$ & $(4)$ \\
& OLS & OLS & OLS & OLS \\
\hline Limit Increase & -0.235 & -0.103 & -0.018 & - \\
& $(0.001)$ & $(0.001)$ & $(0.003)$ & - \\
Jumbo Share & - & - & - & 0.264 \\
& - & - & - & $(0.009)$ \\
\hline Year FE & Yes & Yes & Yes & Yes \\
County FE & Yes & Yes & Yes & Yes \\
\hline Observations & 35,847 & 35,847 & 35,847 & 35,847 \\
$\mathrm{R}^{2}$ & 0.854 & 0.857 & 0.904 & 0.907 \\
\hline \hline
\end{tabular}




\section{Table 7: Structural Estimation - Key Supply Parameters}

This table shows the estimated supply parameters. Panels A and B show financing costs and non-financing marginal costs obtaining from loan production and risk. respectively. Panel $\mathrm{C}$ shows the non-linear parameters that determine the financing cost. Panel D shows the fixed costs of non-fintech shadow banks, which determines entry in equilibrium. Financing costs represent financing costs that any lender must pay, regardless of whether it is financed though GSE financing or on balance sheet. Non-financing costs represent differences in origination or labor costs not coming from financing, including risk. Nonlinear financing costs reflect the tradeoff a bank faces when deciding whether to finance on balance sheet or through GSE financing. Fixed cost parameters include the mean and standard deviation of non-fintech shadow banks together with the number of potential entrants. A detailed description of the economic meaning of these parameters and how they are identified can be found in Section IV.B and IV.C.2, respectively

\section{Panel A: Financing Costs}

\begin{tabular}{ccc}
\hline Parameter & Year & Estimate (SE) \\
\hline$\sigma_{2010}^{b}$ & 2010 & $3.79(0.006)$ \\
$\sigma_{2011}^{b}$ & 2011 & $3.61(0.009)$ \\
$\sigma_{2012}^{b}$ & 2012 & $2.89(0.009)$ \\
$\sigma_{2013}^{b}$ & 2013 & $2.95(0.009)$ \\
$\sigma_{2014}^{b}$ & 2014 & $3.45(0.01)$ \\
$\sigma_{2015}^{b}$ & 2015 & $3.09(0.009)$ \\
$\sigma_{2016}^{b}$ & 2016 & $2.85(0.009)$ \\
$\sigma_{2017}^{b}$ & 2017 & $3.21(0.008)$ \\
\hline \hline
\end{tabular}

Panel: Risk and Non-financing Costs

\begin{tabular}{|c|c|}
\hline Product Characteristic & Cost (SE) \\
\hline \multicolumn{2}{|l|}{ Labor } \\
\hline Bank, purchase & - \\
\hline Bank, refinance & $0.06(0.004)$ \\
\hline Non-bank, non-fintech, purchase & $0.04(0.004)$ \\
\hline Non-bank, non-fintech, refinance & $0.04(0.007)$ \\
\hline Non-bank, fintech, purchase & $0.03(0.009)$ \\
\hline Non-bank, fintech, refinance & $0.08(0.014)$ \\
\hline Conforming production $\left(\sigma_{c}^{G S E}\right)$ & $0.67(0.007)$ \\
\hline \multicolumn{2}{|l|}{ Risk } \\
\hline Low FICO Jumbo $\left(\sigma_{c}^{\Delta}\right)$ & $0.22(0.018)$ \\
\hline Low FICO Conforming $\left(\sigma_{c}^{\Delta, G S E}\right)$ & $0.29(0.003)$ \\
\hline
\end{tabular}

Panel C: Non-linear Financing Costs

\begin{tabular}{ccc}
\hline Parameter & Description & Value (SE) \\
\hline$\sigma^{G S E}$ & GSE funding cost & $0.25(0.049)$ \\
$\sigma^{b 1}$ & Internal coefficient on capital adequacy & $0.27(0.031)$ \\
$\phi$ & Shape parameter for capital adequacy & $1.07(0.035)$ \\
\hline \hline
\end{tabular}

Panel D: Non-fintech shadow bank fixed costs

\begin{tabular}{cl}
\hline \hline Parameter & Value (SE) \\
\hline$\mu$ & $10.37(0.366)$ \\
$\sigma$ & $7.3(0.331)$ \\
$N$ & 815 \\
\hline \hline
\end{tabular}




\section{Table 8: Structural Estimation - Regulatory Burden and Fintech Quality}

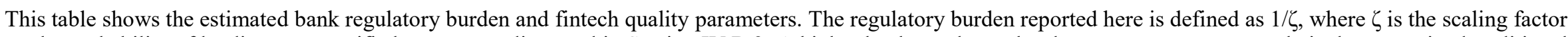

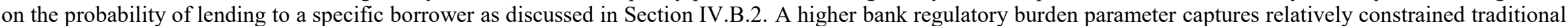

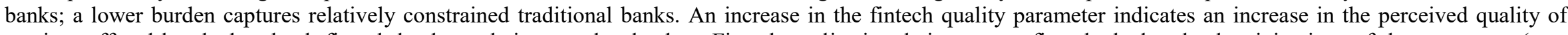

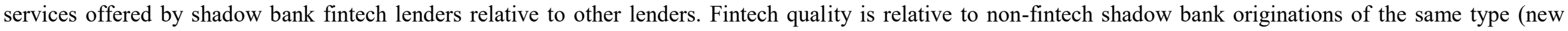
origination or refinance).

\begin{tabular}{cccc}
\hline \hline & & \multicolumn{2}{c}{ Fintech Quality } \\
\cline { 3 - 4 } Year & Bank Regulatory Burden & New Originations & Refinance \\
\hline 2010 & $0.48(0.13)$ & $-0.85(0.21)$ & $1.38(0.14)$ \\
2011 & $0.41(0.15)$ & $-0.73(0.17)$ & $1.37(0.11)$ \\
2012 & $0.42(0.06)$ & $-0.56(0.19)$ & $1.45(0.15)$ \\
2013 & $0.43(0.08)$ & $-0.19(0.1)$ & $1.79(0.1)$ \\
2014 & $0.54(0.09)$ & $-0.03(0.12)$ & $1.97(0.08)$ \\
2015 & $0.54(0.07)$ & $0.06(0.11)$ & $1.74(0.07)$ \\
2016 & $0.48(0.05)$ & $0.15(0.07)$ & $1.7(0.07)$ \\
2017 & $0.63(0.09)$ & $0.36(0.11)$ & $1.86(0.09)$ \\
\hline \hline
\end{tabular}




\section{Table 9: Counterfactual Analysis - Capital Requirements}

This table shows the impact of various tier-one risk-adjusted capital requirements. Column (1) shows the case a $3 \%$ capital requirement. Column (2) for a $4.5 \%$ capital requirement.

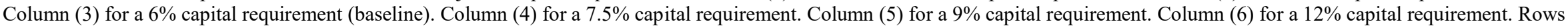
show the predicted impact of the counterfactual change on various outcomes.

\begin{tabular}{|c|c|c|c|c|c|c|}
\hline \multirow{4}{*}{ Lending Volumes } & \multicolumn{6}{|c|}{ Capital Requirement } \\
\hline & \multirow{2}{*}{$\begin{array}{l}1) \\
3 \% \\
\end{array}$} & \multirow{2}{*}{$\begin{array}{l}2) \\
4.5 \% \\
\end{array}$} & \multirow{2}{*}{$\begin{array}{l}3) \\
6 \% \text { (Baseline) } \\
\end{array}$} & \multirow{2}{*}{$\begin{array}{l}4) \\
7.5 \% \\
\end{array}$} & \multirow{2}{*}{$\begin{array}{l}5) \\
9 \% \\
\end{array}$} & \multirow{2}{*}{$\begin{array}{l}6) \\
12 \% \\
\end{array}$} \\
\hline & & & & & & \\
\hline & & & & & & \\
\hline Overall Lending Volume (\$b) & 1,840 & 1,782 & 1,710 & 1,630 & 1,528 & 1,500 \\
\hline Conforming Volume (\$b) & 1,537 & 1,508 & 1,484 & 1,485 & 1,495 & 1,499 \\
\hline Jumbo Volume (\$b) & 303 & 274 & 226 & 145 & 32 & 1 \\
\hline Bank Volume (\$b) & 929 & 860 & 775 & 689 & 579 & 548 \\
\hline \multicolumn{7}{|l|}{ Loan Financing } \\
\hline Balance Sheet Lending (\$b) & 929 & 853 & 382 & 171 & 46 & 2 \\
\hline Share of Loans Financed on Balance Sheet (\%) & $51 \%$ & $48 \%$ & $22 \%$ & $11 \%$ & $3 \%$ & $0 \%$ \\
\hline Share of Conforming Loans Financed on Balance Sheet (\%) & $41 \%$ & $38 \%$ & $10 \%$ & $2 \%$ & $1 \%$ & $0 \%$ \\
\hline Shadow Bank Market Share (\%) & $49 \%$ & $52 \%$ & $55 \%$ & $58 \%$ & $62 \%$ & $63 \%$ \\
\hline Shadow Bank Share of Conforming Loans (\%) & $59 \%$ & $61 \%$ & $63 \%$ & $63 \%$ & $63 \%$ & $64 \%$ \\
\hline \multicolumn{7}{|l|}{ Interest Rates (deviation from baseline) } \\
\hline Conforming Interest Rate (\%) & $-0.05 \%$ & $-0.02 \%$ & - & $0.00 \%$ & $0.00 \%$ & $0.00 \%$ \\
\hline Jumbo Interest Rate (\%) & $-0.41 \%$ & $-0.27 \%$ & - & $0.65 \%$ & $2.92 \%$ & - \\
\hline Jumbo - Conforming Spread (\%) & $-0.36 \%$ & $-0.25 \%$ & - & $0.64 \%$ & $2.92 \%$ & - \\
\hline \multicolumn{7}{|l|}{ Profits and Consumer Welfare (deviation from baseline) } \\
\hline Overall Lender Profits (\$b) & 7 & 4 & - & -4 & -10 & -11 \\
\hline Bank Profits (\$b) & 8 & 4 & - & -5 & -10 & -12 \\
\hline Shadow Bank Profits (\$b) & -1 & -1 & - & 0 & 1 & 1 \\
\hline Average \# of shadow bank lenders per market & 101 & 101 & 101 & 101 & 101 & 101 \\
\hline Overall Consumer Surplus (\$b) & 9 & 4 & - & -1 & -1 & -1 \\
\hline Individual Consumer Surplus (\$) & 410 & 203 & - & -35 & -30 & -28 \\
\hline Overall Consumer Surplus for Top Income Market (\$b) & 3 & 2 & - & 0 & 0 & 0 \\
\hline Overall Consumer Surplus for Bottom Income Market (\$b) & 1 & 1 & - & 0 & 0 & 0 \\
\hline Individual Consumer Surplus for Top Income Quartile (\$) & 541 & 270 & - & -63 & -84 & -92 \\
\hline Individual Consumer Surplus for Bottom Income Quartile (\$) & 323 & 159 & - & -23 & -10 & -5 \\
\hline
\end{tabular}




\section{Table 10: Counterfactual Analysis - Secondary Market Intervention}

This table shows the impact of secondary market intervention that impacts GSE financing costs. Columns (1)-(3) show the impact of lowering GSE financing costs by 100,25 , and 10 basis

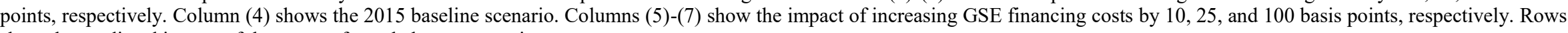
show the predicted impact of the counterfactual change on various outcomes.

\begin{tabular}{|c|c|c|c|c|c|c|c|}
\hline & & & Chan & o GSE Fin & ing Costs & & \\
\hline & (1) & (2) & (3) & (4) & (5) & & (7) \\
\hline & $-100 \mathrm{bps}$ & $-25 \mathrm{bps}$ & $-10 \mathrm{bps}$ & Baseline & $+10 \mathrm{bps}$ & $+25 \mathrm{bps}$ & $+100 \mathrm{bps}$ \\
\hline Lending Volumes & & & & & & & \\
\hline Overall Lending Volume (\$b) & 3,943 & 2,087 & 1,847 & 1,710 & 1,606 & 1,490 & 1,170 \\
\hline Conforming Volume $(\$ \mathrm{~b})$ & 3,737 & 1,865 & 1,622 & 1,484 & 1,378 & 1,261 & 936 \\
\hline Jumbo Volume (\$b) & 205 & 222 & 225 & 226 & 227 & 229 & 234 \\
\hline Bank Volume (\$b) & 1,480 & 892 & 814 & 775 & 767 & 784 & 881 \\
\hline Loan Financing & & & & & & & \\
\hline Balance Sheet Lending (\$b) & 205 & 222 & 242 & 382 & 659 & 777 & 881 \\
\hline Share of Loans Financed on Balance Sheet (\%) & $5 \%$ & $11 \%$ & $13 \%$ & $22 \%$ & $41 \%$ & $52 \%$ & $75 \%$ \\
\hline Share of Conforming Loans Financed on Balance Sheet (\%) & $0 \%$ & $0 \%$ & $1 \%$ & $10 \%$ & $31 \%$ & $43 \%$ & $69 \%$ \\
\hline Shadow Bank Market Share (\%) & $62 \%$ & $57 \%$ & $56 \%$ & $55 \%$ & $52 \%$ & $47 \%$ & $25 \%$ \\
\hline Shadow Bank Share of Conforming Loans (\%) & $66 \%$ & $64 \%$ & $64 \%$ & $63 \%$ & $61 \%$ & $56 \%$ & $31 \%$ \\
\hline Interest Rates (deviation from baseline) & & & & & & & \\
\hline Conforming Interest Rate $(\%)$ & $-0.99 \%$ & $-0.24 \%$ & $-0.09 \%$ & - & $0.08 \%$ & $0.16 \%$ & $0.31 \%$ \\
\hline Jumbo Interest Rate (\%) & $0.00 \%$ & $0.00 \%$ & $0.00 \%$ & - & $0.00 \%$ & $0.00 \%$ & $0.00 \%$ \\
\hline Jumbo - Conforming Spread (\%) & $0.99 \%$ & $0.24 \%$ & $0.09 \%$ & - & $-0.08 \%$ & $-0.16 \%$ & $-0.31 \%$ \\
\hline Profits and Consumer Welfare (deviation from baseline) & & & & & & & \\
\hline Overall Lender Profits (\$b) & 114 & 19 & 7 & - & -5 & -11 & -28 \\
\hline Bank Profits $(\$ b)$ & 36 & 6 & 2 & - & 0 & 1 & 6 \\
\hline Shadow Bank Profits $(\$ b)$ & 78 & 13 & 5 & - & -5 & -12 & -33 \\
\hline Average \# of shadow bank lenders per market & 122 & 106 & 103 & 101 & 99 & 96 & 79 \\
\hline Overall Consumer Surplus (\$b) & 91 & 15 & 5 & - & -1 & 0 & 10 \\
\hline Individual Consumer Surplus (\$) & 3,335 & 577 & 187 & - & -24 & 93 & 660 \\
\hline Overall Consumer Surplus for Top Income Market (\$b) & 32 & 5 & 2 & - & 0 & 0 & 5 \\
\hline Overall Consumer Surplus for Bottom Income Market (\$b) & 14 & 2 & 1 & - & 0 & 0 & 1 \\
\hline Individual Consumer Surplus for Top Income Quartile (\$) & 4,038 & 713 & 231 & - & -23 & 136 & 898 \\
\hline Individual Consumer Surplus for Bottom Income Quartile (\$) & 2,852 & 482 & 156 & - & -25 & 60 & 487 \\
\hline
\end{tabular}




\section{Table 11: Counterfactual Analysis - Conforming Loan Limit}

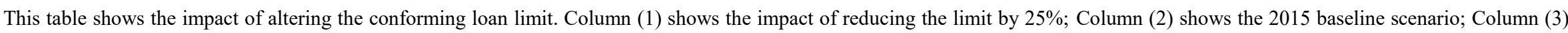

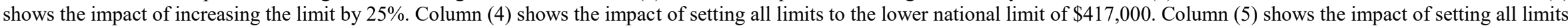
to the higher national limit of $\$ 625,000$. Rows show the predicted impact of the counterfactual change on various outcomes.

\begin{tabular}{|c|c|c|c|c|c|c|}
\hline & \multicolumn{6}{|c|}{ Changes to Conforming Loan Limit } \\
\hline & (1) & (2) & (3) & $(4)$ & $(5)$ & (6) \\
\hline & $-25 \%$ & Baseline & $25 \%$ & No Limit & $\$ 417 \mathrm{k}$ & $\$ 625 \mathrm{k}$ \\
\hline \multicolumn{7}{|l|}{ Lending Volumes } \\
\hline Overall Lending Volume (\$b) & 1,588 & 1,710 & 1,754 & 1,744 & 1,674 & 1,748 \\
\hline Conforming Volume $(\$ \mathrm{~b})$ & 1,239 & 1,484 & 1,604 & 1,734 & 1,406 & 1,610 \\
\hline Jumbo Volume ( $\$ b)$ & 349 & 226 & 151 & 10 & 268 & 138 \\
\hline Bank Volume (\$b) & 818 & 775 & 738 & 638 & 793 & 728 \\
\hline \multicolumn{7}{|l|}{ Loan Financing } \\
\hline Balance Sheet Lending (\$b) & 482 & 382 & 317 & 188 & 417 & 306 \\
\hline Share of Loans Financed on Balance Sheet (\%) & $30 \%$ & $22 \%$ & $18 \%$ & $11 \%$ & $25 \%$ & $17 \%$ \\
\hline Share of Conforming Loans Financed on Balance Sheet (\%) & $11 \%$ & $10 \%$ & $10 \%$ & $10 \%$ & $11 \%$ & $10 \%$ \\
\hline Shadow Bank Market Share (\%) & $49 \%$ & $55 \%$ & $58 \%$ & $63 \%$ & $53 \%$ & $58 \%$ \\
\hline Shadow Bank Share of Conforming Loans (\%) & $62 \%$ & $63 \%$ & $63 \%$ & $64 \%$ & $63 \%$ & $63 \%$ \\
\hline \multicolumn{7}{|l|}{ Interest Rates (deviation from baseline) } \\
\hline Conforming Interest Rate (\%) & $0.00 \%$ & - & $0.00 \%$ & $0.00 \%$ & $0.00 \%$ & $0.00 \%$ \\
\hline Jumbo Interest Rate (\%) & $0.01 \%$ & - & $0.00 \%$ & $0.02 \%$ & $0.00 \%$ & $-0.01 \%$ \\
\hline Jumbo - Conforming Spread (\%) & $0.01 \%$ & - & $0.00 \%$ & $0.02 \%$ & $0.00 \%$ & $0.00 \%$ \\
\hline \multicolumn{7}{|l|}{ Profits and Consumer Welfare (deviation from baseline) } \\
\hline Overall Lender Profits (\$b) & -6 & - & 2 & 2 & -2 & 2 \\
\hline Bank Profits $(\$ b)$ & 2 & - & -2 & -7 & 1 & -2 \\
\hline Shadow Bank Profits (\$b) & -9 & - & 4 & 9 & -3 & 4 \\
\hline Average \# of shadow bank lenders per market & 98 & 101 & 103 & 104 & 100 & 103 \\
\hline Overall Consumer Surplus (\$b) & -9 & - & 4 & 9 & -3 & 5 \\
\hline Individual Consumer Surplus (\$) & -376 & - & 176 & 347 & -106 & 194 \\
\hline Overall Consumer Surplus for Top Income Market (\$b) & -5 & - & 3 & 7 & -2 & 3 \\
\hline Overall Consumer Surplus for Bottom Income Market (\$b) & -1 & - & 0 & 0 & 0 & 0 \\
\hline Individual Consumer Surplus for Top Income Quartile (\$) & -457 & - & 208 & 398 & -127 & 226 \\
\hline Individual Consumer Surplus for Bottom Income Quartile (\$) & -298 & - & 142 & 282 & -85 & 157 \\
\hline
\end{tabular}




\section{Figure 1: Conforming and Jumbo Markets Origination Volumes and Relative Product Pricing}

Panel A shows jumbo origination share (in \%) of all conventional (non-FHA/VA/RHS) mortgages by dollars originated. Conforming loans are defined as "conventional" (non-FHA) in HMDA with loan amounts below the conforming loan limit. Panel B shows aggregate mortgage origination volumes in billions of dollars by conforming and jumbo mortgages. Panel $C$ shows the raw conforming-jumbo interest rate spread (based on BlackKnight data). A negative spread means jumbo loans have higher rates. Panel D shows bank capital ratios over time. The solid line is the (simple) average across all banks; the dashed line is weighted by mortgage originations. Data are from HMDA, BlackKnight, and call reports.

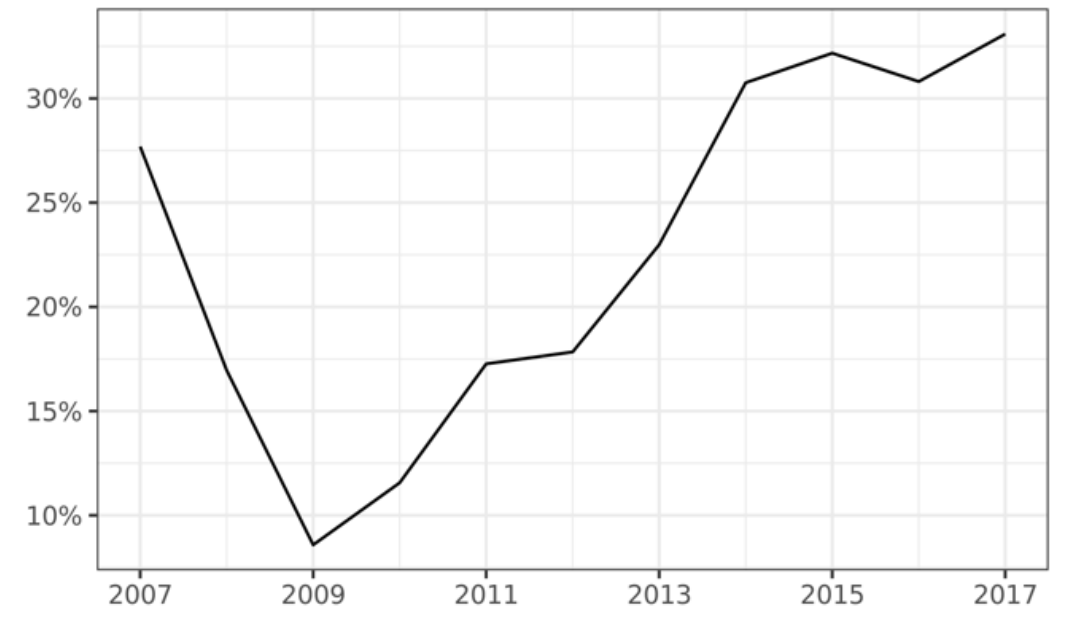

(a) Jumbo market share in total originations

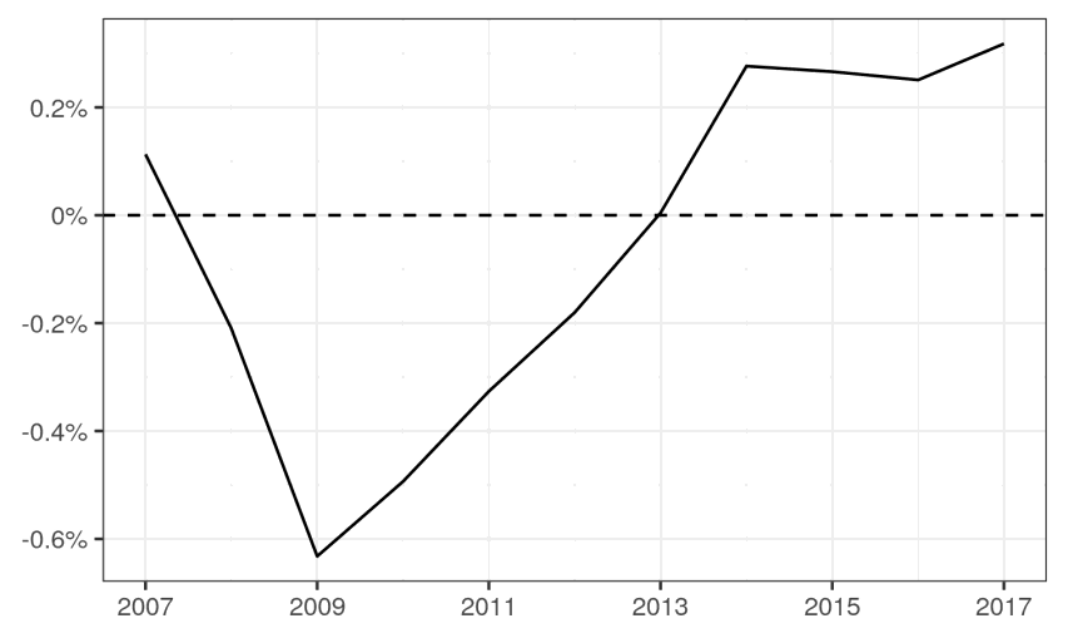

(c) Conforming - jumbo interest rate spread

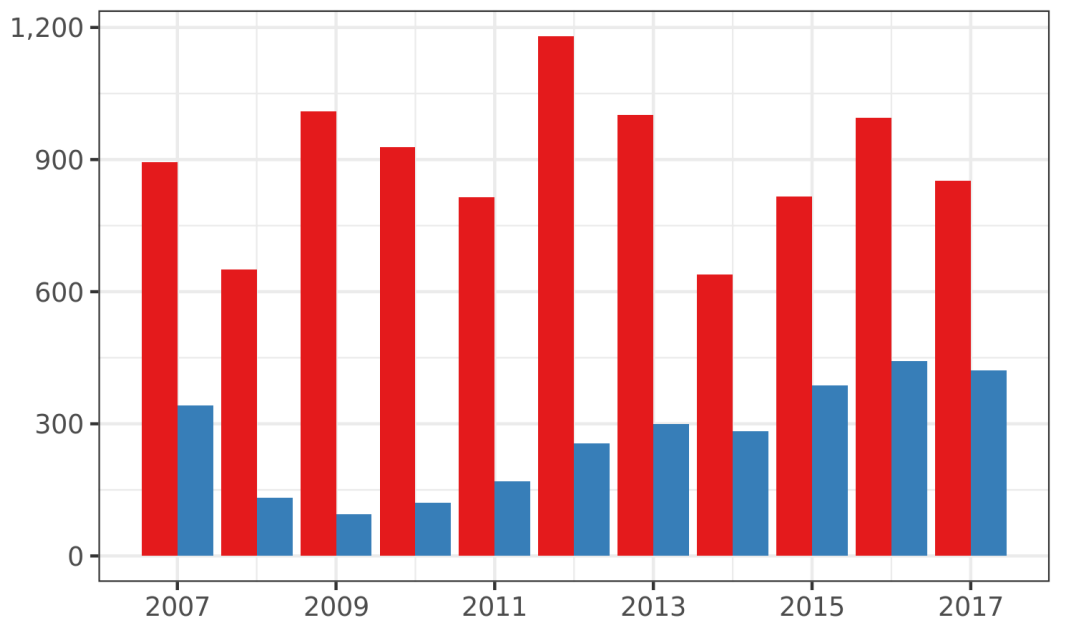

(b) Conforming (black) and jumbo (grey) originations (\$ billions)

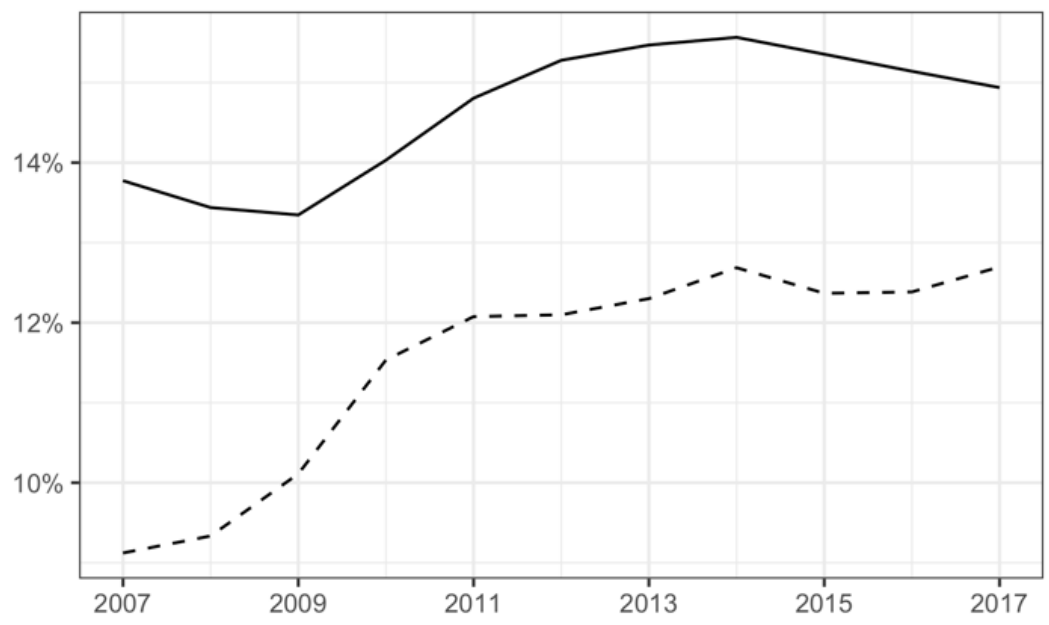

(d) Equal (black) and origination (grey) weighted capital ratios 


\section{Figure 2: Traditional and Shadow Bank Market Shares in the Conforming and Jumbo Markets}

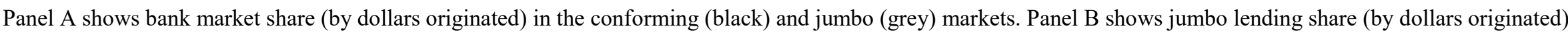

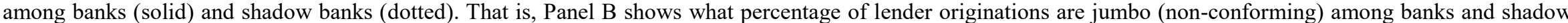

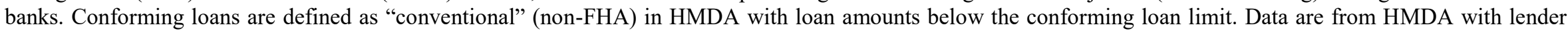
classifications based on Buchak et al. (2018).

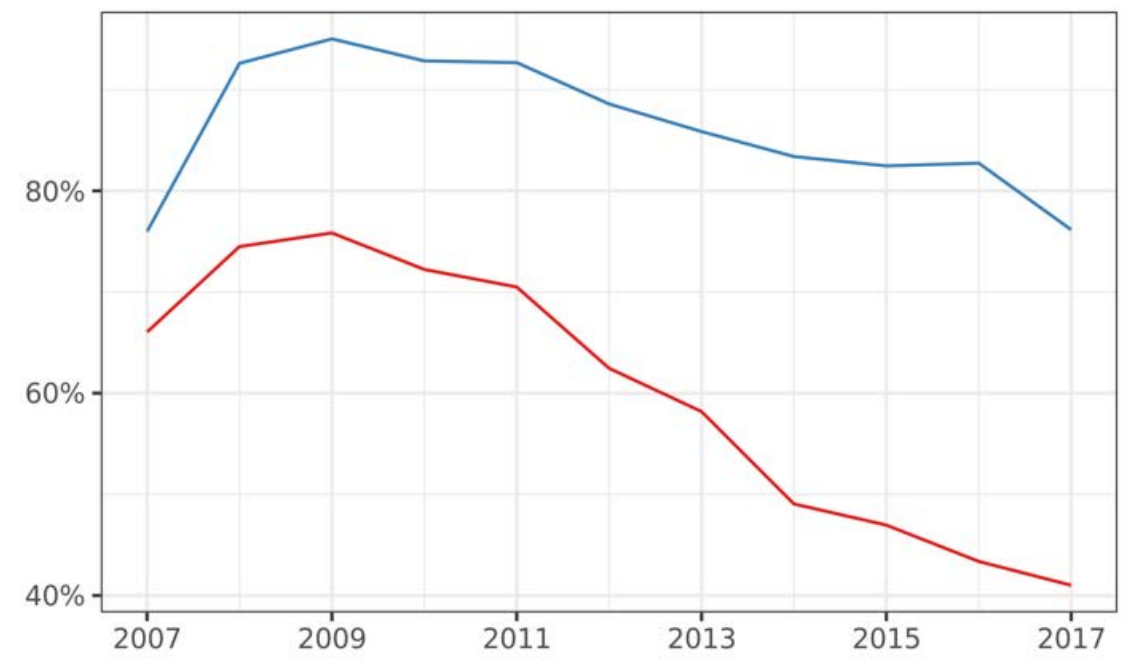

(a) Bank market share among conforming (black) and jumbo (grey) loans

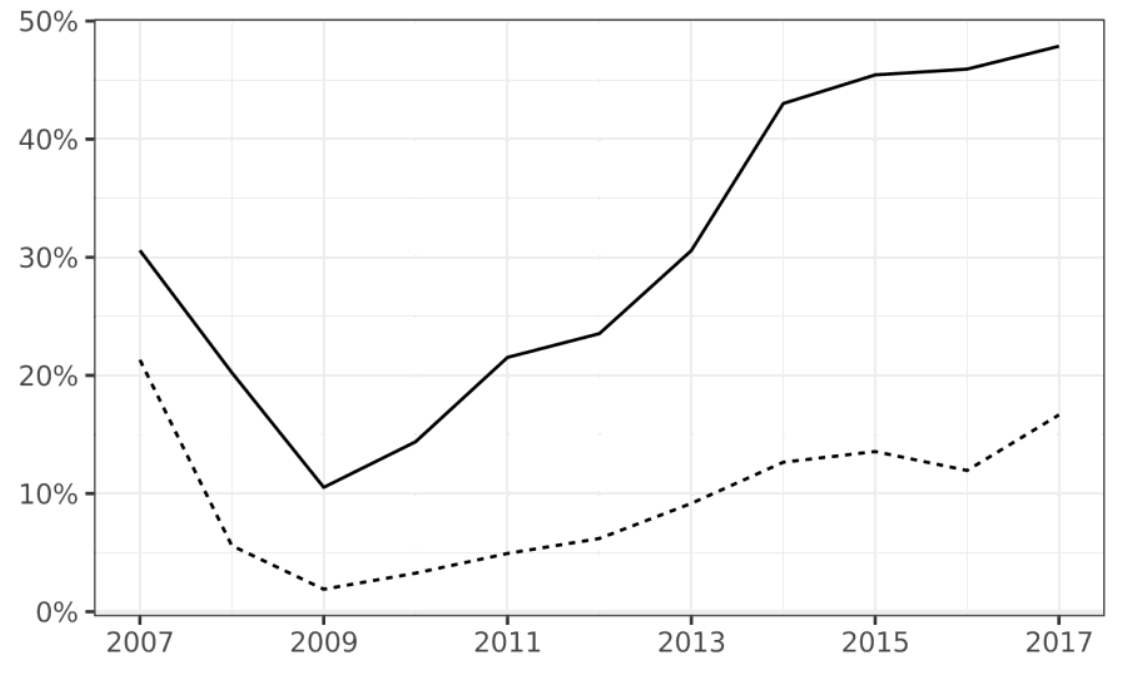

(b) Jumbo share of originations among banks (solid) and shadow banks (dotted) 


\section{Figure 3: Balance Sheet Financing and Bank Lending around the Conforming Loan Limit Cutoffs}

Panel A shows the percentage of mortgage originations retained on balance sheet by the loan amount divided by the conforming loan limit in the county-year of origination. The cutoff is at $100 \%$, shown by a dotted vertical line. Panel B shows the percentage of originations that are done by banks around the conforming loan limit. Panel C shows the percentage of bank originations done by well-capitalized banks, where a bank is well-capitalized if the gap (residual) between the actual and target capital ratio is positive. The target capital ratio is estimated based on bank specific factors. Loan sizes are binned as a proportion of the conforming loan limit in 0.05 buckets, i.e., 0.91-0.95, 0.96-1.00, 1.01-1.05, and so on. In Panel A, a mortgage is retained on balance sheet if it is not sold in the calendar year or sold to an affiliate. Each panel uses HMDA data between 2007 and 2017 and call reports to determine bank capitalization. Panels A and B use all originations; Panel C uses traditional bank originations only.

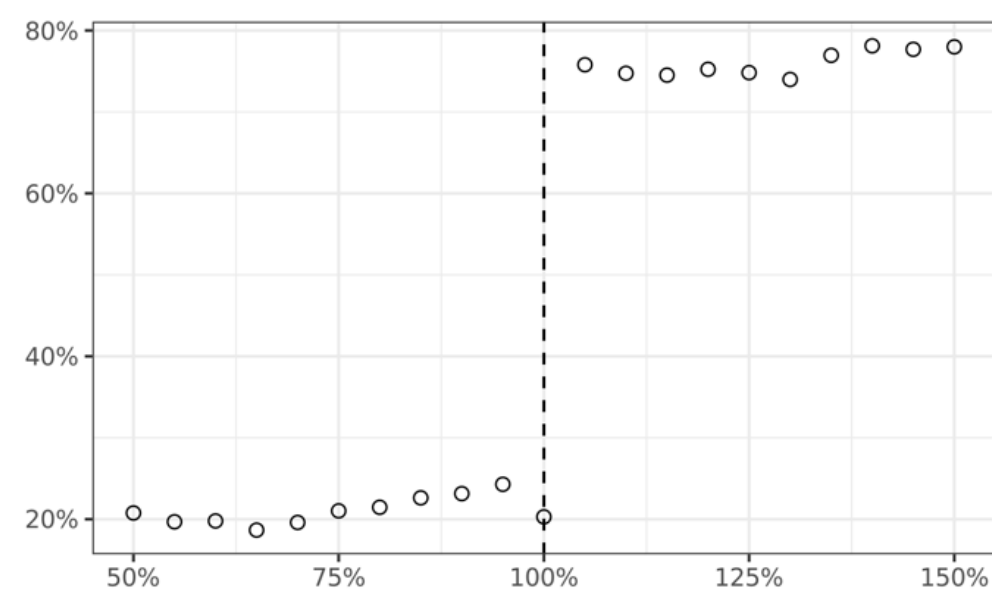

(a) Percentage of loans retained on balance sheet

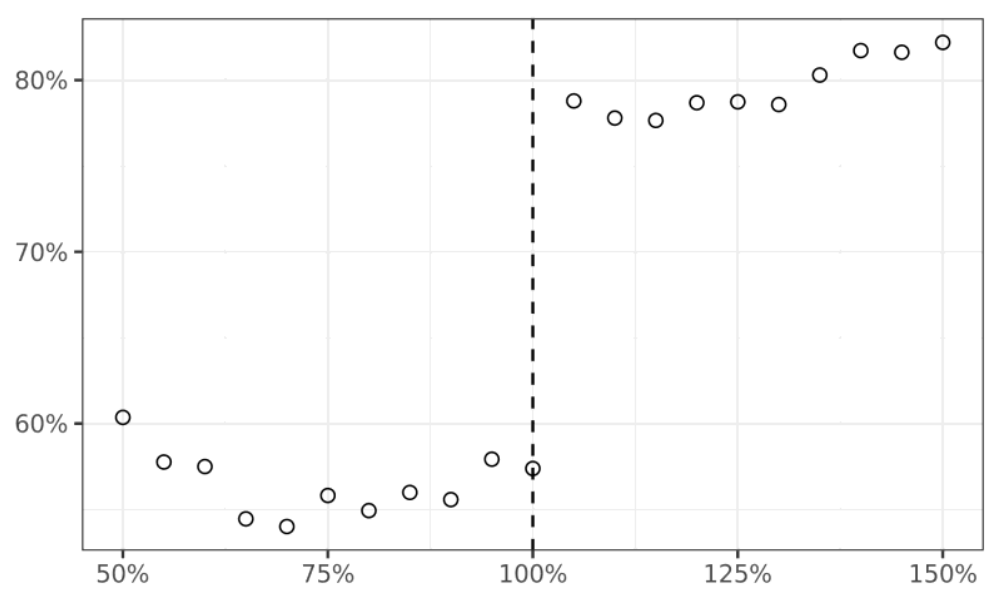

(b) Market share of banks among all lenders

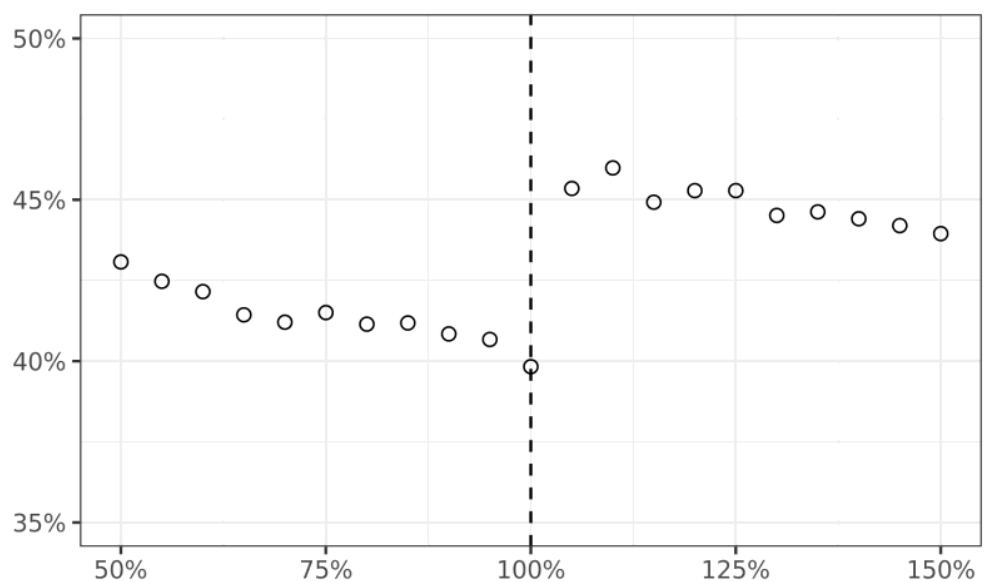

(c) Market share of well-capitalized banks among banks only 


\section{Figure 4: Balance Sheet Financing versus Bank Capital Ratios}

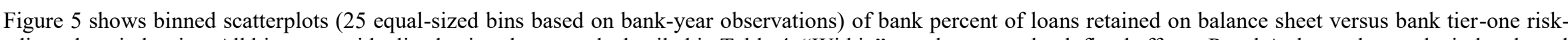

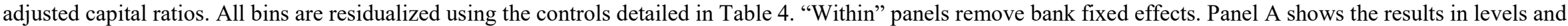

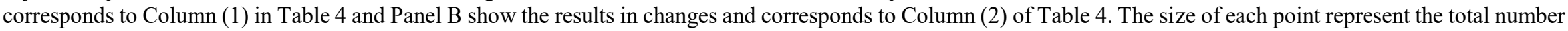
of originations falling within each bin. Data are from HMDA and bank call reports, for years between 2007 and 2017.

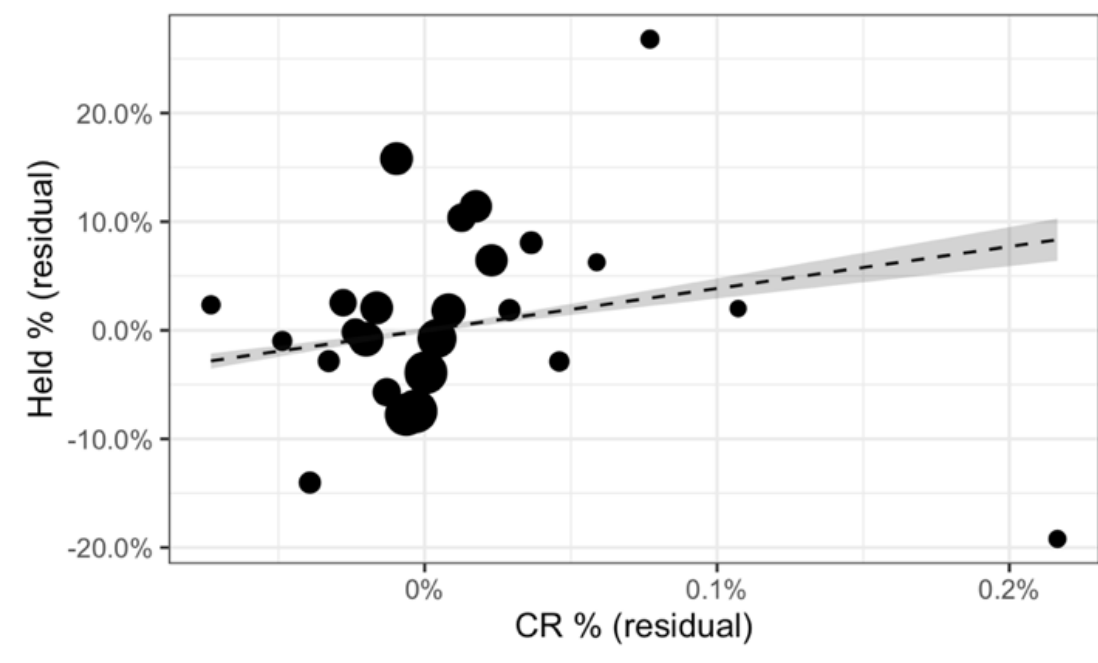

(a) Across banks, levels

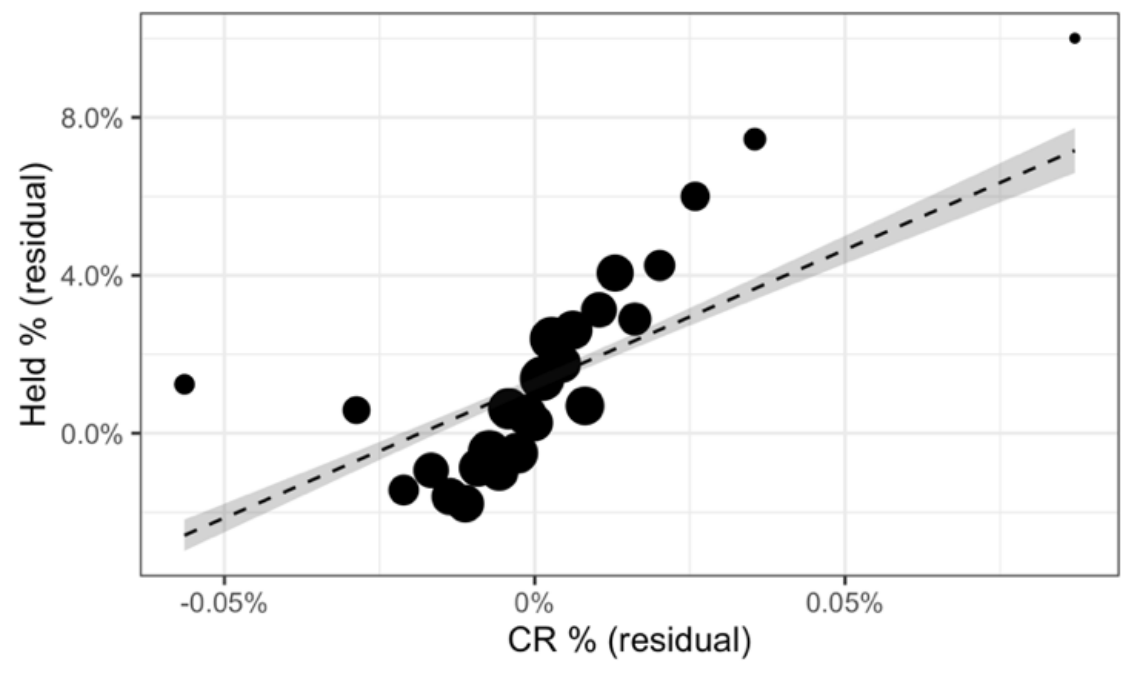

(b) Within banks, changes 


\section{Figure 5: Interest Rates around the Conforming Limit}

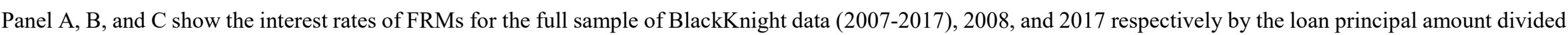

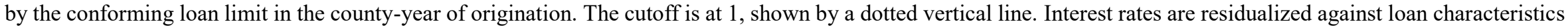
including purpose, credit score, LTV, and term. Shaded regions represent 95\% confidence intervals. Data are from BlackKnight.

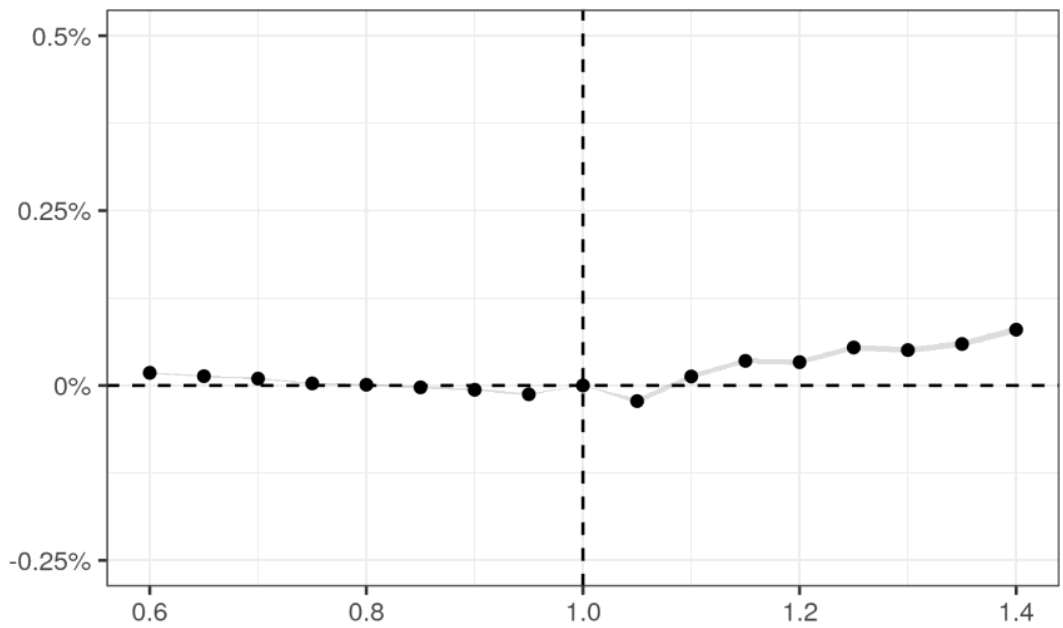

(a) Full sample

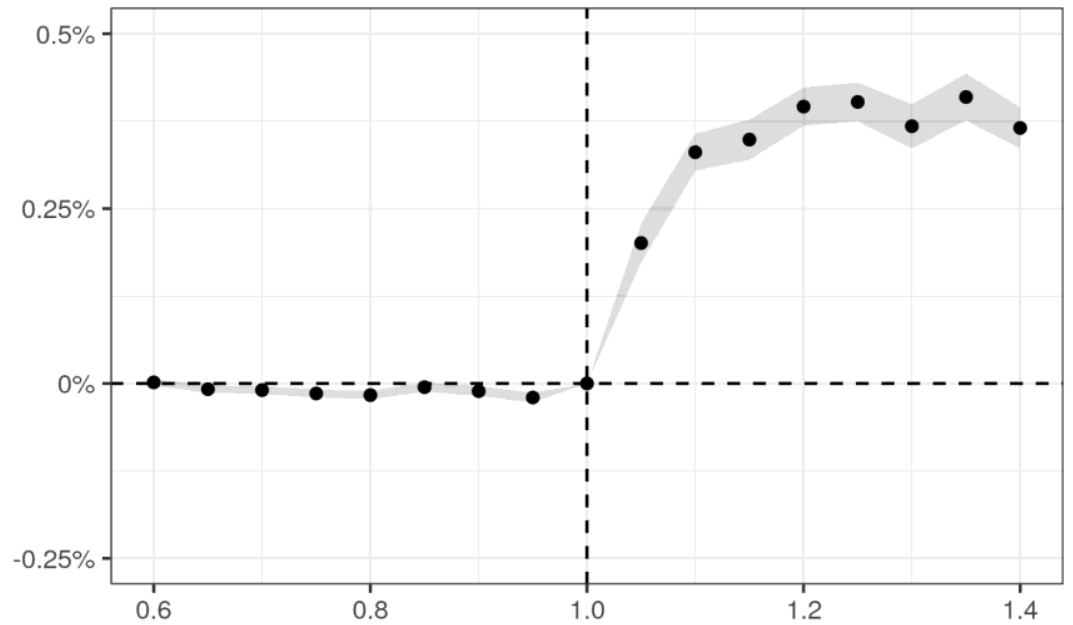

(b) 2008 originations

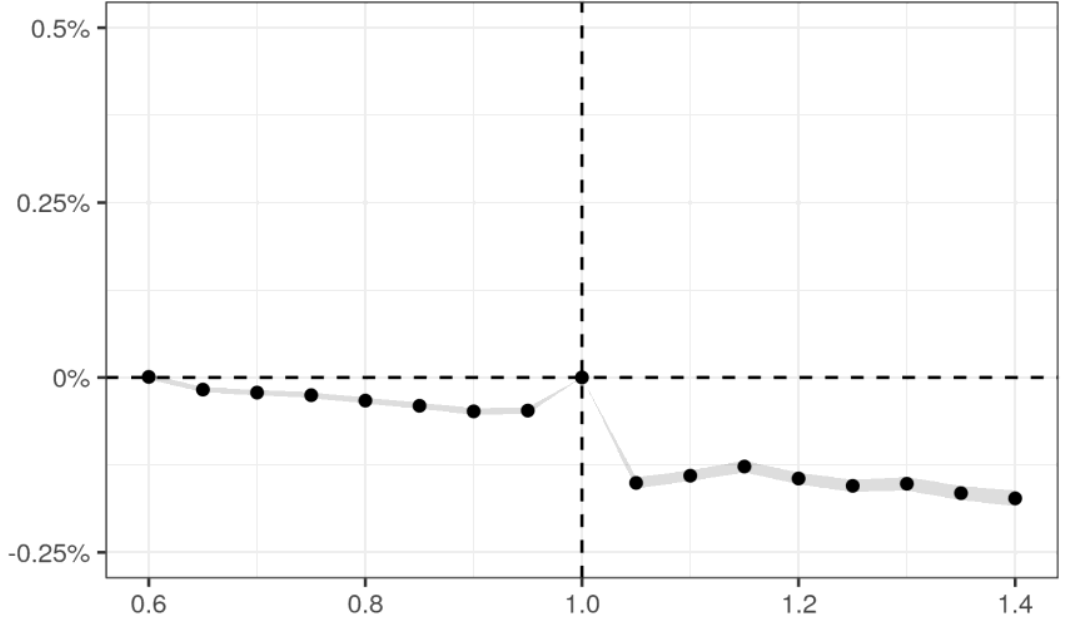

(c) 2017 originations 


\section{Figure 6: Loan Distribution and Borrower Income around the Conforming Loan Limit}

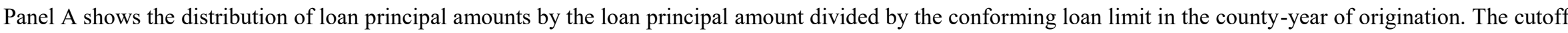

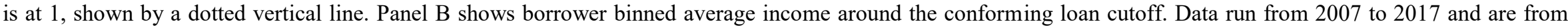

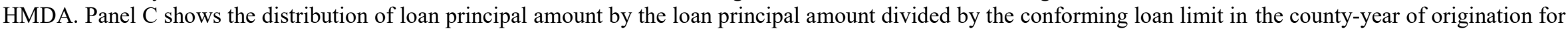
2017 originations only

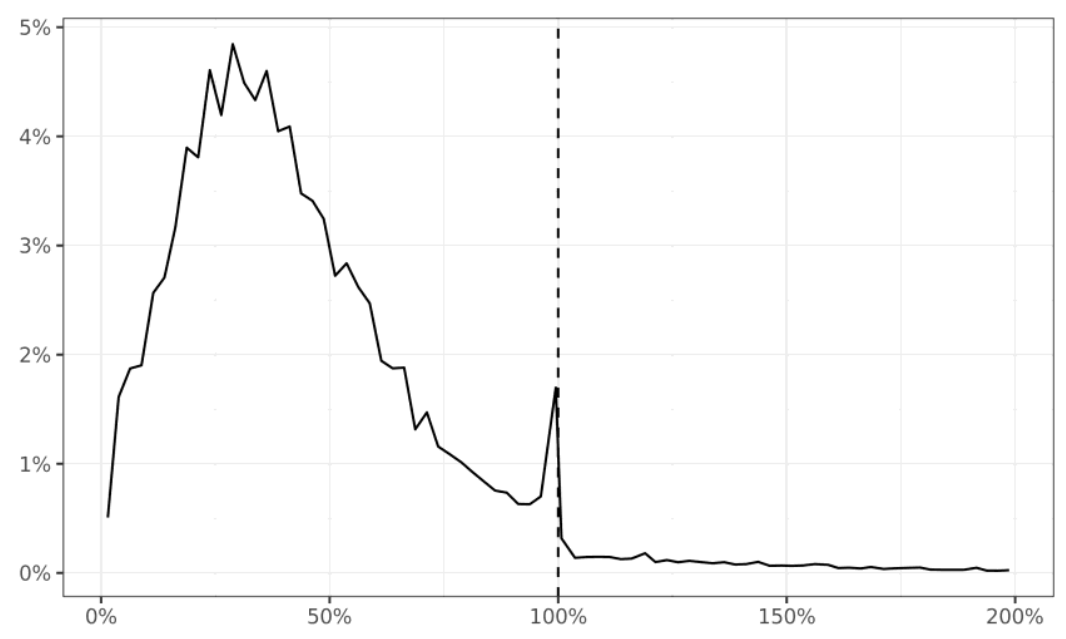

(a) Distribution of loan sizes (2007-2017)

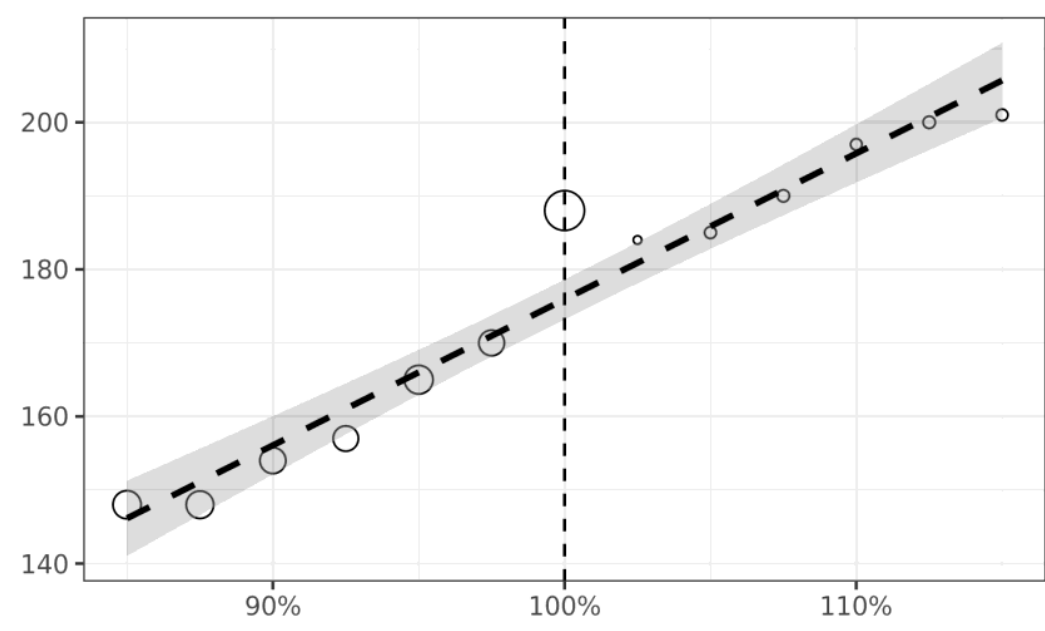

(b) Borrower average income (2007-2017)

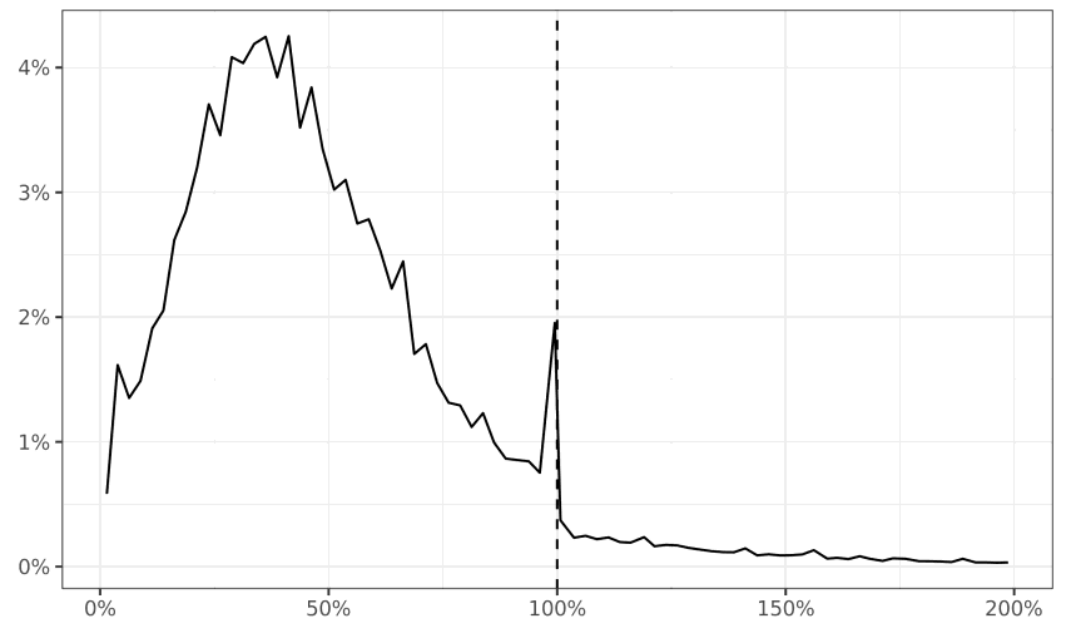

(c) Distribution of loan sizes (2017) 


\section{Figure 7: Empirical versus Model Conforming Loan Bunching}

This figure shows actual and predicted market shares around the conforming loan limit. Panel A bins markets by predicted bunching quantile and plots the average market share of originations within $+/-1 \mathrm{pp}$ of the conforming loan limit, with standard errors shown. The dark gray bars are actual bunching market share; the gray bars are the bunching share predicted by the model. Panel B shows the average market share across all markets for $+/-5 \mathrm{pp}$ of the conforming loan limit. Data are from HMDA and the estimated model.

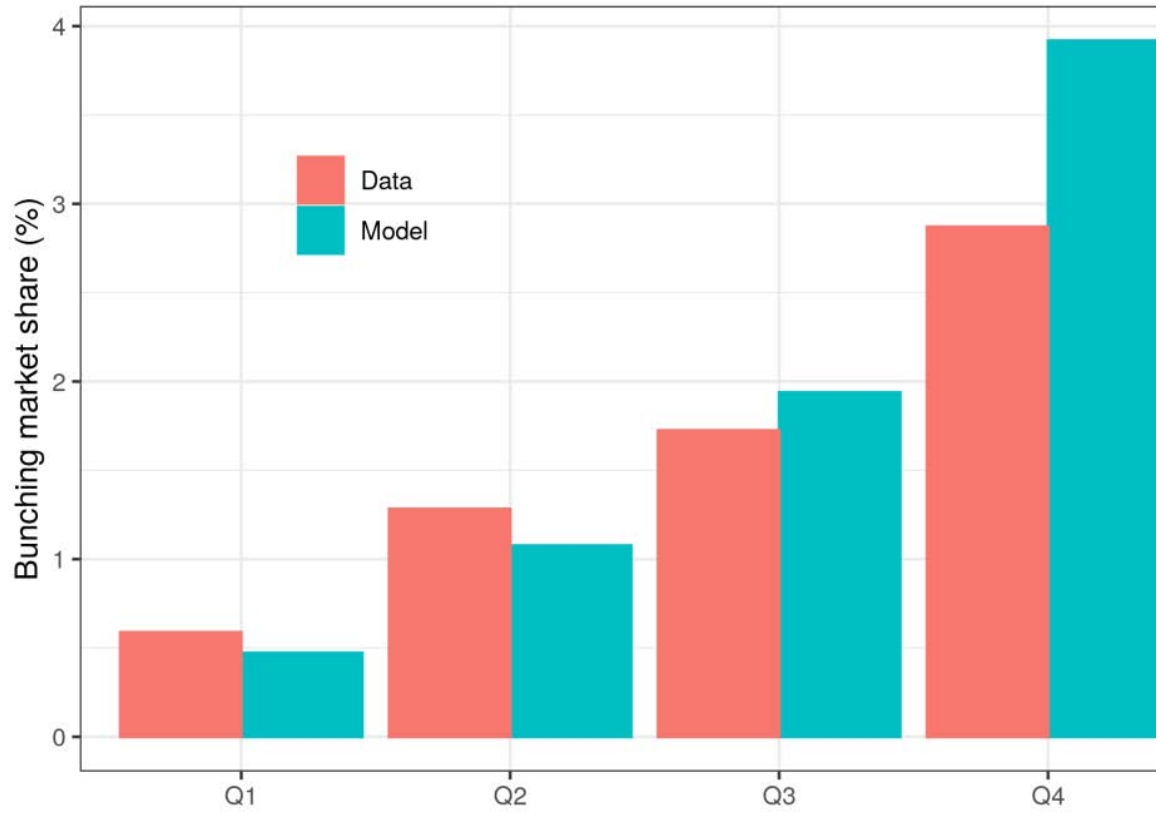

(a) Actual and predicted bunching share by predicted quartile

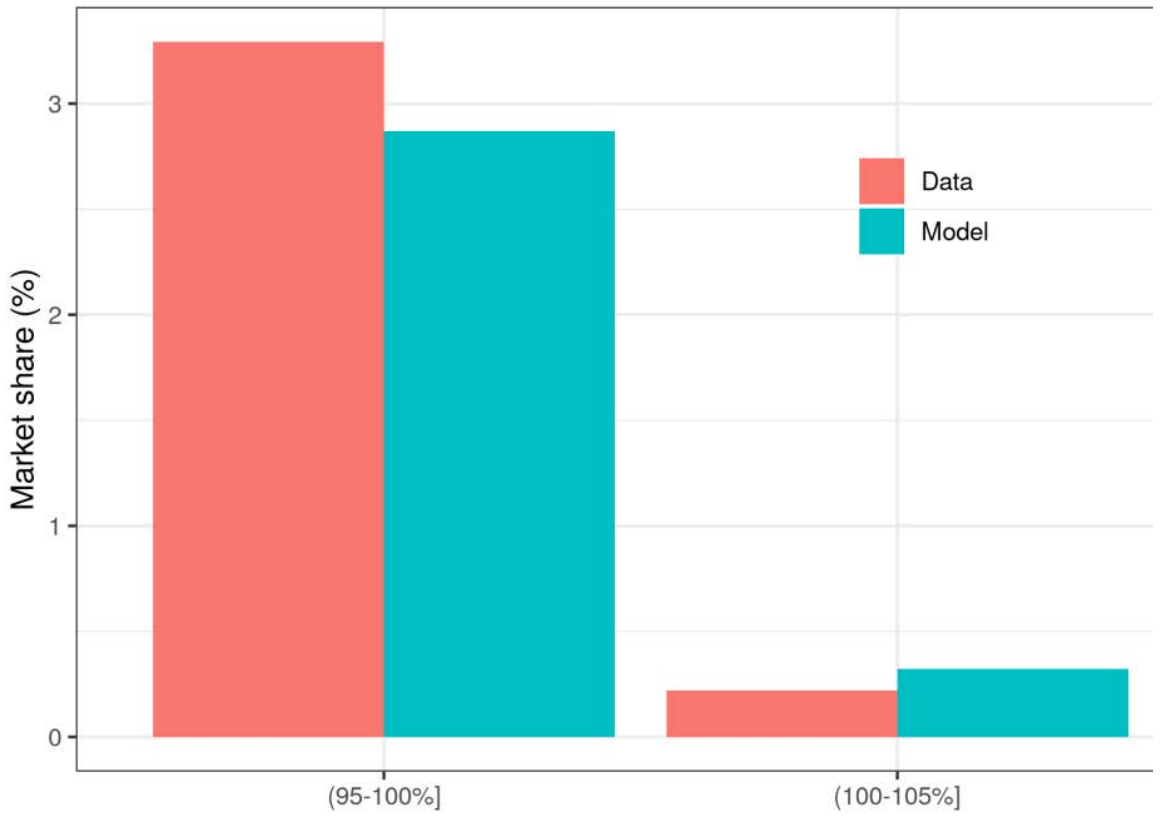

(b) Actual and predicted market share around conforming loan limit 


\section{Figure 8: Marginal Loan Origination Costs for Traditional and Shadow Banks}

This figure shows model-implied marginal costs as a function of excess bank tier-one risk-adjusted capitalization, the difference between the bank's capital ratio and the statutory requirement. The solid line shows the marginal cost for banks originating jumbo loans. The dashed black line shows marginal cost for banks originating conforming loans. The solid grey line shows the marginal cost for shadow banks originating conforming loans. While the financing cost of bank conforming loans are always below that of bank jumbo loans, other components of marginal cost (e.g., labor costs) can push jumbo marginal costs below conforming marginal costs.

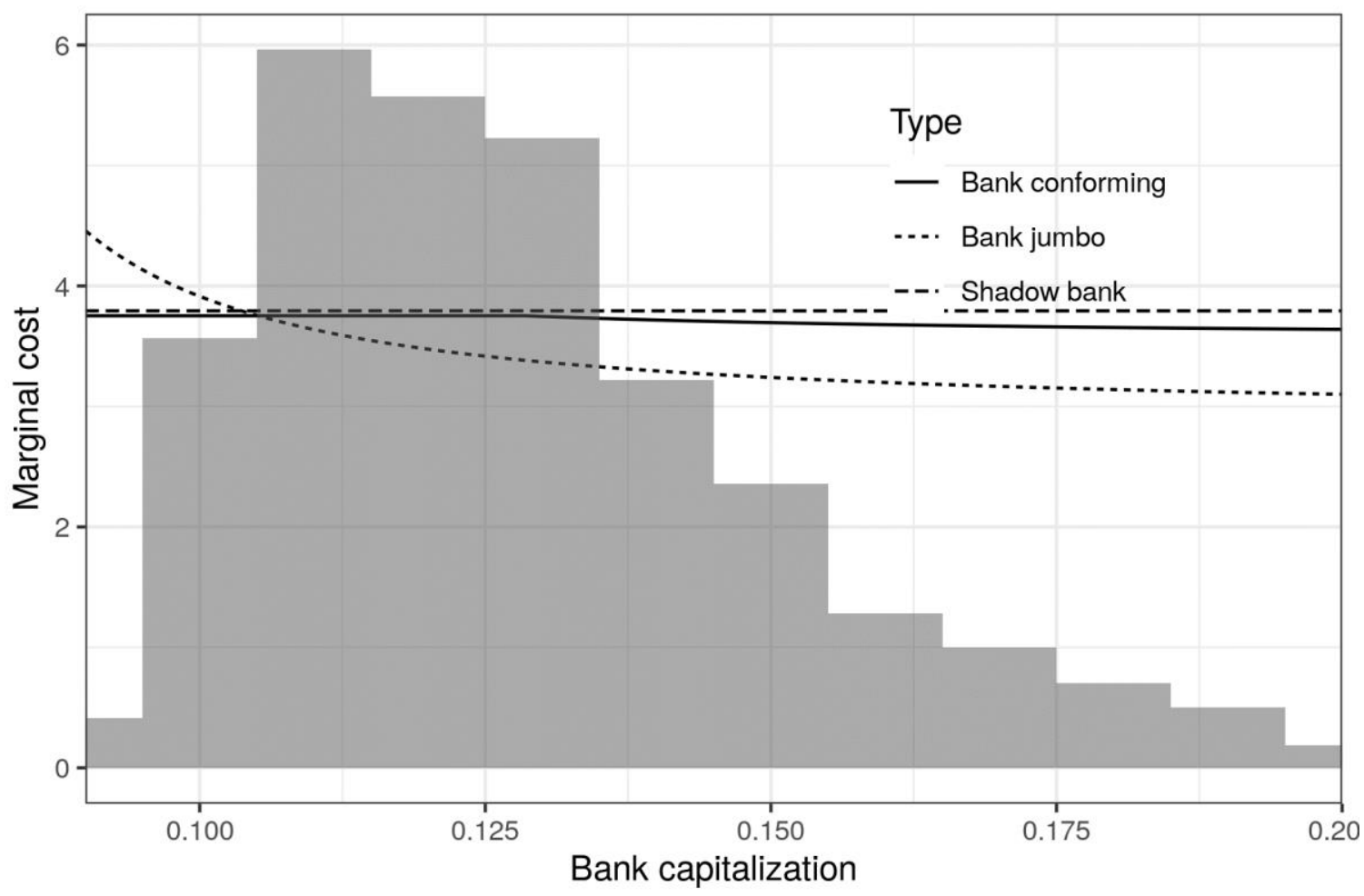




\section{Figure 9: Counterfactual Analysis - Capital Requirements}

Panel A shows aggregate mortgage origination volume (in \$ billions) across various bank tier-one risk-adjusted capital ratio requirements (in \%). Panel B shows the composition of aggregate lending (in \$ billions) split by the shadow bank conforming lending volume (black line), bank conforming lending volume (grey line), and bank jumbo lending volume (dashed line) across various bank capital ratio requirements. Panel C shows the percentage of loans that are retained on banks' balance sheets across various tier-one risk-adjusted capital requirements.

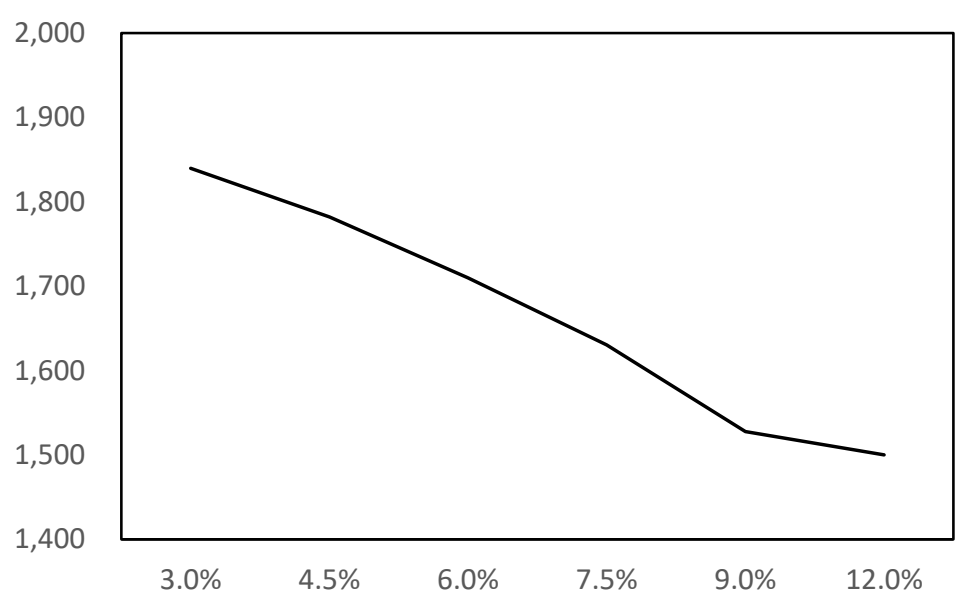

(a) Overall lending volume (\$ billions)

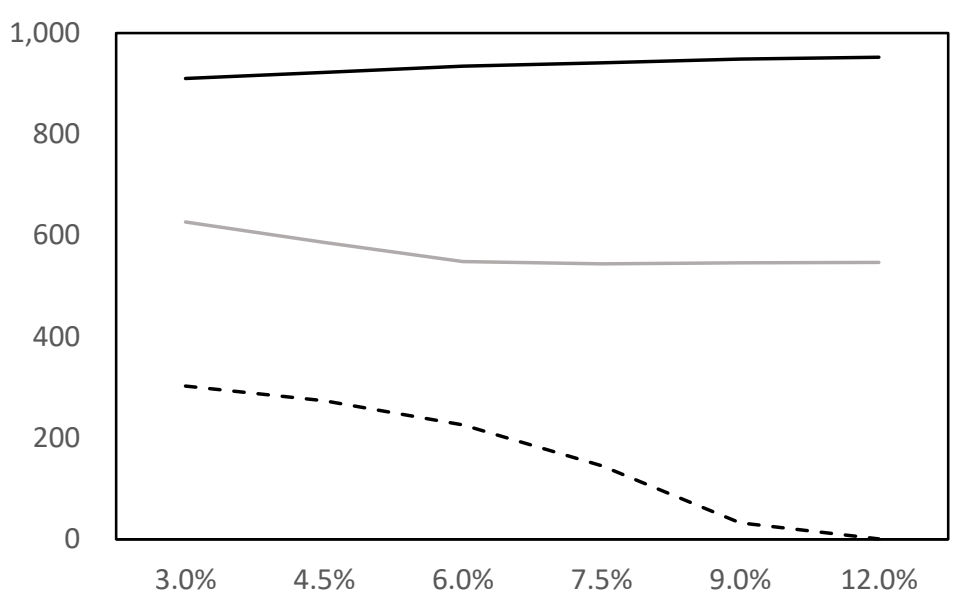

(b) Shadow bank conforming (black), bank conforming (grey) \& jumbo (dashed)

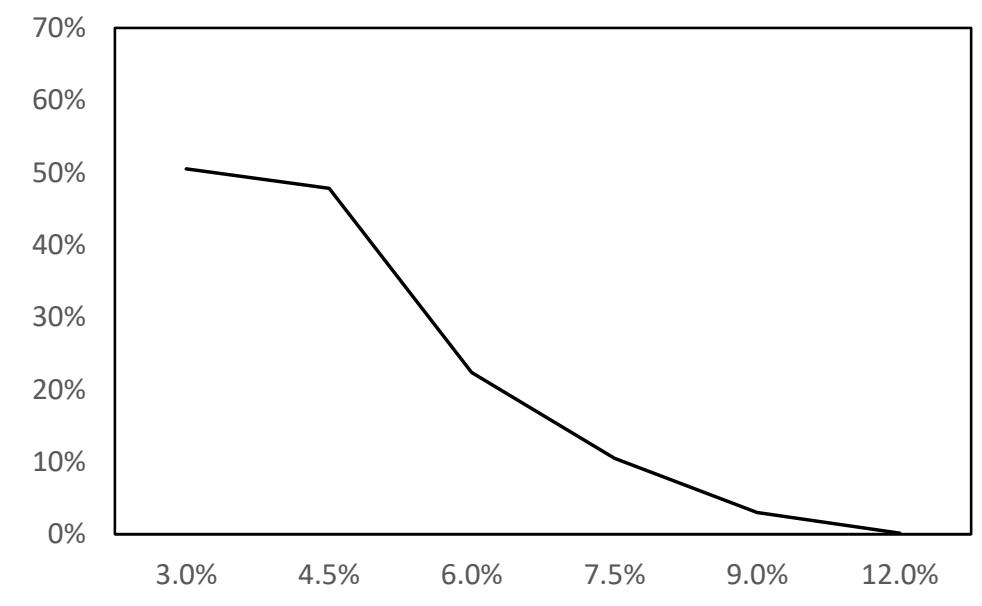

(c) Balance sheet financing share (in \%) 
Figure 10: Counterfactual Analysis - GSE Financing Costs

Panel A shows aggregate mortgage origination volume (in \$ billions) across various changes to the GSE financing costs relative to the baseline (in basis points). Panel B shows the composition of aggregate lending (in \$ billions) split by the shadow bank conforming lending volume (black line), bank conforming lending volume (grey line), and bank jumbo lending volume (dashed line) across various changes to the GSE financing costs. Panel C shows the percentage of loans that are retained on banks' balance sheets across various changes to the GSE financing costs.

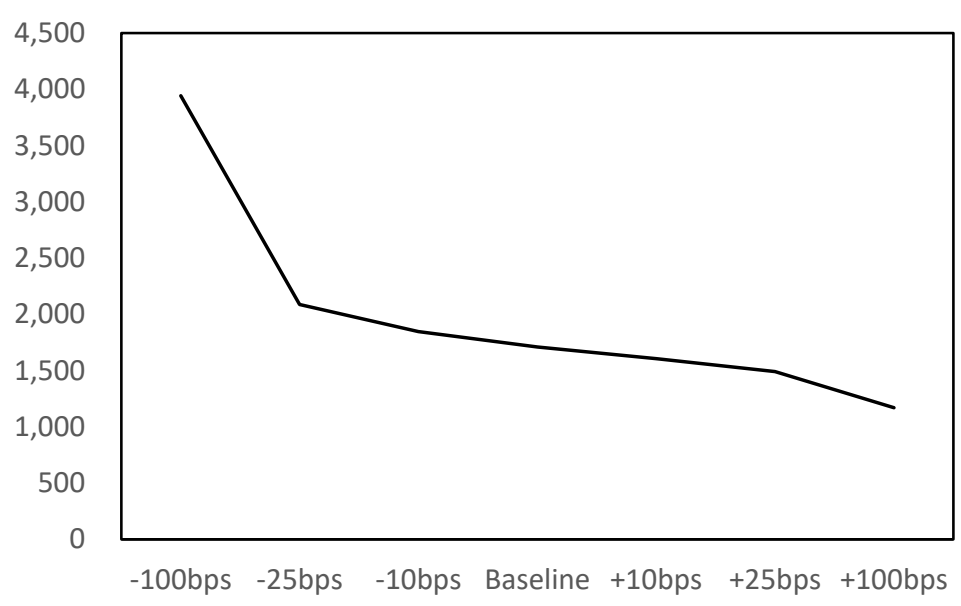

(a) Overall lending volume ( $\$$ billions)

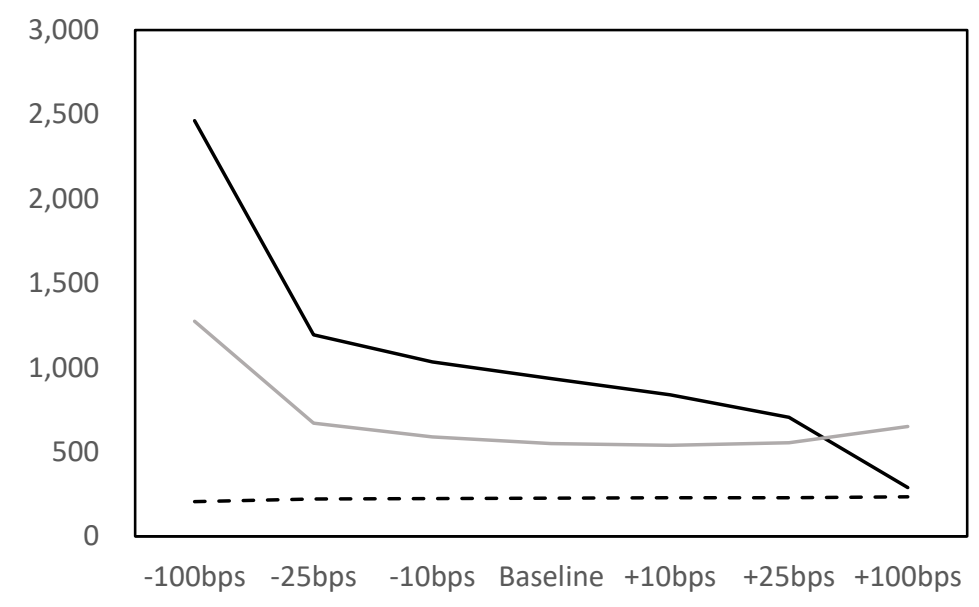

(b) Shadow bank conforming (black), bank conforming (grey) \& jumbo (dashed)

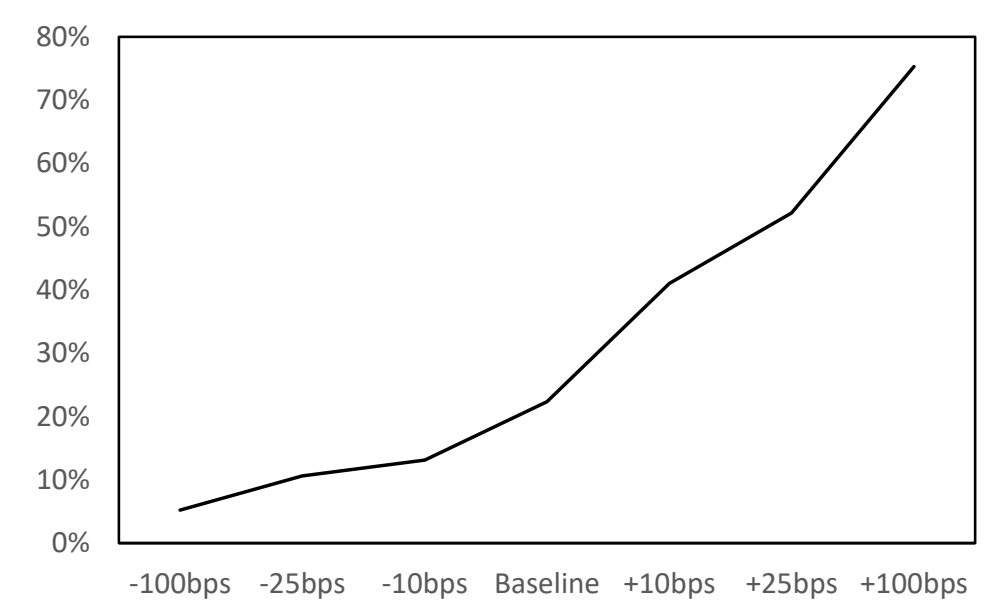

(c) Balance sheet financing share (in \%) 


\section{Figure 11: Counterfactual Analysis - Conforming Loan Limit}

Panel A shows aggregate mortgage origination volume (in \$ billions) across various changes in the conforming loan limit relative to the baseline (in \%). Panel B shows the composition of aggregate lending (in \$ billions) split by the shadow bank conforming lending volume (black line), bank conforming lending volume (grey line), and bank jumbo lending volume (dashed line) across various changes in the conforming loan limit relative to the baseline. Panel C shows the percentage of loans that are retained on banks' balance sheets across various changes in the conforming loan limit.

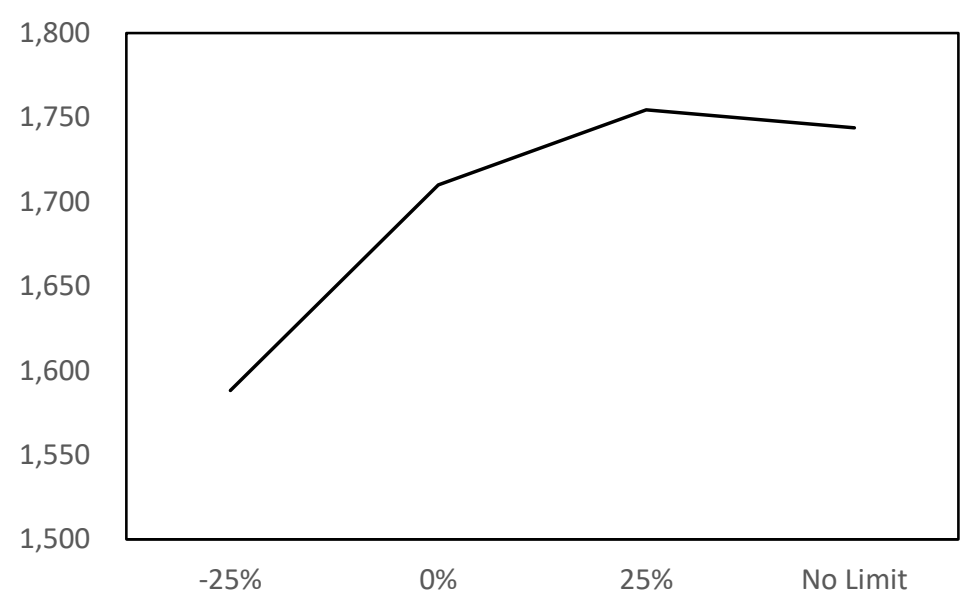

(a) Overall lending volume ( $\$$ billions)

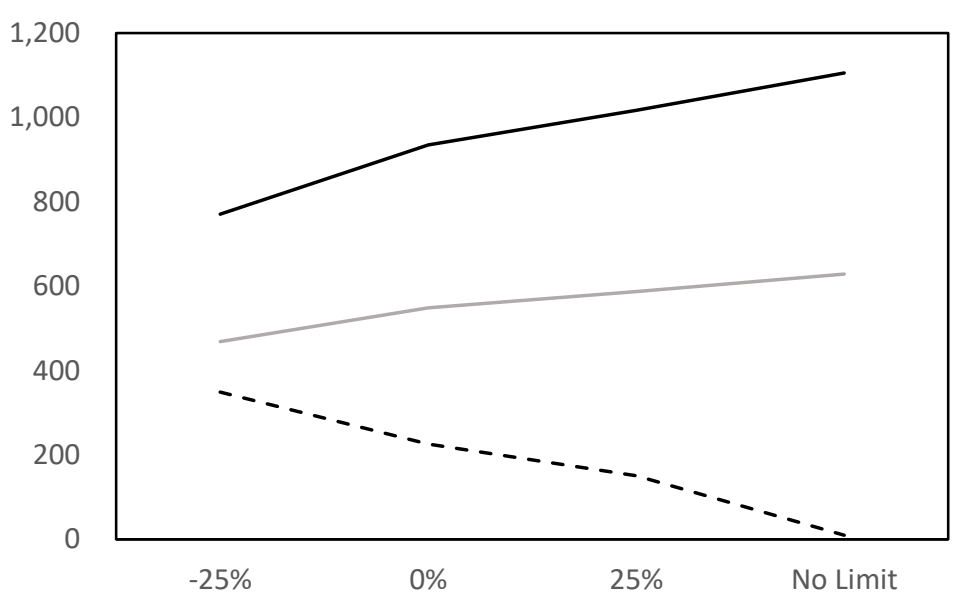

(b) Shadow bank conforming (black), bank conforming (grey) \& jumbo (dashed)

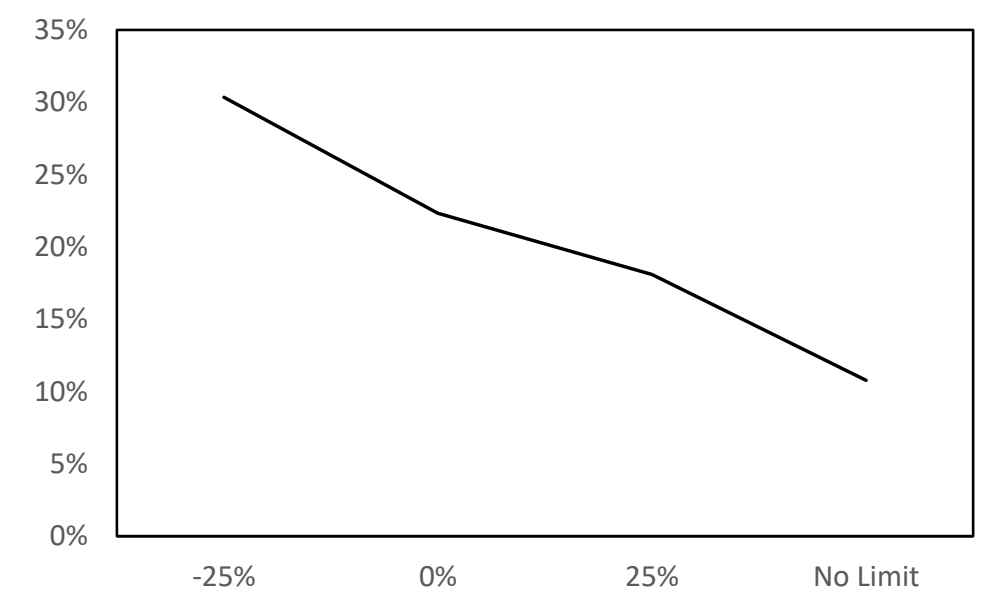

(c) Balance sheet financing share (in \%) 


\section{Figure 12: Counterfactual Analysis - Importance of Balance Sheet Retention and Shadow Bank Migration Margins}

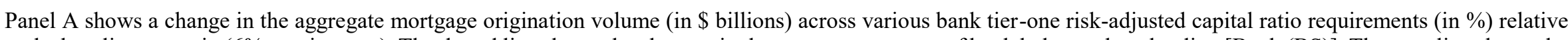

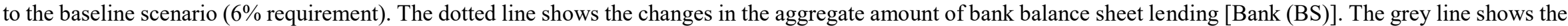

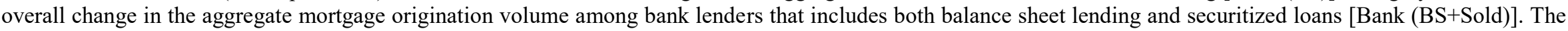

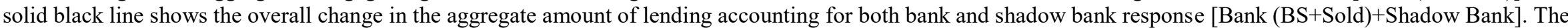

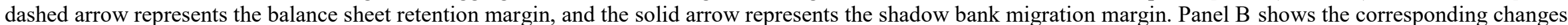

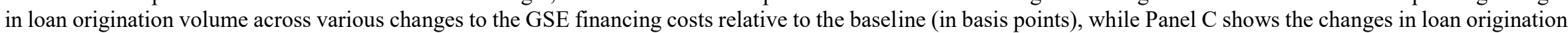
volume across various changes in the conforming loan limit relative to the baseline (in \%). The baseline aggregate origination volume equals $\$ 1,763$ billion.

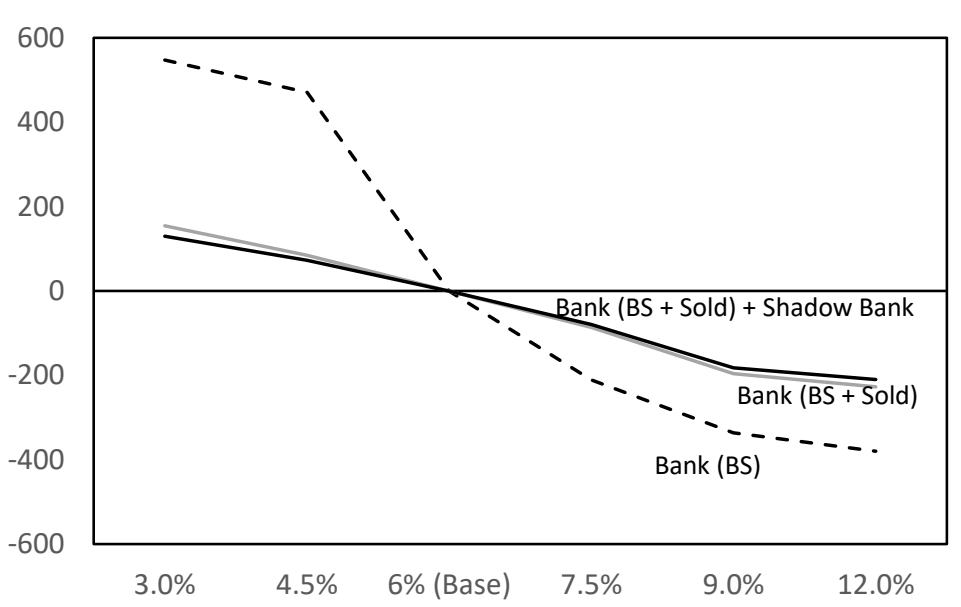

(a) Lending volume changes across bank capital requirements

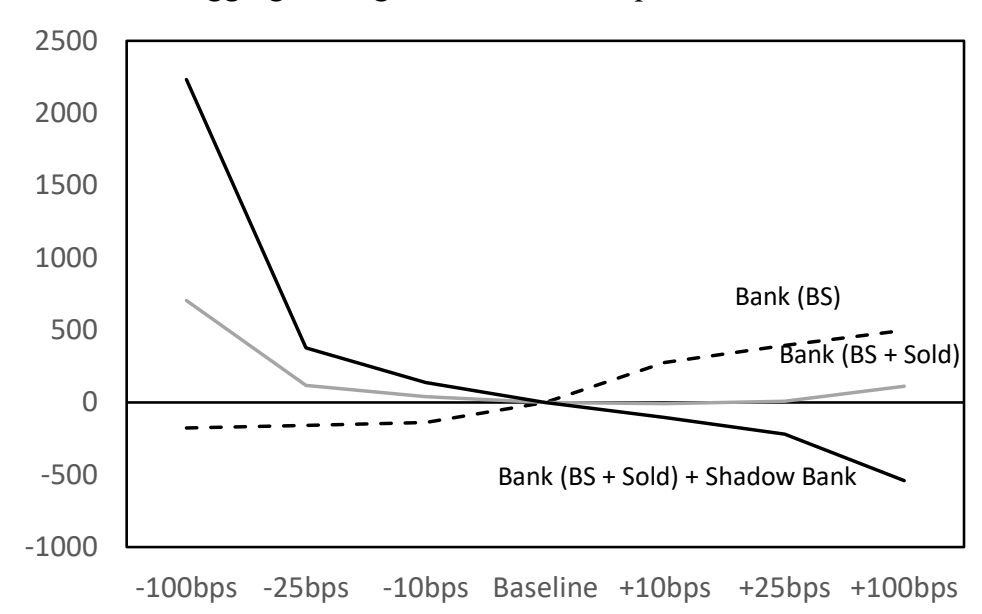

(b) Lending volume changes across changes in the GSE financing costs

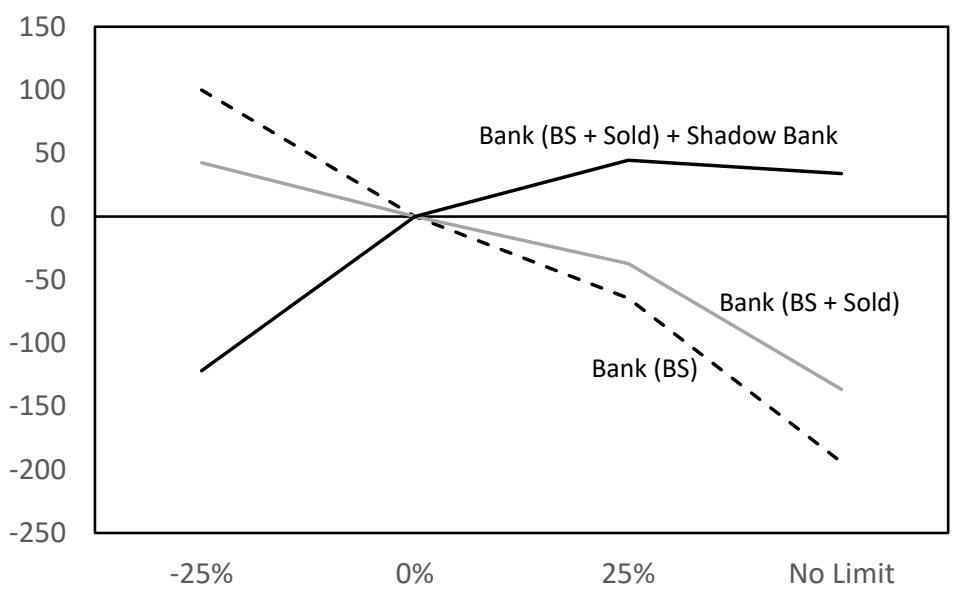

(c) Lending volume changes across changes in the conforming loan limit 


\section{Appendix}

\section{Table A1: Counterfactual Analysis - Capital Requirements with Equity Raising and Asset Sales}

This table shows the impact of various tier-one risk-adjusted capital requirements. Column (1) shows the case a $3 \%$ capital requirement. Column (2) for a $4.5 \%$ capital requirement.

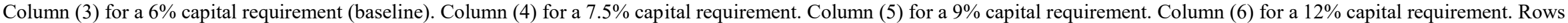
show the predicted impact of the counterfactual change on various outcomes.

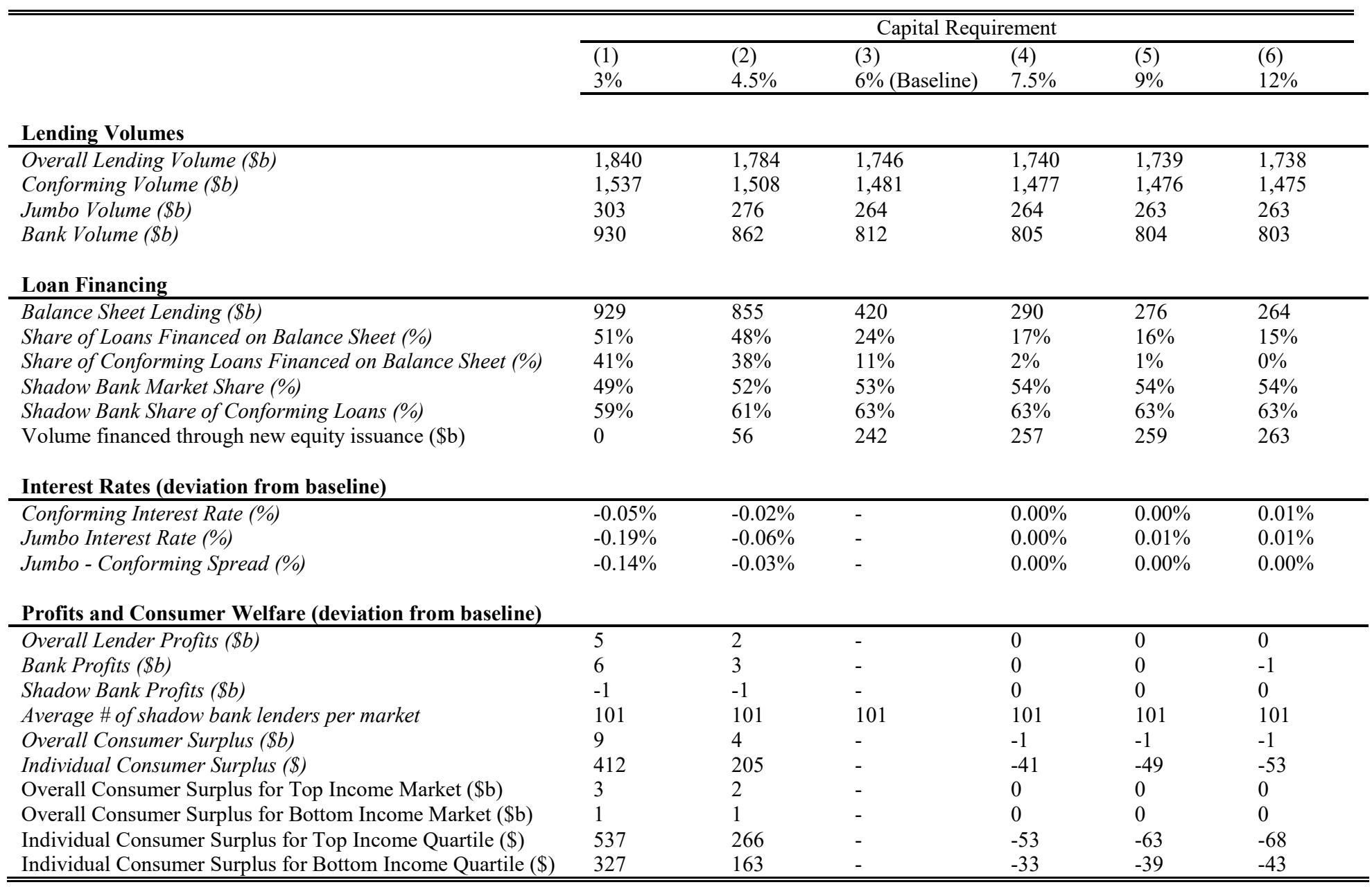




\section{Table A2: Counterfactual Analysis - Capital Requirements with Jumbo Securitization}

This table shows the impact of various tier-one risk-adjusted capital requirements. Column (1) shows the case a $3 \%$ capital requirement. Column (2) for a $4.5 \%$ capital requirement.

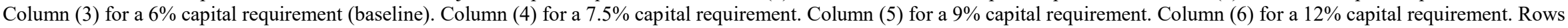
show the predicted impact of the counterfactual change on various outcomes.

\begin{tabular}{|c|c|c|c|c|c|c|}
\hline \multirow{4}{*}{ Lending Volumes } & \multicolumn{6}{|c|}{ Capital Requirement } \\
\hline & \multirow{2}{*}{$\begin{array}{l}1) \\
3 \% \\
\end{array}$} & \multirow{2}{*}{$\begin{array}{l}(2) \\
4.5 \% \\
\end{array}$} & \multirow{2}{*}{$\begin{array}{l}3) \\
6 \% \text { (Baseline) } \\
\end{array}$} & \multirow{2}{*}{$\begin{array}{l}(4) \\
7.5 \% \\
\end{array}$} & \multirow{2}{*}{$\begin{array}{l}5) \\
9 \% \\
\end{array}$} & \multirow{2}{*}{$\begin{array}{l}(6) \\
12 \% \\
\end{array}$} \\
\hline & & & & & & \\
\hline & & & & & & \\
\hline Overall Lending Volume (\$b) & 2,171 & 2,124 & 2,090 & 2,085 & 2,084 & 2,083 \\
\hline Conforming Volume $(\$ b)$ & 1,546 & 1,517 & 1,490 & 1,485 & 1,484 & 1,484 \\
\hline Jumbo Volume (\$b) & 625 & 607 & 600 & 600 & 599 & 599 \\
\hline Bank Volume (\$b) & 827 & 763 & 715 & 708 & 706 & 705 \\
\hline \multicolumn{7}{|l|}{ Loan Financing } \\
\hline Balance Sheet Lending (\$b) & 827 & 717 & 168 & 30 & 16 & 1 \\
\hline Share of Loans Financed on Balance Sheet (\%) & $38 \%$ & $34 \%$ & $8 \%$ & $1 \%$ & $1 \%$ & $0 \%$ \\
\hline Share of Conforming Loans Financed on Balance Sheet (\%) & $40 \%$ & $37 \%$ & $10 \%$ & $2 \%$ & $1 \%$ & $0 \%$ \\
\hline Shadow Bank Market Share (\%) & $62 \%$ & $64 \%$ & $66 \%$ & $66 \%$ & $66 \%$ & $66 \%$ \\
\hline Shadow Bank Share of Conforming Loans (\%) & $60 \%$ & $62 \%$ & $64 \%$ & $64 \%$ & $64 \%$ & $64 \%$ \\
\hline Jumbo securitization (\$b) & 412 & 457 & 585 & 595 & 597 & 599 \\
\hline \multicolumn{7}{|l|}{ Interest Rates (deviation from baseline) } \\
\hline Conforming Interest Rate (\%) & $-0.05 \%$ & $-0.02 \%$ & - & $0.00 \%$ & $0.00 \%$ & $0.01 \%$ \\
\hline Jumbo Interest Rate (\%) & $-0.09 \%$ & $-0.03 \%$ & - & $0.00 \%$ & $0.00 \%$ & $0.00 \%$ \\
\hline Jumbo - Conforming Spread (\%) & $-0.05 \%$ & $0.00 \%$ & - & $0.00 \%$ & $0.00 \%$ & $0.00 \%$ \\
\hline \multicolumn{7}{|l|}{ Profits and Consumer Welfare (deviation from baseline) } \\
\hline Overall Lender Profits (\$b) & 4 & 2 & - & 0 & 0 & 0 \\
\hline Bank Profits (\$b) & 6 & 2 & - & 0 & 0 & 0 \\
\hline Shadow Bank Profits (\$b) & -2 & -1 & - & 0 & 0 & 0 \\
\hline Average \# of shadow bank lenders per market & 108 & 108 & 108 & 108 & 108 & 108 \\
\hline Overall Consumer Surplus (\$b) & 9 & 4 & - & -1 & -1 & -1 \\
\hline Individual Consumer Surplus (\$) & 411 & 204 & - & -41 & -49 & -53 \\
\hline Overall Consumer Surplus for Top Income Market (\$b) & 3 & 2 & - & 0 & 0 & 0 \\
\hline Overall Consumer Surplus for Bottom Income Market (\$b) & 1 & 1 & - & 0 & 0 & 0 \\
\hline Individual Consumer Surplus for Top Income Quartile (\$) & 542 & 268 & - & -54 & -63 & -69 \\
\hline Individual Consumer Surplus for Bottom Income Quartile (\$) & 323 & 161 & - & -32 & -38 & -42 \\
\hline
\end{tabular}




\section{Figure A3: Counterfactual Analysis - Capital Requirements with Equity Issuance}

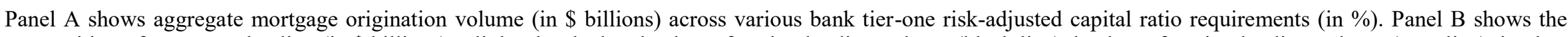

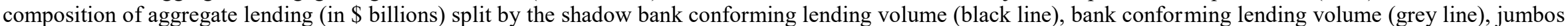

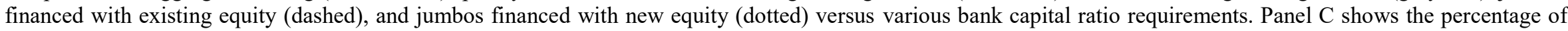

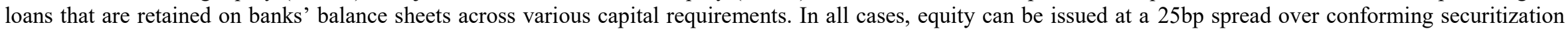
costs.

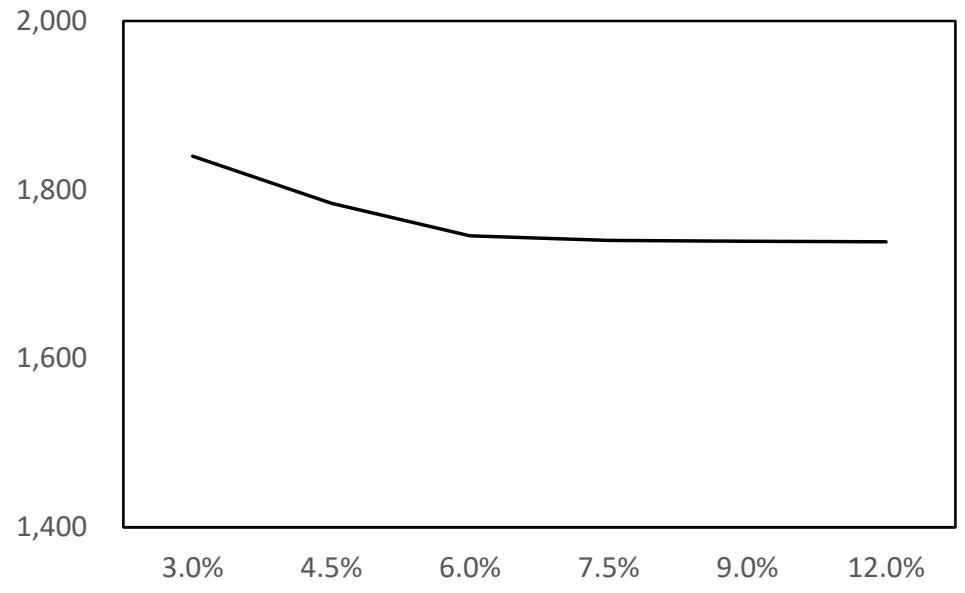

(a) Overall lending volume (\$ billions)

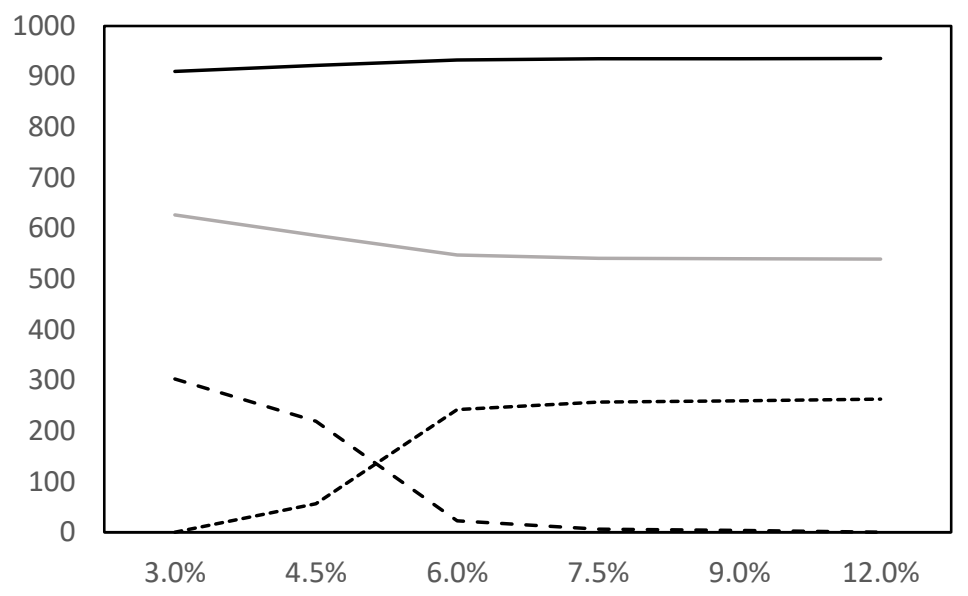

(b) Shadow bank conforming (black), bank conforming (grey), jumbo with existing equity (dashed), and jumbo with new equity (dotted)

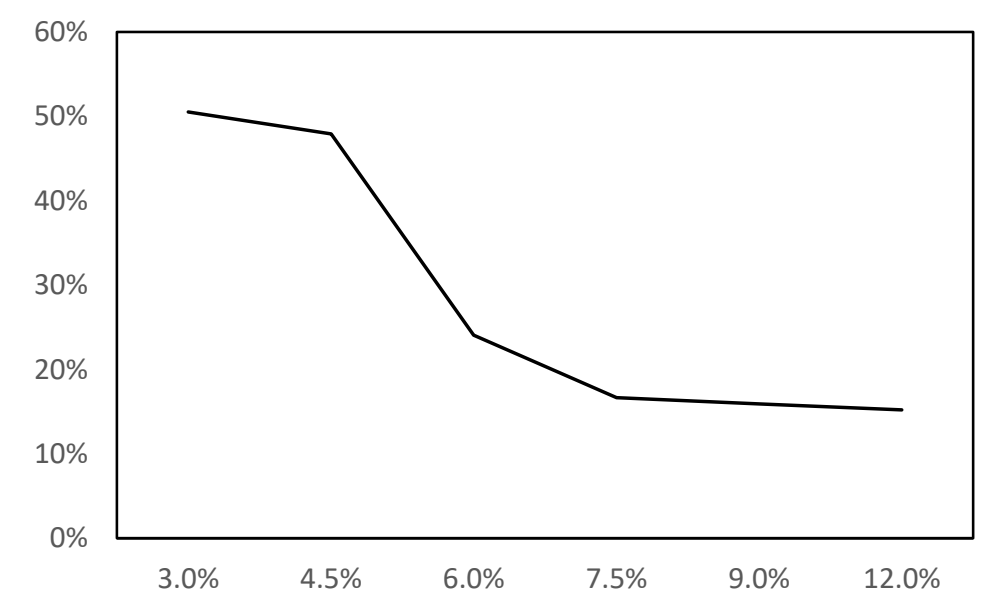

(c) Balance sheet financing share (in \%) 


\section{Figure A4: Counterfactual Analysis - Capital Requirements with Jumbo Securitization}

Panel A shows aggregate mortgage origination volume (in \$ billions) across various bank tier-one risk adjusted capital ratio requirements (in \%). Panel B shows the composition of aggregate lending (in $\$$ billions) split by the shadow bank conforming lending volume (black line), bank conforming lending volume (grey line), securitized jumbo (dashed), and balance sheet jumbo (dotted) versus various bank capital ratio requirements. Panel C shows the percentage of loans that are retained on banks' balance sheets across various capital requirements. In all cases, jumbo loans can be securitized at a $25 \mathrm{bp}$ spread over conforming loans.

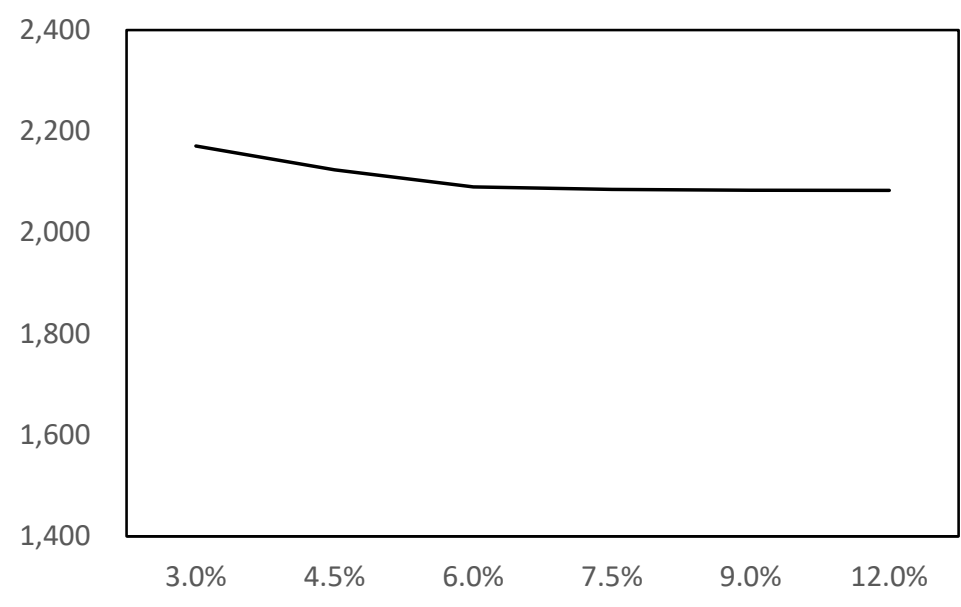

(a) Overall lending volume ( $\$$ billions)

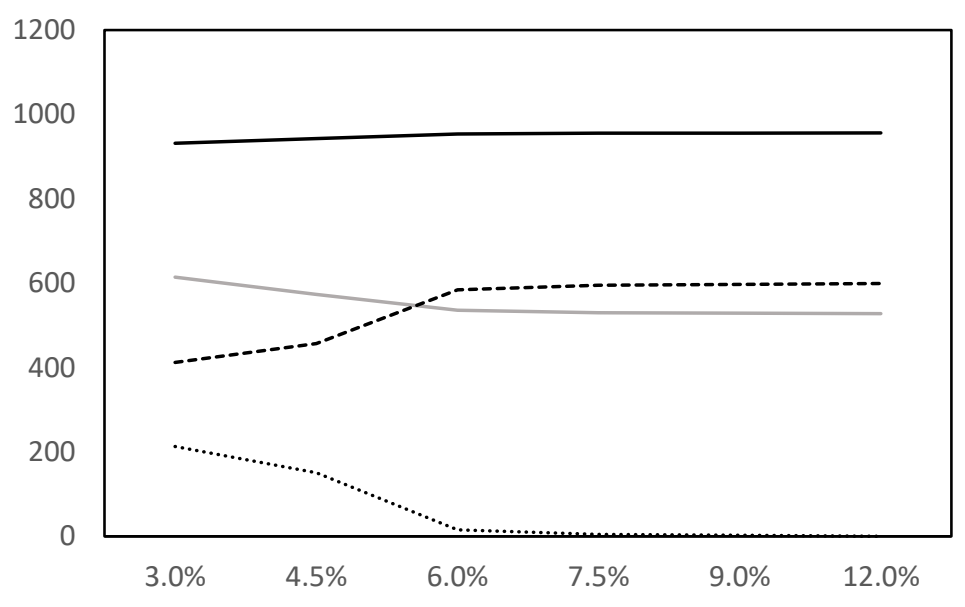

(b) Shadow bank conforming (black), bank conforming (grey), securitized jumbo jumbo (dashed), and balance sheet jumbo (dotted)

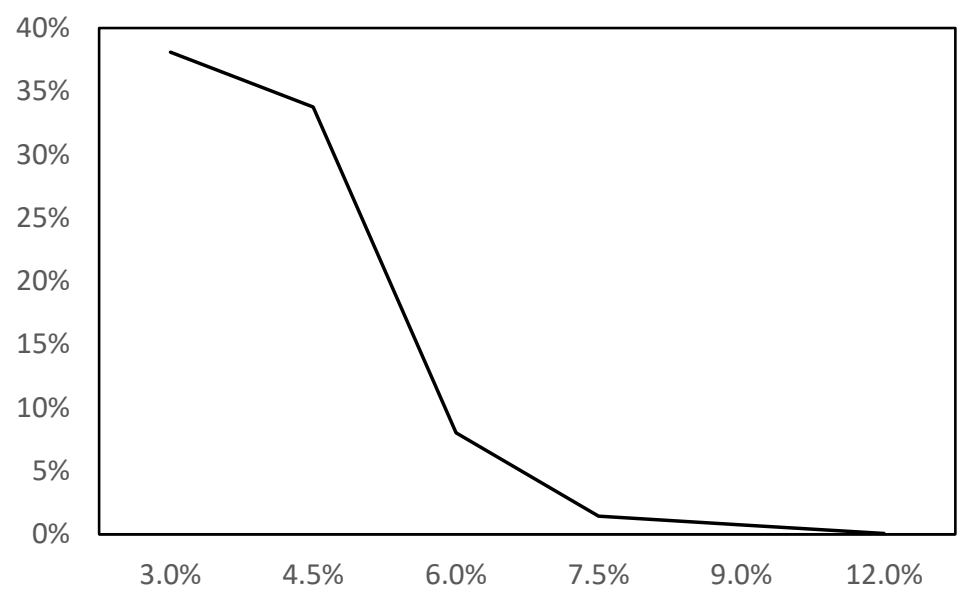

(c) Balance sheet financing share (in \%) 


\section{Figure A5: Number of Banks and Shadow Banks}

This figure shows the average number of banks (panel a) and shadow banks (panel b) that are active in a regional market (MSA). Source: HMDA data covering 20072017 period and MSAs used in our structural estimation.

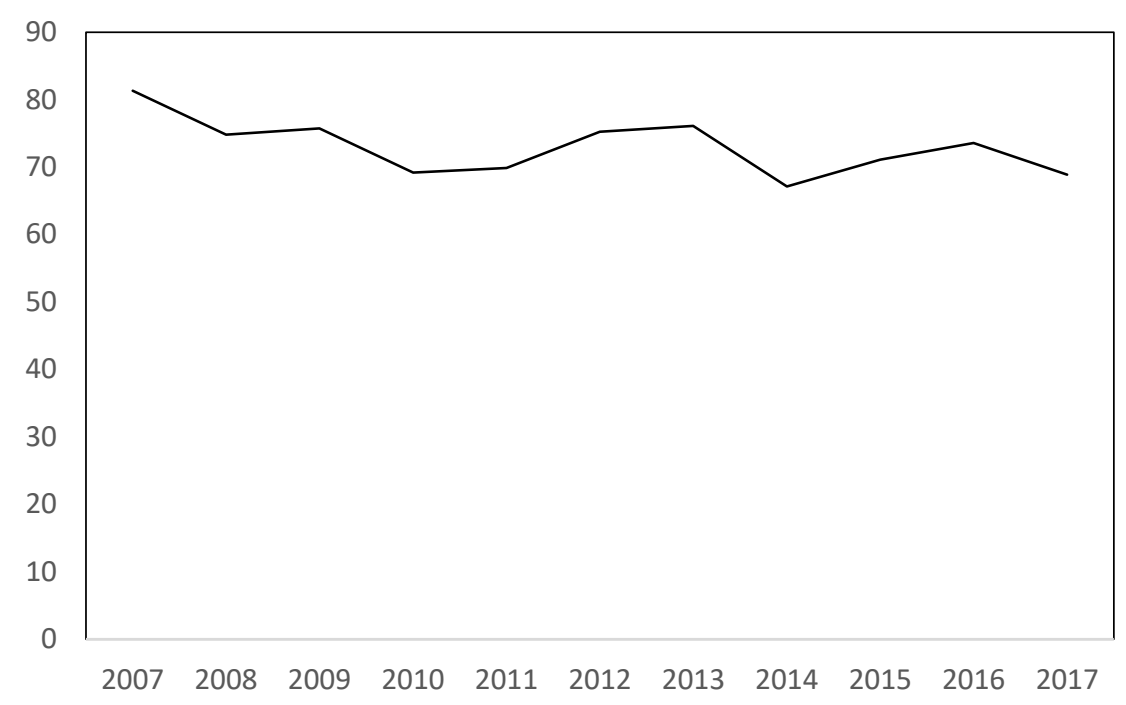

(a) The average number of banks in an MSA

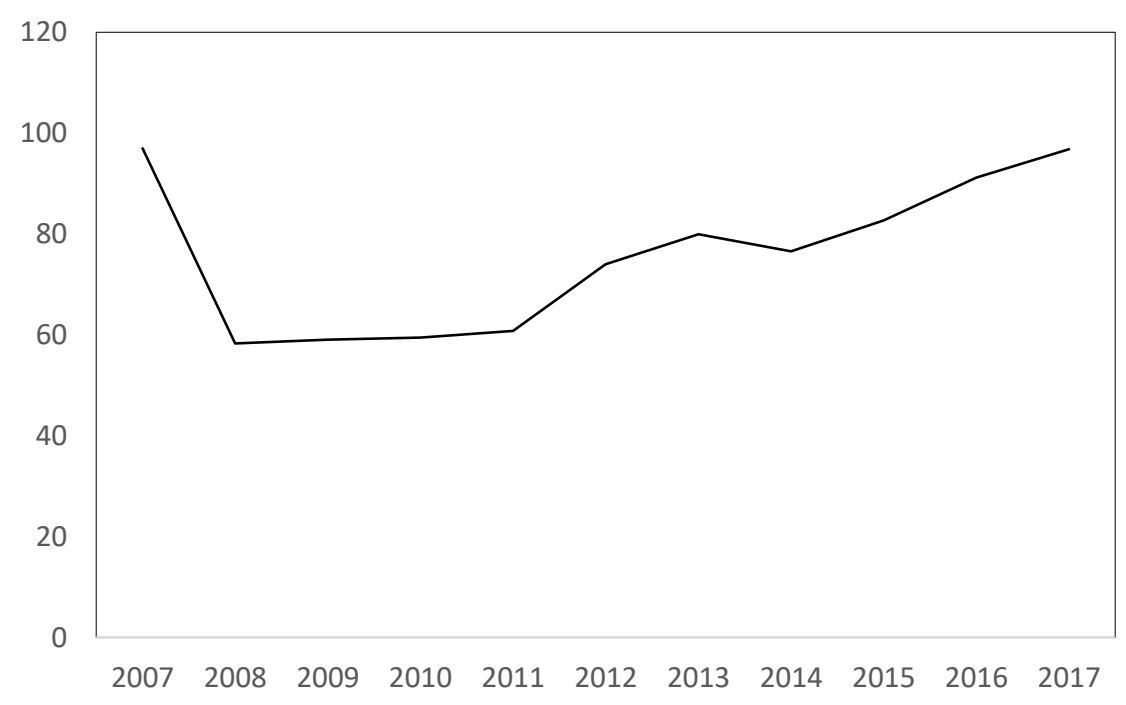

(b) The average number of shadow banks in an MSA 
Appendix A6: Counterfactual sensitivity: Capital Requirements---95\% Prediction intervals

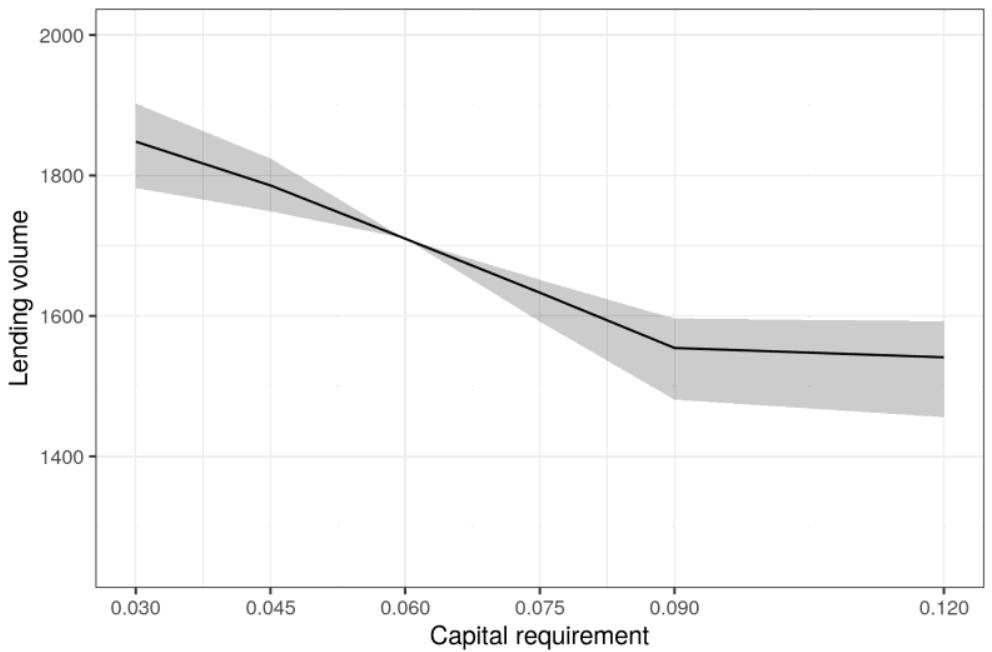

(a) Total lending volumes

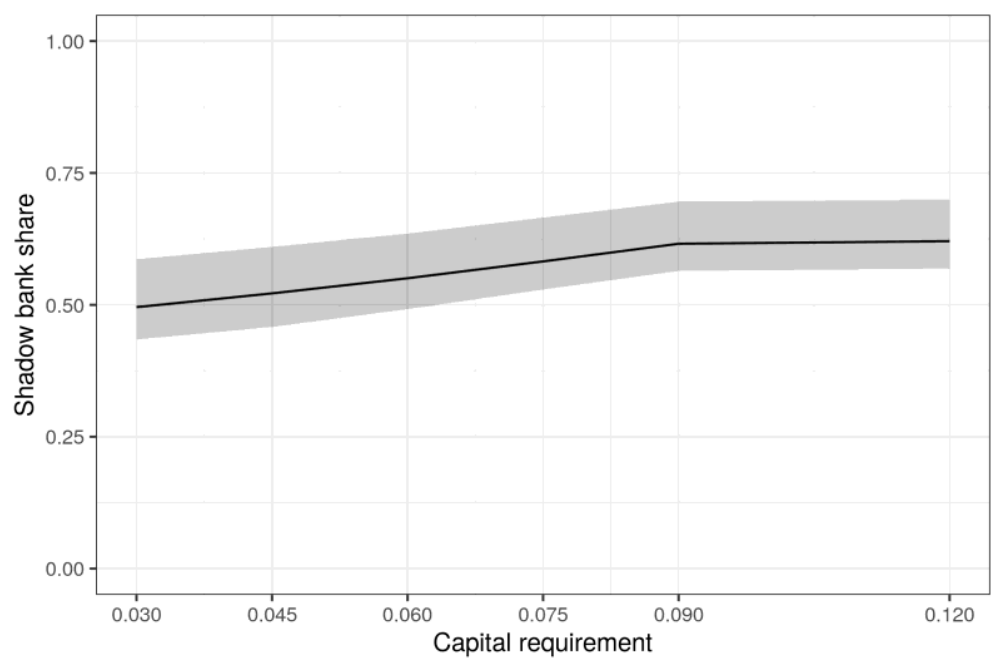

(c) Shadow bank market share

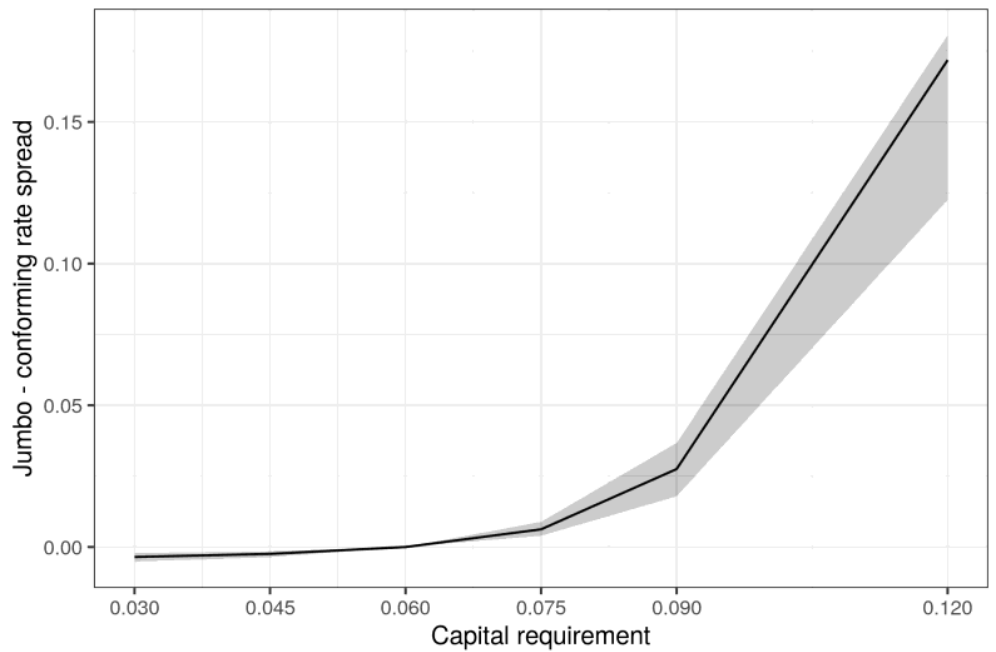

(b) Jumbo - conforming rate spread

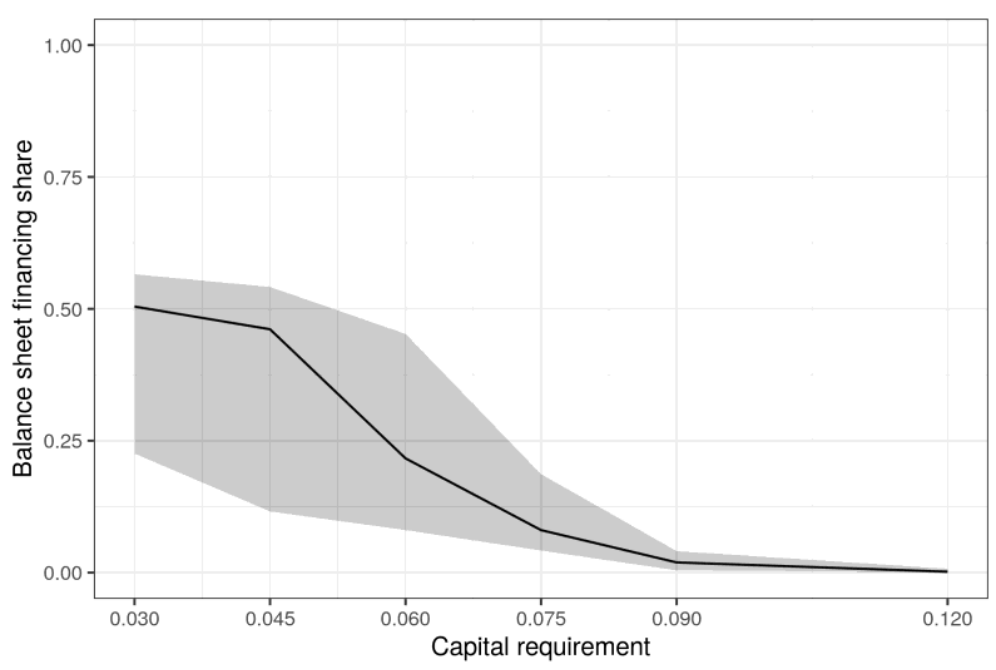

(d) Balance sheet financing share 
Appendix A7: Counterfactual sensitivity: Unconventional Monetary Policy---95\% Prediction intervals

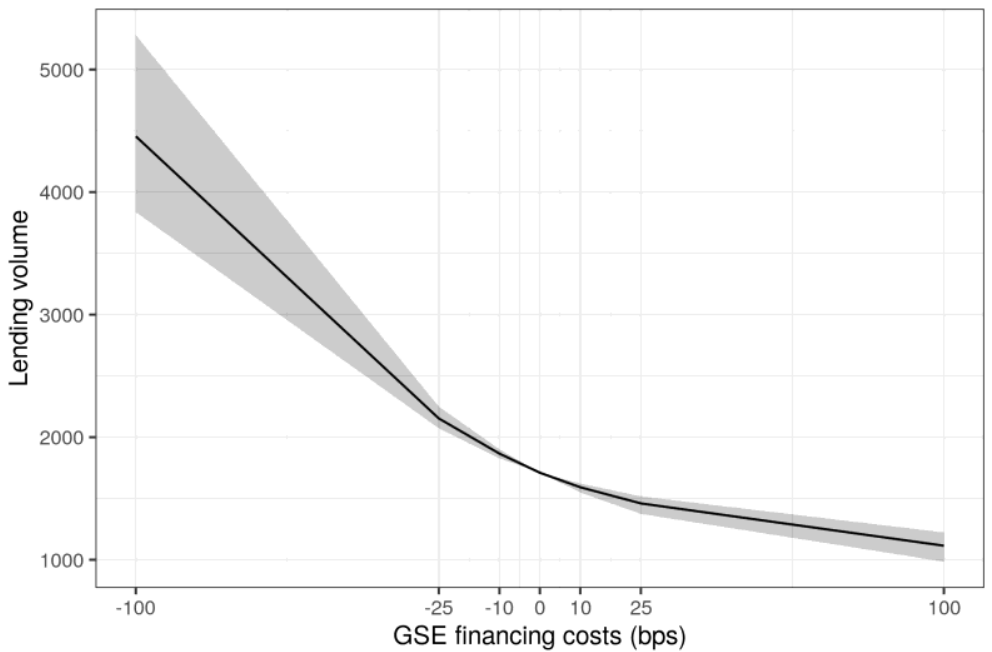

(a) Total lending volumes

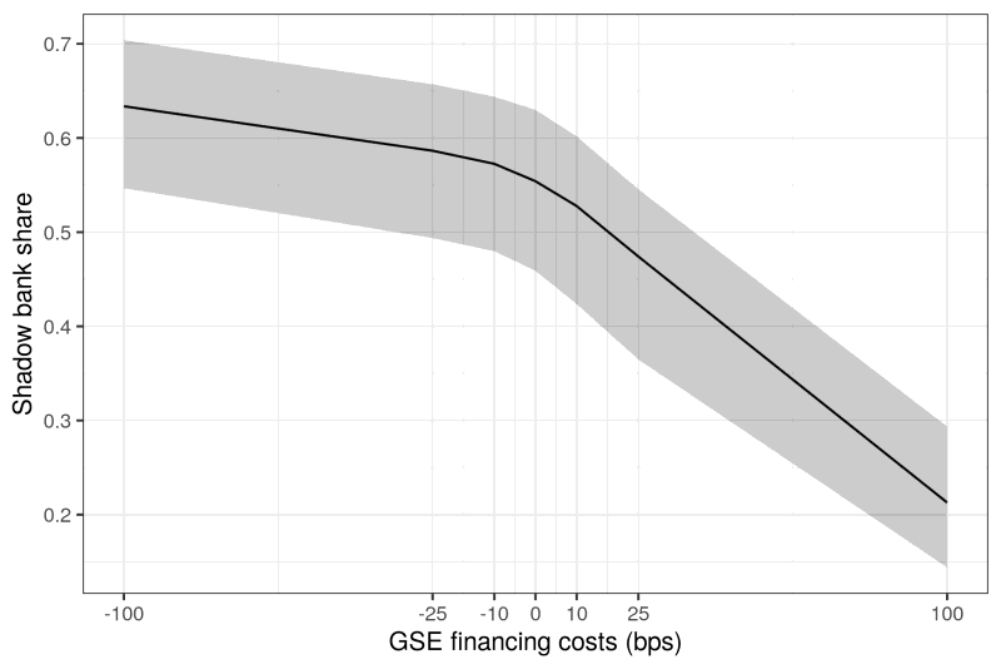

(c) Shadow bank market share

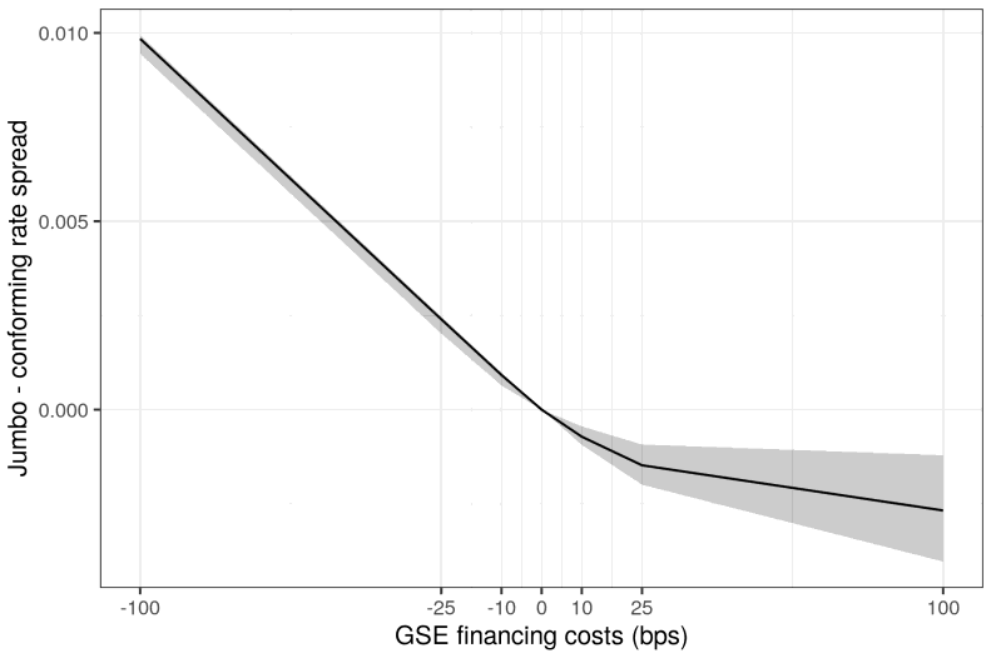

(b) Jumbo - conforming rate spread

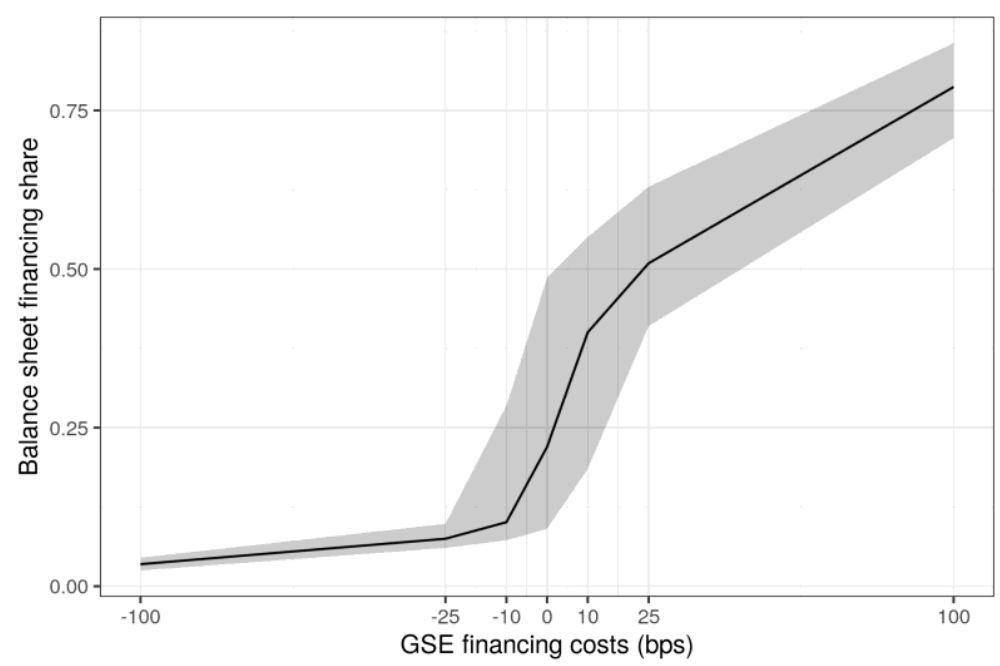

(d) Balance sheet financing share 
Appendix A8: Counterfactual sensitivity: Conforming Loan Limits---95\% Prediction intervals

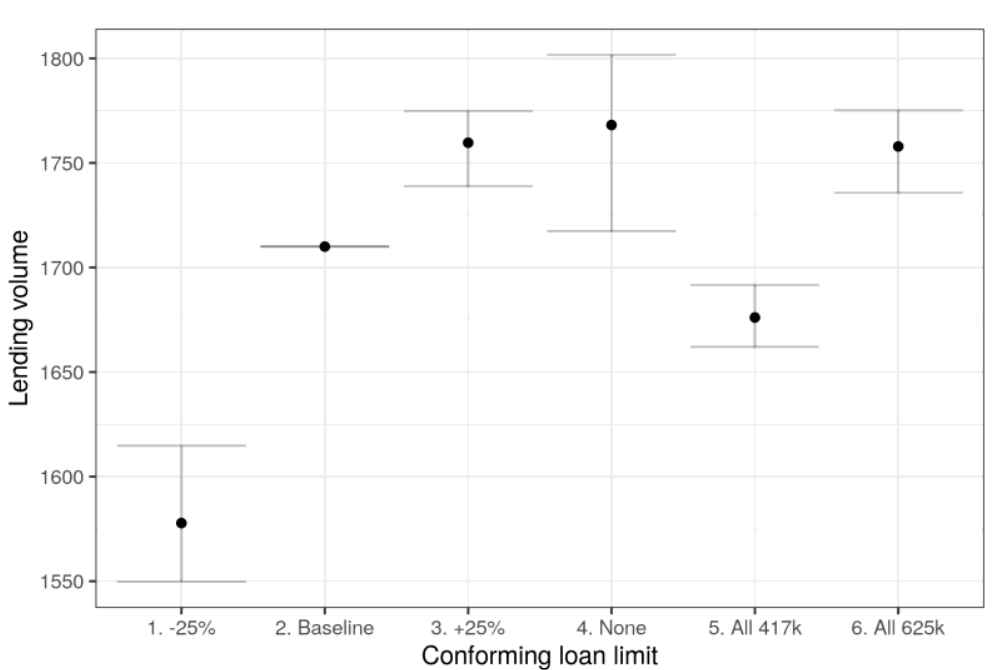

(a) Total lending volumes

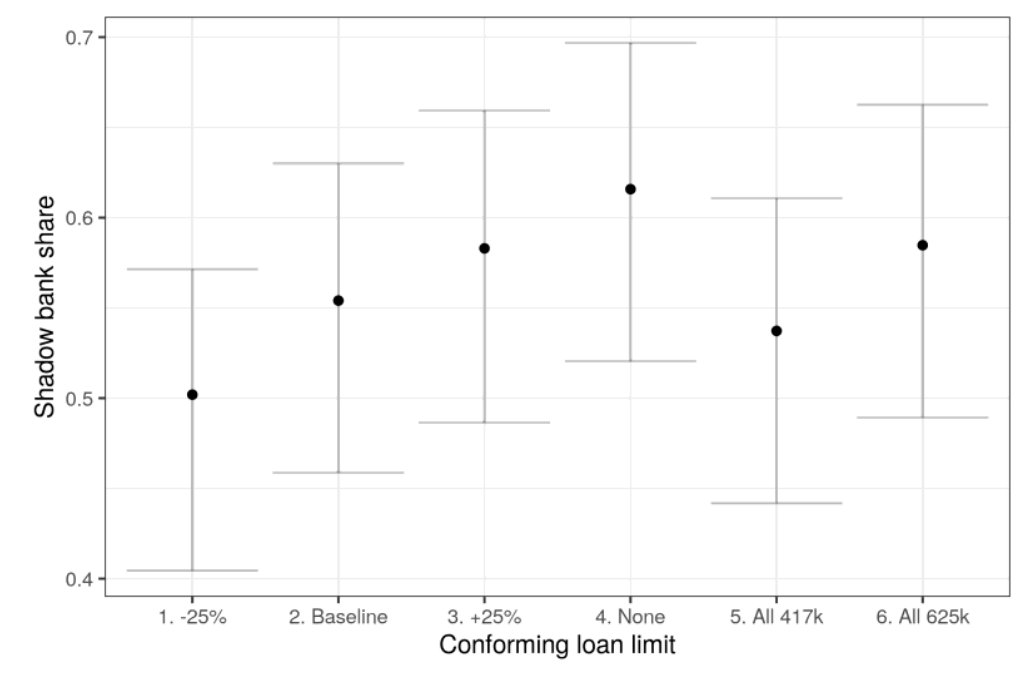

(c) Shadow bank market share

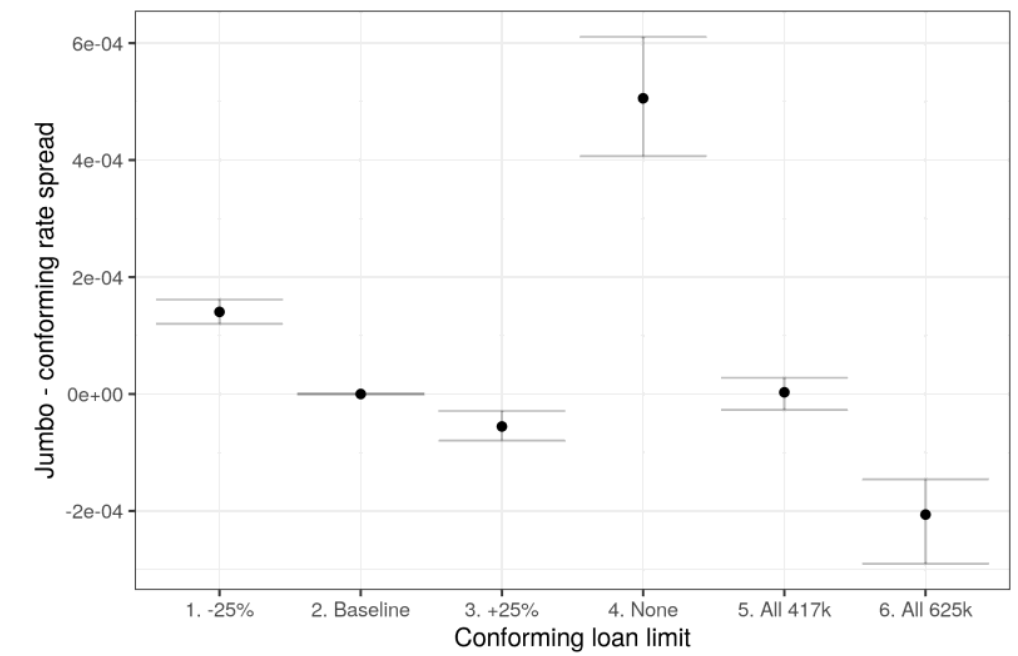

(b) Jumbo - conforming rate spread

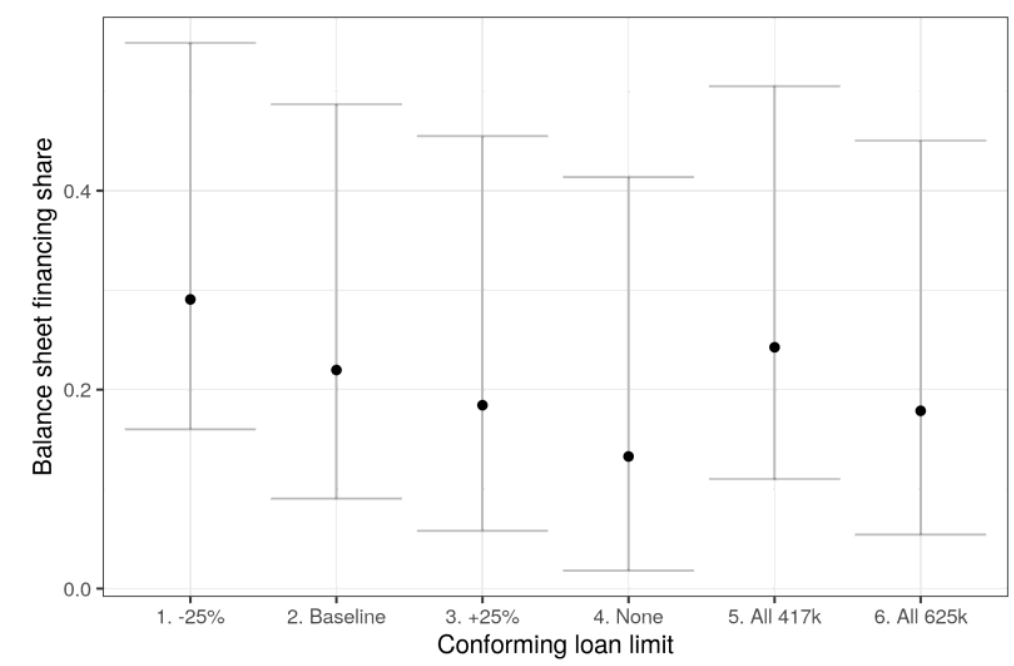

(d) Balance sheet financing share 